\title{
The Acinetobacter baumannii oxymoron: commensal hospital dweller turned pan-drug-resistant menace
}

\author{
Ignasi Roca, Paula Espinal, Xavier Vila-Farrés and Jordi Vila* \\ Department of Clinical Microbiology, School of Medicine, IDIBAPS and Barcelona Centre for International Health Research, Hospital Clínic-Universitat de Barcelona, \\ Barcelona, Spain
}

\section{Edited by:}

Stefania Stefani, University of

Catania, Italy

Reviewed by:

Ilda Santos Sanches,

Universidade nova de Lisboa, Portugal

Paolo Visca, University Roma Tre, Italy

*Correspondence:

Jordi Vila, Department of Clinical

Microbiology, Hospital Clinic of

Barcelona, Villarroel, 170, 08036

Barcelona, Spain.

e-mail: jvila@ub.edu
During the past few decades Acinetobacter baumannii has evolved from being a commensal dweller of health-care facilities to constitute one of the most annoying pathogens responsible for hospitalary outbreaks and it is currently considered one of the most important nosocomial pathogens. In a prevalence study of infections in intensive care units conducted among 75 countries of the five continents, this microorganism was found to be the fifth most common pathogen. Two main features contribute to the success of $A$. baumannii: (i) $A$. baumannii exhibits an outstanding ability to accumulate a great variety of resistance mechanisms acquired by different mechanisms, either mutations or acquisition of genetic elements such as plasmids, integrons, transposons, or resistant islands, making this microorganism multi- or pan-drug-resistant and (ii) The ability to survive in the environment during prolonged periods of time which, combined with its innate resistance to desiccation and disinfectants, makes $A$. baumannii almost impossible to eradicate from the clinical setting. In addition, its ability to produce biofilm greatly contributes to both persistence and resistance. In this review, the pathogenesis of the infections caused by this microorganism as well as the molecular bases of antibacterial resistance and clinical aspects such as treatment and potential future therapeutic strategies are discussed in depth.

Keywords: Acinetobacter baumannii, antimicrobial resistance, pathogenesis, biofilm, antimicrobial peptides

\section{INTRODUCTION}

The Acinetobacter genus comprises Gram-negative nonfermenting coccobacilli with 25 validly named species and 9 genomic species defined by genomic DNA-DNA hybridization (Espinal et al., 2011b). Although Acinetobacter pittii and Acinetobacter nosocomialis (formerly Acinetobacter genomic species 3 and gen. sp. 13TU, respectively (Nemec et al., 2011) are emerging as important pathogens and have been involved in a number of outbreaks in intensive care units, Acinetobacter baumannii is, undoubtedly the species showing the highest clinical relevance, mainly in the nosocomial setting. In fact, the three clinically important members of this group, also known as the A. baumannii (Ab) group (Peleg et al., 2008), are phenotypically related and cannot be differentiated by currently available identification systems. Indeed, $A$. pittii and $A$. nosocomialis are often erroneously identified as A. baumannii by routine commercial systems (Bernards et al., 1996). In a recent report by Espinal et al. (2011c) the use of MALDI-TOF mass spectrometry to differentiate the three species was analyzed, showing that $A$. nosocomialis was misidentified as $A$. baumannii. Inclusion of specific signature profiles for A. nosocomialis within the Bruker database allowed the correct identification of this genomic species, thus, MALDI-TOF MS spectra can be used as a fast, simple, and reliable method to identify members of the $\mathrm{Ab}$ group. Two main features contribute to the success of A. baumannii: (i) They normally exhibit multidrug resistance (MDR), acquired by different mechanisms, either mutations or acquisition of genetic elements such as plasmids, transposons, or resistant islands, and (ii) The ability to survive in the environment, in which, the production of biofilm plays an important role (discussed below). Several reviews dealing with the taxonomy, epidemiology, and infection of A. baumannii have been published on recent years (Dijkshoorn et al., 2007; Peleg et al., 2008; Towner, 2009; Visca et al., 2011). The review presented here provides an updated overview of the clinical and treatment aspects as well as the pathogenesis of antimicrobial resistance in A. baumannii. In addition, future potential therapeutic alternatives are discussed.

\section{PATHOGENESIS AND VIRULENCE FACTORS OF ACINETOBACTER BAUMANNII}

Multiple bacterial virulence factors are required for the pathogenesis of infections caused by A. baumannii. These factors enable microorganisms to colonize/infect the host efficiently. However, very little information is known about the virulence factors in $A$. baumannii and host responses to infection (Cerqueira and Peleg, 2011). Considering that A. baumannii is a multidrug-resistant microorganism, identification of the virulence factors, and the pathogenicity mechanisms could contribute to the development of novel therapeutic alternatives for the control of Acinetobacter infections.

\section{MOTILITY AND ADHERENCE}

Acinetobacter baumannii, has been described as non-motile (Tomaras et al., 2003). Its name is derived from the Greek "akineto," which means motionless or non-motile and was given due to 
the lack of flagella (McBride, 2010). Analysis of new A. baumannii genome sequences has revealed an absence of flagellar genes, therefore swarming, which is mediated by flagella (Clemmer et al., 2011), is unlikely in this microorganism. However, A. baumannii spreads rapidly over surfaces probably as the result of twitching motility, a form of surface translocation previously described in Acinetobacter calcoaceticus (Henrichsen and Blom, 1975). Twitching motility mediated by the extension and retraction of type IV pili is controlled by a large number of genes, some involved in the assembly of type IV pili (pilA, pilB, pilC, pilF, pilM, pilN, pilO, pilP, pilQ, pilZ, pilW), twitching (pilR, pils, pilT, pilU), and the pilin filament (pilA; Mattick, 2002; Jarrell and McBride, 2008). Although there is no current experimental evidence of the actual involvement of type IV pili in A. baumannii motility, a recent publication by Eijkelkamp et al. (2011) has shown the presence of several genes associated with the synthesis of type IV pili in the genomes of fully sequenced A. baumannii strains. The authors have also demonstrated a positive correlation between the degree of sequence conservation of the gene encoding the pilin subunit PilA and the twitching phenotype exhibited. Moreover, type IV pili has also been related to twitching motility in other non-flagellated gamma-proteobacteria (De La Fuente et al., 2007).

Twitching motility is also controlled by a range of signal transduction systems, including two-component sensor-regulators and a complex chemosensory system (Mattick, 2002). In a recent study, Clemmer et al. (2011) found that the motility exhibited by A. baumannii was partially dependent on a functional pilT gene. The loss of this gene in the A. baumannii $\mathrm{M} 2$ strain resulted in a $54 \%$ reduction in motility, suggesting that twitching represents a significant component of the overall motility in A. baumannii.

\section{BIOFILM}

Adherence to host cells represents the initial step of colonization or infection. During colonization, bacteria may form microcolonies which result in a highly structured microbial community, called biofilm. Biofilm constitutes a structural community of multiple bacterial cells associated with a biotic or abiotic surface, enclosed in a polymeric matrix (comprised of carbohydrates, nucleic acids, proteins, and other macromolecules; Costerton, 1995), constituting a protective mechanism to survive in harsh environments and during host infection. These bacteria become more resistant to antimicrobial stressors, antibiotics, or cleaning than their planktonic counterparts and therefore the ability to generate biofilms represents an important virulence factor (Donlan, 2002; Wroblewska et al., 2008; de Breij et al., 2009; Gaddy and Actis, 2009).

Biofilm can be influenced by common factors such as nutrient availability, bacterial appendages, bacterial surface components, quorum sensing (QS), macromolecular secretions (Irie and Parsek, 2008; Gaddy and Actis, 2009; Bhargava et al., 2010), and complex regulatory networks including two-component regulatory systems and transcriptional regulators which are related to the expression of biofilm-associated gene products in response to environmental signals (Stanley and Lazazzera, 2004). Tomaras et al. (2003) demonstrated that the ability of A. baumannii strain ATCC $19606^{\mathrm{T}}$ to form pili and to adhere and form biofilm on abiotic surfaces depends on the expression of the $c s u E$ gene, which is a component of the CsuA/BABCDE chaperone-usher complex important for the assembly and production of pili involved in adhesion to surfaces. Inactivation of $c s u E$ results in the abolition of pili production and biofilm formation suggesting that CsuA/BABCDE-mediated pili play a role in the initial steps of biofilm formation. The expression of this operon is controlled by a two-component regulatory system including a sensor kinase encoded by $b f m S$ and a response regulator encoded by $b f m R$. Inactivation of $b f m R$ results in a loss of expression of the csu operon and, therefore, abolition of pili production and biofilm formation on abiotic surfaces. Additionally, the coupling of pili to host cell receptors may induce the production of inflammatory mediators such as chemokines and cytokines (Sauer et al., 2000).

In addition to the CsuA/BABCDE-mediated pili, de Breij et al. (2009) found that A. baumannii ATCC19606 ${ }^{\mathrm{T}}$ produces a CsuA/BABCDE-independent short pilus, which may be involved in the adherence of the bacteria to biotic surfaces, such as human respiratory cells.

For the development of mature biofilm structures, an ortholog of a staphylococcal biofilm-associated protein (Bap) was found in A. baumannii strain 307-0294. Transposon inactivation of this protein involved in cell-cell interactions resulted in destabilization of the mature biofilm on abiotic or biotic surfaces (Loehfelm et al., 2008).

Several studies have shown that some A. baumannii strains can adhere to human cells and form biofilm on abiotic surfaces. A. baumannii survives on fingertips and inanimate objects such as glass, plastic, and other environmental surfaces, even after exposure to dry conditions and nutrient starvation during extended periods of time (Jawad et al., 1996; Wendt et al., 1997; Lee et al., 2006b; de Breij et al., 2009; Espinal et al., 2012). The survival of A. baumannii has also been attributed to resistance of this microorganism to antimicrobial drugs and desiccation (Jawad et al., 1998; Tomaras et al., 2003). Since A. baumannii can produce biofilm, the resistance phenotype could be attributed to the ability of $A$. baumannii clinical strains to form biofilms on abiotic surfaces, particularly in strains isolated from catheter-related urinary tract or bloodstream infections or even from a case of shunt-related meningitis (Tomaras et al., 2003; Rodríguez-Baño et al., 2008; Gaddy and Actis, 2009). In a recent study, Espinal et al. (2012) performed survival assays with biofilm- and non-biofilm-forming strains on glass coverslips in a desiccated environment. The survival times for the biofilmforming strains were longer than for the non-biofilm-forming strains (36 versus 15 days, respectively, $P<0.001$ ), demonstrating that A. baumannii strains can attach to glass coverslips and also form biofilm, allowing their survival under dry conditions for much longer lengths of time than non-biofilm-forming strains and may contribute to its persistence in the hospital environment, increasing the probability of causing nosocomial infections and outbreaks. A few previous reports have described the ability of clinical isolates of A. baumannii to attach to and form biofilms on glass surfaces comprising an amorphous material similar to exopolysaccharide (Vidal et al., 1996; Tomaras et al., 2003; Espinal et al., 2012). Scanning and transmission electron microscopy (Figure 1) studies have shown appendages and a polysaccharide layer covering the cells only in biofilm-forming strains (Espinal et al., 2012). This 

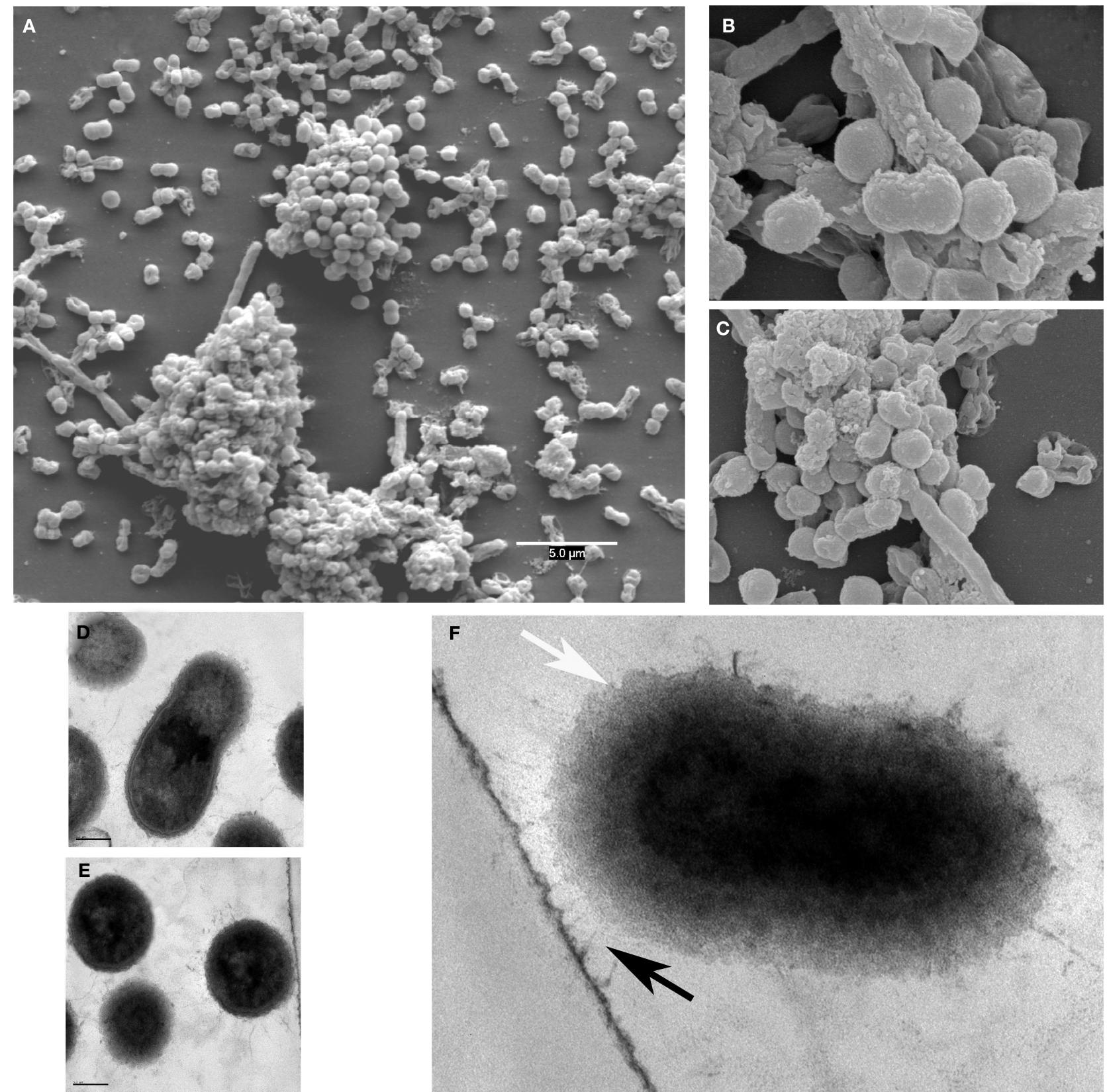

FIGURE 1 | Scanning electron microscopy (SEM) (A-C). Transmission electron microscopy (TEM) (D-F) of an A. baumannii biofilm-forming strain in liquid medium. Black arrow specifies appendage structures (pili or fimbriae), and white arrow the thick exopolysaccharide layer. All electron microscopy images are derived from the work by Espinal et al. (unpublished data)

highly hydrated layer may prevent lethal desiccation and, thus, protect against variations in humidity as well as contribute to mechanical stability, longer survival, and antimicrobial resistance (Sutherland, 2001; Donlan, 2002).

\section{SURFACE POLYSACCHARIDES}

Surface polysaccharide, such as capsule, is considered an important virulence trait in Gram-negative bacteria, but its role in the pathogenesis of A. baumannii is non-existent. Russo et al. (2010) obtained mutants from the A. baumannii strain AB307-0294 and identified two genes: $p t k$, that was predicted to be required for capsule polymerization and encodes a putative protein tyrosine kinase (PTK), and epsA, required for assembly and encoding a putative polysaccharide export outer membrane protein (EpsA). These genes are required for a capsule-positive phenotype and describe the participation of capsule in the pathogenesis of $A$. baumannii. This study demonstrated that the K1 capsule from the A. baumannii strain AB307-0294 was necessary for optimal 
growth in human ascitic fluid and survival in human serum as well as in a rat tissue infection model. The active protection of the capsule allows bacterial resistance to the bactericidal activity of the complement.

On the other hand, the potential of PtK and EpsA as drug targets was observed when the loss of PTK or EpsA resulted in a complete and durable killing of AB307-0294 in vivo.

Other important extracellular polysaccharide is the poly- $\beta$ (1-6)-N-acetyl glucosamine (PNAG) described as a major component of biofilms in Staphylococcus epidermidis and S. aureus (Kropec et al., 2005). In A. baumannii clinical isolates the pgaABCD locus, encoding proteins for the synthesis of PNAG, has been proved critical for biofilm development (Choi et al., 2009). Besides the role in surface and cell-to-cell adherence, PNAG has been described as a virulence factor that also protects bacteria against innate host defenses. Although PNAG is not essential for biofilm formation under static conditions, it is required for maintaining the integrity of A. baumannii biofilms in dynamic and stressful environments. Indeed, PNAG has shown a role in the pathogenesis of $A$. baumannii and is a candidate vaccine against this pathogen (Choi et al., 2009; Cerqueira and Peleg, 2011).

LPS structures containing long O-specific sugar chains (smooth or S-type LPS) have been associated with virulence, and previous studies have shown that nosocomial isolates of $A$. baumannii produce rough $\mathrm{R}$ - and smooth S-type LPS. The differences in the ability of LPS from different isolates of A. baumannii to elicit mitogenic activity could be caused by variations in the fatty acid content of lipid A and in the O-antigens. LPS and lipid A from Acinetobacter have exhibited lethal toxicity in mice, pyrogenicity in rabbits, as well as complement inactivation in vitro (García et al., 1999). Pantophlet et al. (1998) suggested an important role for the LPS from nosocomial strains of A. baumannii as a virulence factor in vivo and that synthesis of endotoxin could be an important factor responsible for the severity of disease observed during sepsis by this microorganism.

Although little is known of the endotoxic potential of A. baumannii LPS with respect to human cells and its ability to stimulate inflammatory signaling via human toll-like receptors (TLRs), Erridge et al. (2007) investigated the biological activity of these endotoxins in human monocytic THP-1 cells and in TLR-deficient HEK-293 cells transfected with human TLR 2 and TLR4 constructs. The results of this study showed that endotoxins derived from clinical isolates of A. baumannii and one Acinetobacter genomic species 9 are potent stimulators of inflammatory signaling in human monocyte cells and the responses to these bacteria are dependent on TLR2 and TLR4.

These results, however, are in apparent conflict with a recently published study by de Breij et al. (2010) that investigated the interplay among biofilm formation, adherence, and induction of an inflammatory response in human airway epithelial cells. De Breij and co-workers concluded that clinically relevant $A$. baumannii strains showing good adherence to human epithelial cells elicit a poor inflammatory response, allowing Acinetobacter strains to evade the host immune system and, therefore, explaining the exceptional survival and persistence capabilities of this microorganism.
These findings were in agreement with those reported in Haemophilus influenzae (Bresser et al., 1997).

\section{OUTER MEMBRANE PROTEINS}

Outer membrane proteins (OMPs) of Gram-negative bacteria have been related to antibiotic resistance, adaptation, and pathogenesis in the host cells. Some OMPs of the OmpA family have been characterized in Acinetobacter strains, and represent one of the major OMP in the genus (Vallenet et al., 2008).

Previous studies have determined that bacterial molecules secreted from A. baumannii are responsible for host cell death (Lee et al., 2001). Among these molecules, OmpA from A. baumannii (AbOmpA) makes up a potential virulence factor with multiple important effects in pathogenesis and signal processing (Perez et al., 2011). AbOmpA is the most abundant surface protein involved in the adherence to and invasion of epithelial cells and induces apoptosis in the early stages of A. baumannii infection (Gaddy et al., 2009).

Acinetobacter baumannii can induce cell death (Hep-2 cells) by means of cell surface death receptors and mitochondrial disintegration. Purified AbOmpA was identified in the mitochondria, where it induced the release of proapoptotic molecules such as cytochrome $c$ and apoptosis-inducing factor (AIF), which mediates caspase-dependent and AIF-dependent apoptosis in epithelial cells and degrades chromosomal DNA (Choi et al., 2005). Apoptosis of epithelial cells can lead to the internalization of bacteria through the disrupted mucosal lining and, therefore, the outcome of infections caused by this microorganism depends on apoptosis induction in the epithelial cells (Choi et al., 2005).

AbOmpA is also implicated in resistance to complement and biofilm formation (Gaddy and Actis, 2009; Kim et al., 2009). Some A. baumannii strains are resistant to the killing activity of human serum by means of genetic components that increase Acinetobacter capabilities to cause bacteremia. The suggested serum-resistant mechanism involves the inhibition of host complement $\mathrm{C} 3$ protein cleavage and binding to the bacterial surface, which inhibit host phagocytic cell recognition and result in a serum-resistance phenotype (Kim et al., 2009). In addition, the binding of complement regulators to OMPs also plays a role in complement activation. Kim et al. (2009) demonstrated that an alternative complement pathway was responsible for the killing of A. baumannii in normal human serum. In vitro assays have indicated that factor $\mathrm{H}$, the main regulator of this pathway, bound to the surface of this microorganism treated with normal human sera, may contribute to the persistence and dissemination of Acinetobacter in the host. Comparisons between A. baumannii ATCC $19606^{\mathrm{T}}$ and isogenic $\mathrm{AbOmpA}^{-}$mutants have shown that mutant strains lose adherence and invasion capability in the host cells, demonstrating that AbOmpA participates in the evasion of the complement attack by interacting with factor $\mathrm{H}$ (Choi et al., 2008). In this sense, AbOmpA is considered the main complement regulator-acquiring surface protein (Choi et al., 2008) whereas secreted AbOmpA induces apoptosis in epithelial cells (Choi et al., 2005). In view of these results, AbOmpA stands out as an important virulence factor in A. baumannii and could be used as a target in the development of antibiotics and vaccines against this microorganism (Kim et al., 2009). 


\section{OUTER MEMBRANE VESICLES}

In addition to OmpA, some Gram-negative bacterial species secrete outer membrane vesicles (OMVs) during bacterial growth. OMVs are spherical nanovesicles with a diameter between 20 and $200 \mathrm{~nm}$ which are composed of lipopolysaccharides, OMPs, lipids, and DNA or RNA (Kwon et al., 2009; Jin et al., 2011). Secreted OMVs have been shown to participate in QS, the transport of virulence factors, the inhibition of phagosome-maturation in macrophages, biofilm formation, and gene transfer (McConnell et al., 2011b; Rumbo et al., 2011). The surface factors of OMVs mediate adherence to host cells as well as the internalization of vesicular components suggesting that OMVs function as a transport vehicle of effector molecules into host cells (Kwon et al., 2009; Jin et al., 2011). Kwon et al. demonstrated that A. baumannii secretes OMVs during in vitro growth in association with some virulence-associated proteins and immune modulators suggesting that OMVs play a role in the pathogenicity of $A$. baumannii. AbOmpA, mediating the adherence to and invasion of A. baumannii to epithelial cells (Choi et al., 2008) was detected as a major protein component in the OMV fraction. Packaged in OMVs, AbOmpA induces cytotoxicity and host cell death. The results obtained in this study revealed that AbOmpA derived from OMVs was found in the cytoplasm of receiving cells, suggesting that OMVs can deliver virulence factors directly to host cells in the absence of bacteria.

Proteomic analysis of the OMVs from A. baumanii ATCC $19696^{\mathrm{T}}$ and the clinical isolate DU202 identified more than 110 proteins derived from the outer membrane, periplasmic space, inner membrane, cytosol, and other additional undetermined sites. OMVs contained putative serine and $\mathrm{Zn}$ dependent proteases, phospholipases, bacterioferritin, catalase, and a ferrichrome-iron receptor, as well as several proteins displaying secretion signals and pathogen-associated molecular patterns, such as LPS and lipoproteins (Kwon et al., 2009; Jin et al., 2011).

Since OMVs contain multiple antigenic proteins from the bacterial outer membrane, they could be used as vaccine antigens. Previous studies have shown that vaccination with OMVs resulted in the recovery of antibodies against multiple bacterial antigens displaying bactericidal activity and the ability to provide protection in animal models of infection (Schild et al., 2008). McConnell et al. (2011b) evaluated the immune response elicited after immunization with $A$. baumannii OMVs and found that the serum recovered from vaccinated mice reacted against multiple proteins present in the OMVs as well as against many proteins from the bacterial outer membrane. The robust and protective response elicited by this serum suggests that OMVs might constitute a viable immunization approach to control the infection and mortality caused by A. baumannii.

Vesicles have also been shown to be involved in the transfer of genetic material among similar bacterial species (Klieve et al., 2005). Rumbo et al. (2011) have demonstrated that OMVs vehiculate plasmids carrying carbapenem resistance genes such as the $b l a_{\text {OXA-24 }}$ gene, which can be readily transferred between different strains of A. baumannii. In this respect, OMVs might be considered as important virulence factors not only because they participate in host-pathogen interactions but also by allowing the spread of antibiotic resistance genes (such as those related to carbapenem resistance) to surrounding bacteria. The genetic material contained inside OMVs is protected from nucleases, thereby favoring the exchange of genetic material. These results might point toward a new mechanism for dissemination of resistance genes in addition to conjugation, transformation, and transduction processes.

\section{HYDROLYTIC ENZYMES}

Additional proteins proposed as virulence factors in A. baumannii also include Phospholipase D and Phospholipase C (Antunes et al., 2011a).

Phospholipase D, which is important for human serum resistance, epithelial cell invasion, and pathogenesis in a murine model of pneumonia, also plays a role in the systemic dissemination of bacterial pathogens within infected animals and is considered the main virulence determinant in Corynebacterium pseudotuberculosis (McKean et al., 2007). Jacobs et al. (2010) characterized a mutant A. baumannii strain harboring a transposon insertion within a putative phospholipase $\mathrm{D}$ (PLD) encoding-gene. In this study not only was phospholipase activity affected, but reduced $A$. baumannii epithelial cell invasion (in vitro) and serum proliferation were also reported. As a consequence, a decrease in bacteremia and colonization of visceral host organs was observed in a murine infection model. As suggested with AbOmpA, phospholipase D is an A. baumannii virulence factor that is required for wild-type levels of pathogenicity and is also a potential target for the therapeutic treatment of Acinetobacter infections (Jacobs et al., 2010).

Phospholipase $\mathrm{C}$ has also been shown to enhance the toxicity of epithelial cells. Camarena et al. (2010) demonstrated that an insertional mutant carrying a kanamycin cassette in the coding region of plc1 displayed a reduction in the cytotoxic effect caused by A. baumannii on epithelial cells, thereby indicating that phospholipase $\mathrm{C}$ is an important factor in cellular damage.

\section{ETHANOL-INDUCED PATHOGENESIS}

In A. baumannii, ethanol is assimilated as a carbon source and enters the glyoxylate cycle which, in many pathogens, has been related to virulence. Smith et al. (2004) observed that ethanol promoted bacterial growth when A. baumannii was co-incubated with yeast and also demonstrated that low concentrations of ethanol stimulated Acinetobacter growth and contributed to endure salt stress. To understand the virulence of $A$. baumannii in the presence of ethanol, Camarena et al. (2010) characterized the transcriptional profile of this microorganism in the presence and absence of ethanol. They found 70 genes whose expression was affected by the presence of ethanol in the growth medium and suggested that virulence of A. baumannii in the presence of ethanol was due to increased metabolic capacity and the expression of some factors related to stress responses.

The genes that were induced by growth in the presence of ethanol during the exponential phase encoded proteins related to central metabolism or ethanol/acetate assimilation, such as ethanol dehydrogenase (AIS_2098) and aldehyde dehydrogenase (AIS_2102), genes encoding for pta (AIS_0481; phosphate acetyltransferase) and ackA (AIS_0482; acetate kinase), which are related to Acetyl-CoA synthesis.

Ethanol also induced genes involved in stress response and pathogenesis during exponential phase. Eleven genes encoded 
hypothetical proteins; five unique to A. baumannii ATCC 17978 and, among the remaining six, AIS_2195 was exclusive of the Acinetobacter genus and AIS_2509 was only present in A. baumannii ATCC 17978 and the non-pathogenic A. baylyi ADP1. AIS_2509 was shown to contribute to ethanol stress survival together with AIS_2510 (HSP70-like), which is mildly induced by ethanol.

Ethanol can also enhance the virulence of A. baumannii by inducing heat-shock proteins such as Hsp90, GroEL, and Lon. Furthermore, ethanol promotes the expression of plc1 (AIS_0043) which encodes the A. baumannii phospholipase C.

Additional genes detected in stationary phase cultures grown in the presence of ethanol include AIS_2381, which is required for acinetobactin synthesis, and AIS_2566 and AIS_2578, encoding a protein involved in siderophore synthesis and a siderophore receptor, respectively, which are required for the iron-uptake systems. Camarena et al. (2010) also demonstrated that ethanol induces a stress response enhancing bacterial fitness to survive in the host.

\section{PENICILLIN-BINDING PROTEINS}

Penicillin binding proteins (PBPs) are a family of enzymes that share a common evolutionary origin. These enzymes catalyze the synthesis of peptidoglycan, the primary component of the bacterial cell wall, and are also associated with cell morphogenesis and cell division complexes. The inhibition of PBPs causes instability in the cell wall, resulting in growth inhibition, or cell lysis (Cayo et al., 2011). PBPs have been classified as either high- or low-molecular mass PBPs. High-molecular mass PBPs enable peptidoglycan polymerization and insertion into the preexisting cell wall, and low-molecular mass PBPs contribute to cell separation and peptidoglycan remodeling (Sauvage et al., 2008). Although little is known about low-molecular mass PBPs, the putative lowmolecular-mass penicillin-binding protein 7/8 (PBP-7/8) has been postulated to play a role in cell wall remodeling. PBP-7/8 is a hydrolase/endopeptidase. PBP-8 is an OmpT-mediated degradation product of PBP-7, and both PBPs stabilize and enhance soluble lytic transglycosylase 70 (in vitro). Although PBP-7/8 could be non-essential for normal elongation, it has been related to modulation of cell morphology and daughter cell separation. Russo et al. (2009) also demonstrated that a PBP-7/8-deficient mutant derivative of the wild A. baumannii AB307-0394 strain contributed to the pathogenesis of $A$. baumannii and participated in the growth and survival of A. baumannii in human ascites (in vitro and in vivo) in rat soft-tissue infection and pneumonia models. In addition, PBP$7 / 8$ contributed either directly or indirectly to the serum resistance of AB307-0394.

\section{IRON UPTAKE}

Iron constitutes an important resource that it is not readily available in the human host. It is found complexed with iron-binding molecules such as heme, lactoferrin, and transferrin. A common alternative to more conventional human host defenses against bacterial infections involves the reduction of free extracellular iron concentration by means of iron-binding proteins. However, bacteria are able to survive and multiply under iron-limiting conditions found both in natural and host environments by exploiting a number of strategies for high-affinity iron acquisition, including production of ferric iron chelators (siderophores) that are released outside cells, uptake of exogenous chelators, such as heme and heterologous siderophores, and acquisition of ferrous iron (Dorsey et al., 2003a; Vallenet et al., 2008; Antunes et al., 2011a).

\section{SIDEROPHORES}

Siderophores are low-molecular-mass high-affinity iron chelating compounds classified according to their chemical structures (Dorsey et al., 2003a), as in catechols, high-affinity iron chelating molecules containing catecholate groups which are part of the iron-binding site.

The A. baumannii 8399 isolate, recovered during a nosocomial outbreak, was shown to contain a high-affinity iron-uptake system which included a catechol siderophore capable of scavenging iron from the high-affinity iron-binding proteins present in the human host (Dorsey et al., 2003b). The latter property was associated with the finding of $d h b$ genes in the genome of $A$. baumannii 8399. Genetic complementation assays have proven that $d h b \mathrm{~A}, d h b \mathrm{~B}$, and $d h b \mathrm{E}$ genes encode active proteins that restore enterobactin biosynthesis and iron uptake when introduced in Escherichia coli mutants. These results demonstrated that A. baumannii 8399 harbors all the genetic determinants required for the biosynthesis of the catechol siderophore detected in iron-limited culture supernatants of this microorganism.

Acinetobacter baumannii 8399 also contains genes encoding proteins that are highly related to iron-transport proteins: OM73, an iron-regulated OMP detected in iron-starved A. baumannii 8399 cells; the $\mathrm{P} 45$ protein, the expression of which is regulated by both iron and Fur and could have a possible role in the secretion of the catechol siderophore produced by A. baumannii 8399; and the P114 protein, which may also participate in siderophore secretion in conjunction with the P45 protein (Dorsey et al., 2003b).

The mixed catechol-hydroxamate compound known as acinetobactin, (structurally similar to anguibactin and vibriobactin produced by Vibrio cholerae), was the first siderophore to be described in A. baumannii. Acinetobactin is produced by A. baumannii ATCC $19606^{\mathrm{T}}$ and some clinical isolates (Yamamoto et al., 1994) but is absent in the non-clinical isolate SDF (Antunes et al., 2011b).

A comparison between the complete genomes derived from AYE, SDF, and ACICU clinical strains has demonstrated that AYE and ACICU express independent siderophore-mediated iron acquisition systems together with acinetobactin and hemin ironcapturing systems. Iron acquisition in the SDF strain, however, depends on the expression of a hemin system rather than on the expression of biosynthesis and transport functions for a particular siderophore. Several associated ABC transporters probably involved in the translocation of heme/hemoglobin from the periplasm to the cytosol have also been detected in this strain (Zimbler et al., 2009; Antunes et al., 2011a).

Furthermore, some A. baumannii-producing acinetobactin strains utilize $30 \%$ iron-saturated transferrin and 15\% ironsaturated lactoferrin as the sole sources of iron for growth by scavenging iron bound to these proteins. None of these strains use heme or hemoglobin as an iron source. Insertional analysis has demonstrated that inactivation of bauA and basD, encoding for acinetobactin transport and biosynthesis functions, respectively, affects the ability of isogenic derivatives to grow under 
iron-limiting conditions (Mihara et al., 2004; Zimbler et al., 2009). These findings suggest that $A$. baumannii is a versatile pathogen with the ability to acquire iron and survive under iron-limiting conditions and highlights the role of acinetobactin-mediated iron acquisition mechanisms in the pathogenesis of A. baumannii infections (Mihara et al., 2004; Zimbler et al., 2009).

The ferric-siderophore complex is transported inside bacterial cells with the aid of specific outer-membrane receptors, periplasmic proteins, and inner-membrane-associated proteins, such as the iron-regulated outer membrane proteins system (IROMPs; Dorsey et al., 2003b; Mihara et al., 2004; Vallenet et al., 2008). In Gram-negative bacteria, these receptors are localized on the outer membrane, where internalization of siderophores or heme is associated with dissipation of the proton gradient on the inner membrane and is mediated by the TonB protein complex in the periplasmic space. The TonBExbBD energytransducing system is required for hemin utilization in many bacteria. Once internalized, the ferric-siderophore complexes are reduced to release iron by an enzyme with ferric reductase activity (Vallenet et al., 2008; Zimbler et al., 2009; Antunes et al., 2011b).

In addition to the previously mentioned acinetobactin siderophore, Antunes et al. (2011b) have described two siderophore synthesis/transport gene clusters, which include genes for putative hydroxylase and acetyltransferase enzymes, suggestive of the synthesis of hydroxamate-type siderophores. One of these clusters was only present in the ATCC 17978, while the other was present in the ACICU, ATCC 17978, AYE, AB0057, AB307-294, and ATCC $19606^{\mathrm{T}}$ A. baumannii strains, but not in the non-human SDF isolate.

Another alternative mechanism for bacterial iron assimilation involves the direct uptake of iron by the Feo system, a homolog of the E. coli feoB. This system, found in ACICU, ATCC 17978, AYE, AB0057, AB307-294, ATCC $19606^{\mathrm{T}}$, and SDF strains, consists of the cytosolic FeoA protein, the inner membrane $\mathrm{Fe}(\mathrm{II})$ permease $\mathrm{FeoB}$, and the putative transcriptional repressor FeoC (Antunes et al., 2011b). The expression of the proteins implied in iron acquisition systems, including siderophore biosynthetic enzymes, depends on the transcriptional regulation of the global iron-binding repressor protein Fur, for ferric uptake regulator (Mihara et al., 2004; Vallenet et al., 2008), which acts as a transcription repressor of genes involved in the siderophore/heme(globin) systems. A bioinformatic search for Fur-binding sites revealed that putative Fur boxes were present in the intergenic regions of the abovementioned gene clusters, demonstrating the participation of these clusters in iron capture.

\section{QUORUM SENSING}

Bacteria elaborate chemical signals excreted from the cells to perform intercellular communication and environmental adaptation. This ability of bacteria to monitor cell density before expressing a phenotype is known as "quorum sensing" (Whitehead et al., 2001). QS is a widespread regulatory mechanism among Gram-negative bacteria and often takes place with the aid of acyl-homoserine lactone (AHL)-like signal molecules produced by the LuxI family of AHL synthases (Sarkar and Chakraborty, 2008; González et al., 2009). Modulation of the physiological processes controlled by acyl HSLs and, non-acyl HSL-mediated systems occurs in a cell density- and growth phase-dependent manner. AHLs-mediated QS has been linked with the production of virulence factors, motility, nodulation, plasmid transfer, antibiotic production, bioemulsan production, bioluminescence, and biofilm formation (Whitehead et al., 2001; Vallenet et al., 2008). These autoinducers bind to transcriptional regulatory proteins and activate or regulate gene expression in the organism (Bhargava et al., 2010). In a previous study, González et al. (2001) detected QS signal molecules capable of activating AHL biosensors in A. baylyi ADP1 cultures and in culture supernatants of some clinical Acinetobacter strains. A common AHL system of Gram-negative bacteria is mediated by two proteins: LuxI proteins which interact with the LuxR protein. This complex binds to a specific promoter sequence known as lux-box, which regulates the expression of QS target genes. In Acinetobacter, the lux-box is found upstream from the putative ATG of $a b a \mathrm{I}$, representing a binding site for AbaR. AbaI protein belongs to the LuxI family of autoinducer synthases, producing $\mathrm{N}$-(3-hydroxydodecanoyl)-L-HSL (3-hydroxy-C(12)-HSL) as the primary signal and performing the function of signal transduction and QS. The AbaR protein, which is an autoinducer receptor in $A$. baumannii, interacts with AHL and controls gene expression (Niu et al., 2008).

Acinetobacter quorum signals have been shown to vary in virulent and non-virulent strains, thus differentiation between them on the basis of QS is difficult. On the other hand, communication among bacteria with respect to cell density is related to maturation of biofilm. It was observed that mutations in abaI led to a reduction in biofilm production compared with the isogenic parental strain but the original phenotype could be restored when a exogenous Acinetobacter AHL was added to the mutant (Niu et al., 2008; Bhargava et al., 2010). Thus, QS signal molecules influence biofilm formation which represents an important virulence factor related to the survival and antibiotic resistance of $A$. baumannii (Gaddy and Actis, 2009; Bhargava et al., 2010). Kang and Park (2010a) evaluated the effect of QS signals on hexadecane biodegradation and biofilm formation in the Acinetobacter spp. strain DR1, and found phenotypic changes in the strain associated with three putative QS signals that strongly indicated their relation in biofilm formation. Particularly, $\mathrm{C}_{12}$-AHL, which was a major QS signal and controlled the biofilm formation in A. baumannii M2 previously described by Niu et al. (2008). The poor biodegradability of hydrocarbons was one of the significant changes observed when QS signals where eliminated, and consequently resulted in alterations of bacterial hydrophobicity, cellular motility by fimbriae or pili, biofilm formation, and other environmental factors (Clemmer et al., 2011). Thus, in the DR1 strain, the QS system and putative AHLs directly regulated the biofilm formation and growth on hydrocarbons. In another study, Kang and Park (2010b) described a trade-off between antibiotic resistance and biological fitness (Kang and Park, 2010b). The biological fitness of the Acinetobacter strain DR1 was influenced by the in situ acquisition of antibiotic resistance, probably attributable to the reduced ability to produce QS signals, lack of motility, and reduced substrate utilization.

As a concluding remark, it has been hypothesized that interference with bacterial virulence and/or cell-to-cell signaling 
pathways, such as interruption of QS signals, known as quorum quenching (QQ; Chan et al., 2011), represents an important target for pathogenesis inhibition and development of novel therapeutics for the treatment of bacterial infections (Whitehead et al., 2001; Bhargava et al., 2010; Rasko and Sperandio, 2010).

\section{PUTATIVE ALIEN ISLANDS}

New insights into the pathogenesis of A. baumannii has demonstrated that mutagenesis and genomic sequencing can uncover and evaluate many virulence factors for a better understanding of the pathogenicity of this bacterium. Smith et al. (2007) performed a genomic analysis between $A$. baumannii and $A$. baylyi and found $55.74 \%$ homology at the protein level. One of the most interesting differences between both was the presence of 28 putative alien islands (pAs) in A. baumannii (Smith et al., 2007). These islands were found to contain the majority of the drug resistance and virulence factors, many acquired from their environment, indicating their role in the pathogenicity of A. baumannii. Some of these islands contained genes associated with pathogenesis, encoding heavy metal resistance, iron uptake and metabolism, fimbrial genes, autoinducer processing, and cell envelope biogenesis. Other pAs contained hypothetical genes and mobile elements that remain uncharacterized. Thus, gene shuffling mutagenesis revealed that pAs might (Camarena et al., 2010) play an important role in the pathogenesis of $A$. baumannii.

\section{ANTIMICROBIAL RESISTANCE}

While other human pathogens stand out due to their virulence and pathogenicity, A. baumannii is not known to be particularly virulent or to produce diffusible toxins or cytolysins, and only a few virulence factors have been described to date (Vallenet et al., 2008). There is, however, one feature at which this microorganism excels, and that is antimicrobial resistance. Indeed, A. baumannii has an outstanding ability to accumulate different resistance mechanisms which, together with its innate resistance to desiccation, contribute to the survival and persistence of A. baumannii under selective environmental pressure, making this microorganism a phenomenal nosocomial pathogen.

Acinetobacter baumannii has become resistant to almost all commonly used antimicrobial agents, including aminoglycosides, quinolones and broad-spectrum $\beta$-lactams, and multidrug or pandrug-resistant strains are becoming a frequent problem in the clinical setting (Livermore et al., 2008; Rossolini and Mantengoli, 2008; Morgan et al., 2009; Table 1).

Overall, antimicrobial resistance can be achieved by means of two main mechanisms: acquisition of novel genetic information through horizontal gene transfer and genetic modification of endogenous genes.

Acquisition of novel genetic determinants in A. baumannii takes place by the combined effect of mobile genetic elements (insertion sequences, IS and transposons), integrons, and transferable plasmids, while the genetic modification of endogenous genes implies either spontaneous mutations that modify drug targets or the insertion/deletion of mobile elements that alter the expression of endogenous resistance mechanisms or modify membrane permeability.

\section{$\beta$-LACTAMS}

The mechanisms involved in resistance to $\beta$-lactams in A. baumannii typically include: (i) enzymatic mechanisms or production of $\beta$-lactam hydrolyzing enzymes ( $\beta$-lactamases) and (ii) nonenzymatic mechanisms that involve modification of membrane permeability by either the loss of or decrease in the expression of OMPs or an increased expression of efflux pumps as well as sequence variation of PBPs.

\section{ENZYMATIC MECHANISMS}

The main mechanism of resistance to $\beta$-lactam antibiotics in $A$. baumannii lies in the production of $\beta$-lactamases encoded either chromosomally or in plasmids. The common genome of A. baumannii possesses two intrinsic $\beta$-lactam hydrolyzing enzymes; a non-inducible cephalosporinase (AmpC; Bou and MartinezBeltran, 2000b) and a class D oxacillinase (OXA-51/69 variants; Brown et al., 2005).

\section{Chromosomal cephalosporinases (AmpC)}

AmpC enzymes are class $C \beta$-lactamases responsible for resistance to all penicillins and extended-spectrum cephalosporins, except cefepime, as well as to $\beta$-lactam- $\beta$-lactamase inhibitor combinations (Drawz et al., 2010). Several allelic variants of the AmpC enzyme have been reported and a new designation for this family of cephalosporinases has been defined (Acinetobacter-derived cephalosporinases, or ADC). According to sequence similarities as well as preferred substrates, AmpCs found within Acinetobacter have been classified in up to 56 different ADC types, with more than 25 variants being found in A. baumannii (Hujer et al., 2005; Zhao and $\mathrm{Hu}, 2012$ ). Being non-inducible, the basal expression levels of AmpC enzymes from A. baumannii do not significantly alter susceptibility to $\beta$-lactams, although the presence of an upstream IS element (known as ISAbaI) promotes increased expression of $b l a_{\mathrm{ampC}}$ and resistance to expanded-spectrum cephalosporins but not to cefepime and carbapenems. Expression of $b l a_{\mathrm{ampC}}$ is apparently driven by promoter sequences within the ISAbaI element (Héritier et al., 2006).

\section{Oxacillinases}

Ambler Class D enzymes, also known as oxacillinases (OXA; Ambler, 1980), are distinguished by their ability to hydrolyze cloxacillin and oxacillin, and some also oxyimino- $\beta$-lactams, but not carbapenems and might be inhibited by clavulanic acid. The oxacillinase enzymes present in Acinetobacter spp., however, constitute an atypical subgroup of OXA enzymes since they present carbapenem-hydrolyzing activities (they hydrolyze imipenem and meropenem but not extended-spectrum cephalosporins and aztreonam) and, therefore, are also termed as carbapenem-hydrolyzing class D $\beta$-lactamases (CHDLs; Poirel and Nordmann, 2006a) and have their own group (2df) in the updated functional classification of $\beta$-lactamases recently published by Bush and Jacoby (2010). In A. baumannii, five phylogenetic subgroups of class $\mathrm{D} \beta$-lactamases have currently been identified: the naturally occurring OXA-51/69 and four clusters of acquired CHDLs (OXA-23, OXA-24/40, OXA58 , and OXA-143), each with a variety of enzymes that represent different sequence substitutions.

Similar to $b l a_{\mathrm{ampC}}$, basal expression of the naturally occurring OXA-51 oxacillinase in A. baumannii only allows for 
Table 1 | Antimicrobial resistance mechanisms in A. baumannii.

\begin{tabular}{|c|c|c|c|c|c|}
\hline Antimicrobial & Resistance mechanism & $\begin{array}{l}\text { Class/ } \\
\text { family }\end{array}$ & Protein & $\begin{array}{l}\text { Described in } \\
\text { association with }\end{array}$ & Selected reference \\
\hline \multirow[t]{20}{*}{$\beta$-Lactams } & $\begin{array}{l}\text { Chromosomal } \\
\text { cephalosporinase }\end{array}$ & Class C & $\mathrm{AmpC}$ & IS & Hujer et al. (2005) \\
\hline & Carbapenem-hydrolyzing & Class D & OXA-51-like & IS & Turton et al. (2006) \\
\hline & class $D \beta$-lactamases & & OXA-23-like & IS, Tn, AbaR & Corvec et al. (2007), Adams et al. (2008) \\
\hline & & & OXA-24/40-like & XerC/XerD & Merino et al. (2010) \\
\hline & & & OXA-143-like & & Higgins et al. (2009) \\
\hline & Metallo- $\beta$-lactamases & Class B & IMP & Integron & Cornaglia et al. (2011) \\
\hline & & & VIM & Integron & Cornaglia et al. (2011) \\
\hline & & & SIM-1 & Integron & Cornaglia et al. (2011) \\
\hline & & & NDM & IS, Tn & Espinal et al. (2011a), Pfeifer et al. (2011) \\
\hline & Minor relevance & Class A & TEM & AbaR & Adams et al. (2008), Shakil and Khan (2010) \\
\hline & & & PER & IS, Tn, integron & Poirel et al. (2005a), Bonnin et al. (2011b) \\
\hline & & & VEB & IS, integron, AbaR & Fournier et al. (2006), Poirel et al. (2009) \\
\hline & & & CTX-M & $\mathrm{Tn}$ & Potron et al. (2011) \\
\hline & & & GES & Integron & Moubareck et al. (2009) \\
\hline & & & $\mathrm{KPC}$ & & Robledo et al. (2010) \\
\hline & & Class D & OXA-2, 10, 20, 37 & Integron, AbaR & $\begin{array}{l}\text { Navia et al. (2002), Fournier et al. (2006), } \\
\text { Adams et al. (2008) }\end{array}$ \\
\hline & Decreased permeability & & CarO & IS & Ravasi et al. (2011) \\
\hline & & & 47 kDa OMP & & Quale et al. (2003) \\
\hline & & & 44 kDa OMP & & Quale et al. (2003) \\
\hline & & & 37 kDa OMP & & Quale et al. (2003) \\
\hline \multirow[t]{6}{*}{ Aminoglycosides } & Aminoglycoside-modifying & & Acetyltransferases & IS, Tn, Integron, & Cho et al. (2009) \\
\hline & enzymes & & Nucleotidyltransferases & AbaR & Cho et al. (2009) \\
\hline & & & Phosphotransferases & & Cho et al. (2009) \\
\hline & $\begin{array}{l}\text { Target binding site } \\
\text { modification }\end{array}$ & & 16S rRNA methylases & IS, Tn & Doi et al. (2007) \\
\hline & Efflux & RND & AdeABC & IS & Magnet et al. (2001) \\
\hline & & MATE & AbeM & & Su et al. (2005) \\
\hline \multirow[t]{6}{*}{ Quinolones } & Target site mutations & & GyrA/ParC & & Hamouda and Amyes (2004) \\
\hline & Efflux pump & RND & AdeABC & IS & Magnet et al. (2001) \\
\hline & & & AdelJK & & Damier-Piolle et al. (2008) \\
\hline & & & AdeFGH & & Coyne et al. (2010b) \\
\hline & & MATE & AbeM & & Su et al. (2005) \\
\hline & & SMR & Abes & & Srinivasan et al. (2009a) \\
\hline \multirow[t]{3}{*}{ Chloramphenicol } & Efflux pump & RND & AdeABC & IS & Magnet et al. (2001) \\
\hline & & & AdelJK & & Damier-Piolle et al. (2008) \\
\hline & & & AdeFGH & & Coyne et al. (2010b) \\
\hline
\end{tabular}


Table 1 | Continued

\begin{tabular}{|c|c|c|c|c|c|}
\hline Antimicrobial & Resistance mechanism & $\begin{array}{l}\text { Class/ } \\
\text { family }\end{array}$ & Protein & $\begin{array}{l}\text { Described in } \\
\text { association with }\end{array}$ & Selected reference \\
\hline & & MFS & $\mathrm{CmlA}$ & AbaR & Fournier et al. (2006), Vila et al. (2007) \\
\hline & & & CraA & & Roca et al. (2009) \\
\hline & & MATE & AbeM & & Su et al., 2005 \\
\hline & & SMR & AbeS & & Srinivasan et al. (2009a) \\
\hline \multirow[t]{3}{*}{ Tetracyclines } & Efflux pump & MFS & TetA & IS, Tn, AbaR & Ribera et al. (2003a), Fournier et al. (2006) \\
\hline & & & TetB & & Vila et al. (2007) \\
\hline & Ribosomal protection & & TetM & & Ribera et al. (2003b) \\
\hline \multirow[t]{2}{*}{ Tigecycline } & Efflux pump & RND & AdeABC & IS & Magnet et al. (2001) \\
\hline & & & AdelJK & & Damier-Piolle et al. (2008) \\
\hline \multirow[t]{3}{*}{ Polymyxins } & Lipid A modification & & PmrCAB & & Arroyo et al. (2011), Beceiro et al. (2011) \\
\hline & Loss of lipopolysaccharide & & LpxABC & IS & Moffatt et al. (2011) \\
\hline & Porin loss & & & & Fernández-Reyes et al. (2009) \\
\hline
\end{tabular}

IS, Insertion sequence; Tn, transposon; AbaR, resistance island; RND, resistance-nodulation-cell division family; MFS, major facilitator superfamily; MATE, multidrug and toxic compound extrusion family; SMR, small multidrug resistance family.

weak hydrolysis of $\beta$-lactamic substrates, mainly penicillins and carbapenems (they are not active against expanded-spectrum cephalosporins; Héritier et al., 2005a) unless ISAbaI or ISAba9 elements are located upstream from bla $a_{\text {OXA-51-like genes to increase }}$ their expression (Turton et al., 2006; Figueiredo et al., 2009). Over 68 different OXA-51 sequence variants are classified as Class D enzymes (Zhao and Hu, 2012).

Originally named ARI-1, the acquired OXA-23 enzyme shares $56 \%$ identity at the protein level with OXA-51/69 and was initially identified in a plasmid from an A. baumannii isolate in Scotland, constituting the first oxacillinase with carbapenemase activity to be reported (Paton et al., 1993). Since then, the bla OXA-23 gene has been identified all over the world, both in the chromosome or in plasmids, and it is apparently exclusive of the Acinetobacter genus, with a Proteus mirabilis isolate from France being the sole exception (Bonnet et al., 2002). OXA-27, OXA-49, and OXA-73 are also included within this cluster (Afzal-Shah et al., 2001; see also http://www.lahey.org/studies/).

The second cluster of acquired class D enzymes is named after the OXA-24/40 enzyme (OXA-24 and OXA-40 were initially identified as different enzymes but re-sequencing has shown that they are indeed indistinguishable; see http://www.lahey.org/studies/), which was originally isolated from the chromosome of a carbapenem-resistant A. baumannii isolate from Spain (Bou et al., 2000c). This class also includes the OXA-25, OXA-26, and OXA72 (Afzal-Shah et al., 2001; Wang et al., 2007) enzymes and shares roughly 63 and $60 \%$ amino acid identity with the OXA-51/69 and OXA-23 clusters, respectively. Although the OXA-26 enzyme has been identified in Belgium (Afzal-Shah et al., 2001), the OXA-72 in isolates from Asia (Wang et al., 2007; Lee et al., 2009a; Lu et al., 2009) and more recently also from Croatia (Goic-Barisic et al., 2011), and the bla OXA-40 gene has also been found in the United States (Lolans et al., 2006; Qi et al., 2008), the bla OXA-40-like genes seem to be highly prevalent in Spain and Portugal (Quinteira et al., 2007; Ruiz et al., 2007) and they can also be found either in the chromosome or be plasmid-borne.
The third cluster of acquired CHDLs is represented by OXA-58, identified in A. baumannii by Poirel et al. (2005b), sharing 59\% amino acid identity with OXA-51/69 and less than 50\% amino acid identity with OXA-23 and OXA-24/40. The bla OXA-58 gene has only been found in Acinetobacter spp. so far, and it has been detected in A. junii in Romania and Australia (Marqué et al., 2005; Peleg et al., 2006), in A. pittii and Acinetobacter phenon 6/ct 13TU in Spain (Martí et al., 2008a,b), in A. nosocomialis in Taiwan (Lin et al., 2010), and Wang et al. (2007) also reported the first identification of a bla $a_{\mathrm{OXA}} 58^{-}$-like gene in Acinetobacter genomic species 14TU in China.

The bla ${ }_{\text {OXA-58 }}$ gene is usually plasmid-encoded, which most likely accounts for its wide distribution throughout the world, although it is especially prevalent in Italy and Greece (D'Arezzo et al., 2009; Papa et al., 2009; Donnarumma et al., 2010; Di Popolo et al., 2011; Gogou et al., 2011), where carbapenemresistant A. baumannii strains producing OXA-58 have caused several outbreaks in intensive care and pediatric units (Poirel et al., 2006; Pournaras et al., 2006; Tsakris et al., 2008). OXA-96 (Koh et al., 2007b) and OXA-97 (Poirel et al., 2008b) constitute pointmutation derivatives of OXA-58 included within the same cluster and with similar hydrolytic properties.

The fourth cluster of acquired CHDLs present in A. baumannii was identified more recently upon the isolation of a novel OXA143 enzyme recovered from an A. baumannii clinical isolate in Brazil (Higgins et al., 2009). At the protein level, this enzyme is 88,63 , and 52\% identical to OXA-24/40, OXA-23, and OXA-58 respectively, but exhibits a similar substrate profile to that of other CHDLs from A. baumannii.

Overall, the level of carbapenem-hydrolysis by CHDLs is considerably low, with imipenem being the preferred substrate over meropenem, thereby raising a debate as to the exact contribution of these enzymes to carbapenem resistance (Queenan and Bush, 2007). Héritier et al. (2005b) addressed this issue by studying changes in susceptibility to carbapenems using either knockout mutants or transformation experiments with both natural 
and recombinant plasmids containing bla $a_{\text {OXA-23 }}, b l a_{\text {OXA-40, }}$, and $b l a_{\text {OXA-58 }}$ in different hosts and genetic backgrounds. These experiments demonstrated that acquired CHDLs significantly contribute to the resistant phenotype, with OXA-40 and especially OXA-23 showing a significantly greater impact on resistance than OXA-58. In addition, they also noticed that CHDLs expressed from natural plasmids originated greater levels of carbapenem resistance than those expressed in recombinant vectors, pointing out the importance of IS elements to enhance the expression of acquired class D oxacillinases in A. baumannii (Héritier et al., 2005b). The role of mobile genetic elements in the expression and transfer of resistance determinants will be discussed further on.

\section{Metallo- $\beta$-lactamases}

Since their introduction back in 1985, carbapenems have probably been (and still are) the most important antimicrobial agents for the treatment of infections caused by multidrug-resistant A. baumannii. During the last decades, however, resistance to carbapenems is increasing worldwide (Gopalakrishnan and Sureshkumar, 2010; Davies et al., 2011; Gogou et al., 2011; Lee et al., 2011a) and carbapenem-resistant A. baumannii strains are commonly resistant to all other classes of antibiotics as well, showing intermediate susceptibility to rifampicin and only being susceptible to tigecycline and colistin, although resistance to both antimicrobials has also recently been reported (Al-Sweih et al., 2011; Taneja et al., 2011).

There is another class of acquired $\beta$-lactamases in A. baumannii which, together with Ambler class $\mathrm{D}$ enzymes, contributes to the carbapenem-resistant phenotype, the Ambler class B of metallo- $\beta$-lactamases or MBLs. This group of enzymes differs from other $\beta$-lactamases in its broad substrate profile (they are capable of hydrolyzing all $\beta$-lactams except the monobactam aztreonam), potential for horizontal transfer and the fact that they are zinc-dependent metalloproteins inhibited by EDTA but not by carbapenem or $\beta$-lactamase inhibitors such as clavulanic acid, tazobactam, and sulbactam (Bush and Jacoby, 2010).

Although MBLs are not as much widespread as class D enzymes in $A$. baumannii, they display a significantly higher hydrolytic activity toward carbapenems (100- to 1,000-fold; Poirel and Nordmann, 2006a). Of the several groups of MBLs described to date, only IMP, VIM, SIM, and the novel NDM have been found in A. baumannii and, with the exception of NDM, they are typically identified within class 1 integrons containing an array of resistance gene cassettes as well, usually including some aminoglycosideresistance determinants (Riccio et al., 2000; Houang et al., 2003; Zarrilli et al., 2004; Lee et al., 2005; Tsakris et al., 2006). The importance of integrons and their contribution to the MDR phenotype will be further expanded later in this review.

IMP metallo- $\beta$-lactamases (named for being active on imipenem) were first described in Japan from a Pseudomonas aeruginosa isolate in 1990 (Watanabe et al., 1991). After that initial isolation, IMP enzymes have been reported worldwide in several Gram-negative bacteria, including A. baumannii (Queenan and Bush, 2007). So far there are up to 33 different IMP variants (according to http://www.lahey.org/studies/) but only 8 (IMP-1, $2,-4,-5,-6,-8,-11$, and -19$)$ have been identified in A. baumannii, mostly in Asia but also in Europe and parts of South America (Riccio et al., 2000; Chu et al., 2001; Da Silva et al., 2002; Towner et al., 2002; Gales et al., 2003; Lee et al., 2003, 2008; Yamamoto et al., 2011). Enzymes belonging to the IMP type have broad substrate specificity and are especially active against cephalosporins and carbapenems.

The first VIM enzyme (VIM-1) was initially described in 1999 from a $P$. aeruginosa isolate in the Italian location of Verona (hence, Veronese imipenemase; Lauretti et al., 1999) but the first VIM enzyme (VIM-2) in A. baumannii was not described until a few years later (Yum et al., 2002). VIM MBLs display $<40 \%$ amino acid identity with IMP enzymes and share a similar substrate profile, albeit with a higher affinity toward carbapenems (Docquier et al., 2003). During the past decade several VIM variants (VIM-1, $-2,-3,-4$, and -11) have been identified in A. baumannii isolates, mainly in European and Asian countries (Yum et al., 2002; Lee et al., 2003, 2008; Tsakris et al., 2006; Wroblewska et al., 2007; Figueiredo et al., 2008) but also in clinical isolates of the closely related A. nosocomialis and A. pittii (Espinal et al., 2011b).

SIM-1 was originally found in A. baumannii in a tertiary care hospital in Seoul, Korea (hence, Seoul imipenemase), and so far this isolate contains the only bla $a_{\mathrm{SIM}-1}$ gene reported in this microorganism (Lee et al., 2005). SIM-1 exhibits $64-69 \%$ amino acid identity with IMP enzymes and, similar to IMP and VIM, it is capable of hydrolyzing penicillins, narrow-, and expanded-spectrum cephalosporins as well as carbapenems.

More recently, a novel class B metallo- $\beta$-lactamase enzyme has been reported. This enzyme was first identified in Klebsiella pneumoniae and E. coli clinical isolates recovered in Sweden from a traveler returning from India and has, hence, been termed NDM1 for New Delhi metallo- $\beta$-lactamase (Yong et al., 2009). Similar to other MBL enzymes, NDM- 1 confers resistance to all $\beta$-lactams except aztreonam. After its initial isolation, several reports have identified $b l a_{\mathrm{NDM}}$ genes in Enterobacteriaceae worldwide due to their plasmidic localization that allows for rapid transfer and dissemination (Nordmann et al., 2011, 2012; Poirel et al., 2011a). In 2010 the $b l a_{\mathrm{NDM}-1}$ gene was first identified in an intensive care unit in India from an A. baumannii isolate that also contained the bla OXA-23 gene and armA (Karthikeyan et al., 2010), a gene encoding a 16S rRNA methylase conferring resistance to aminoglycosides (Yamane et al., 2005). The chromosomal or plasmidic location of this gene, however, was not clear. Kaase et al. (2011) identified the first NDM variant in an A. baumannii isolate from Egypt, NDM-2, which differed from NDM-1 by a single amino acid substitution but shared an identical spectrum of hydrolysis. Although not fully demonstrated, $b l a_{\mathrm{NDM}-2}$ was thought to be chromosomally located. Several reports have subsequently described NDM enzymes in A. baumannii isolates from China, Germany, and Israel (Chen et al., 2011; Espinal et al., 2011 a; Pfeifer et al., 2011) but also in an Acinetobacter lwoffii isolate from China (Hu et al., 2011). Interestingly, while the bla $a_{\mathrm{NDM}-1}$ and bla $a_{\mathrm{NDM}-2}$ from Germany (Pfeifer et al., 2011) and Israel (Espinal et al., 2011a), respectively, were found on the chromosome of $A$. baumannii, the bla $a_{\mathrm{NDM}-1}$ from Chinese isolates were located on several plasmids ranging from 30 to $50 \mathrm{~kb}$ in size (Chen et al., 2011) and as was the bla $a_{\mathrm{NDM}-1}$ gene found in A. lwoffii of Chinese origin. 


\section{Minor relevance $\beta$-lactamases}

Additional $\beta$-lactamase enzymes belonging to the Ambler class A have also been described in A. baumannii but they are generally regarded of minor relevance since the prevalence of these enzymes as well as their specific contribution to the resistant phenotype is usually hindered by the presence of more prevalent mechanisms such as the intrinsic AmpC cephalosporinase or the naturally occurring OXA-51, among others (Poirel and Nordmann, 2006a).

Narrow-spectrum serine $\beta$-lactamases such as TEM-1, SCO1, CARB-2, -4, and -8 as well as OXA-20, OXA-21, and OXA37 have all been detected in A. baumannii (Vila et al., 1997a; Navia et al., 2002; Mammeri et al., 2003; Zarrilli et al., 2004; Koh et al., 2007b; Poirel et al., 2007; Wang et al., 2007; Ramírez et al., 2010b), but some other extended-spectrum $\beta$-lactamases and serine-carbapenemases are also present.

PER-1 was the first ESBL enzyme identified in A. baumannii (Vahaboglu et al., 1997) but also PER-2 and -7 (Pasterán et al., 2006; Bonnin et al., 2011b), VEB-1 (Poirel et al., 2003), TEM variants TEM-92, -116, and -150 (Naiemi et al., 2005; Endimiani et al., 2007; Shakil and Khan, 2010), GES-11, -12, and -14 (Bogaerts et al., 2010), the atypical expended-spectrum carbenicillinase CARB-10 (Potron et al., 2009), capable of hydrolyzing fourth generation cephalosporins but not ceftazidime or cefotaxime, at least three different SHV-type ESBLs (SHV-2, -5, and -12; Naiemi et al., 2005; Naas et al., 2007) as well as three different types of the plasmid-mediated CTX-M enzymes (CTX-M-2, -15, -43; Nagano et al., 2004; Celenza et al., 2006; Shakil and Khan, 2010) have been reported so far in this microorganism.

Interestingly, while PER and VEB are usually regarded as second-class $\beta$-lactamases in Enterobacteriaceae (Naas et al., 2008), they are more commonly found in A. baumannii and seem to be emerging in certain geographic regions where they are responsible for nosocomial outbreaks (Vahaboglu et al., 1997; Naas et al., 2006a,b). On the other hand, CTX-M variants, especially CTX-M-15, are widely disseminated among Enterobacteriaceae worldwide (Canton and Coque, 2006) but, until recently, were rare in A. baumannii. Recent reports seem to indicate an increase in A. baumannii strains bearing CTX-M variants within the AsiaPacific region, most likely associated with transposon-mediated mobilization events (Nagano et al., 2004; Shakil and Khan, 2010; Potron et al., 2011).

It is worth mentioning that $10 \mathrm{KPC}$ enzymes, including a novel variant, KPC-10, have also recently been identified among isolates belonging to the A. calcoaceticus-A. baumannii complex in Puerto Rico, although identification to the species level was not conclusive (Robledo et al., 2010).

\section{NON-ENZYMATIC MECHANISMS Membrane permeability}

Resistance to $\beta$-lactams by means of non-enzymatic mechanisms includes any alteration in the permeability of bacterial membranes that either prevents the entry of antimicrobial agents or promotes their efflux. Very little is known about the OMPs of A. baumannii, but several studies have highlighted the relevance of such proteins in resistance to $\beta$-lactams. In 2002, Viale and co-workers demonstrated that the loss of a $29-\mathrm{kDa}$ protein, named CarO, was associated with carbapenem resistance in A. baumannii in the absence of any known carbapenemase (Limansky et al., 2002). The loss of CarO in several carbapenem-resistant A. baumannii isolates was due to the presence of distinct insertion elements that disrupted the carO gene (Mussi et al., 2005). Structural studies on this protein, however, showed that although CarO presented some pore-forming properties, it did not contain any specific binding site for carbapenems and was rather a non-specific channel (Siroy et al., 2005). Several other investigations have also identified a variety of OMP proteins mainly involved in carbapenem resistance upon OMP-loss or reduced expression, including a set of endemic carbapenem-resistant A. baumannii isolates from New York presenting reduced expression of 47-, 44-, and 37-kDa OMPs together with an increased expression of the class $\mathrm{C}$ cephalosporinase (Quale et al., 2003); an A. baumannii isolate in Spain that had lost a 33- to 36-kDa OMP associated with carbapenem resistance (del Mar Tomas et al., 2005); and, also similar to what has already been described in Enterobacteriaceae (Kitchel et al., 2010; Pitart et al., 2011), the combined effect of reduced expression of 22- and 33-kDa OMPs and an acquired carbapenemase enzyme (OXA-23; Bou et al., 2000a).

Proteomic studies have also highlighted some OMPs that might have a relevant role in the resistant phenotype to $\beta$-lactams, such as the heat-modifiable HMP-AB, which constitutes the major OMP of A. baumannii and resembles the OmpA protein from Enterobacteriaceae (Gribun et al., 2003), OmpW (Siroy et al., 2006; Vila et al., 2007), and a 43-kDa protein similar to OprD from $P$. aeruginosa (Dupont et al., 2005).

More recently, Fernández-Cuenca et al. investigated the virulence phenotype of a pan-drug-resistant A. baumannii clinical isolate and found an association between attenuated virulence and the decreased expression of genes encoding CarO and OprD-like porins. Attenuated virulence in this work was attributed to a higher biological cost when losing certain OMPs (Fernández-Cuenca et al., 2011).

The role of efflux proteins in the antibiotic susceptibility profile of A. baumannii will be discussed in more detail within the following pages, however, it should be mentioned that the contribution to $\beta$-lactam resistance of the three resistance-nodulationcell division (RND) efflux pumps identified so far in A. baumannii (AdeABC, AdeIJK, and AdeFGH) has not been extensively studied. Disruption of either adeABC or adeIJK has been shown to cause 4 - and 12-fold decreases in the MICs of cefotaxime and cefepime, respectively, with that of imipenem remaining unchanged. AdeFGH, on the other hand, does not seem to affect susceptibility to $\beta$-lactams (Magnet et al., 2001; DamierPiolle et al., 2008; Coyne et al., 2010b). Interestingly, Wong et al. (2009) showed that disruption of adeB in three A. baumannii strains significantly altered susceptibility to meropenem but not to imipenem and, more recently, Roca et al. (2011) characterized an AdeABC-type efflux pump in an isolate of the closely related A. nosocomialis which was able to extrude monobactams, thirdgeneration cephalosporins, cefoxitin, and meropenem but, again, not imipenem.

Overall, $\beta$-lactam extrusion by means of efflux systems leads to small increases in the MIC, and high-level resistance can only be achieved in combination with additional resistance mechanisms (Héritier et al., 2005a). 


\section{Penicillin-binding proteins}

Another non-enzymatic mechanism of resistance to $\beta$-lactams involves changes in the affinity or expression levels of PBPs. Several reports have identified differences in the expression patterns of PBPs between carbapenem-susceptible and carbapenem-resistant A. baumannii strains. In some of these strains, carbapenem resistance has been associated with the overexpression of PBP types with low affinity for carbapenem in the absence of any other known resistance mechanism (Gehrlein et al., 1991; Urban et al., 1995) but also with the reduced expression of PBP types together with the production of several $\beta$-lactamases or the loss of a 22.5kDa OMP (Fernández-Cuenca et al., 2003; Cayo et al., 2011). Overall, the contribution of PBP variants to carbapenem resistance is marginal unless associated with $\beta$-lactamases, overexpression of efflux pumps or decreased expression of OMPs, and the mechanisms leading to altered expression levels of these proteins have yet to be elucidated (Yun et al., 2011).

\section{AMINOGLYCOSIDES}

Resistance to aminoglycosides in A. baumannii can be achieved by means of efflux proteins extruding these compounds (reviewed below) or by the expression of aminoglycoside-modifying enzymes (AMEs), specifically acetyltransferases, nucleotidyltransferases, and phosphotransferases (Cho et al., 2009). Activity of AMEs results in the modification of hydroxyl or amino groups present within aminoglycosides that decrease their affinity for the target site (Smith and Baker, 2002). AMEs can be located in either the bacterial chromosome or in plasmids and are usually associated with class 1 integrons and resistance islands where two or more aminoglycoside-resistance genes often occur in combination (Cho et al., 2009). Nemec et al. showed that more than 95\% out of 106 European multidrug-resistant A. baumannii isolates contained at least one aminoglycoside-resistance gene and $84 \%$ contained a combination of two to five different genes with more than 12 distinct combinations. Seventy-eight percent of the strains contained class 1 integrons as well, highlighting the major role of horizontal gene transfer in the dissemination of AMEs in A. baumannii (Nemec et al., 2004).

More recently, 16S rRNA methylation mediated by armA has also been described in A. baumannii, conferring high-level resistance to all clinically relevant aminoglycosides, such as gentamicin, tobramycin, and amikacin (Doi and Arakawa, 2007). armA has been found in China, Korea, and the United States (Lee et al., 2006a; Doi et al., 2007; Yu et al., 2007), and it is also commonly found in combination with the bla OXA-23 gene (Kim et al., 2008; Karthikeyan et al., 2010).

\section{QUINOLONES}

The mechanisms of fluoroquinolone resistance in A. baumannii parallel those of other Gram-negative bacteria and are mainly achieved by point mutations originating amino acid substitutions within the quinolone-resistance determining regions (QRDR) of DNA gyrase and DNA topoisomerase IV (Fàbrega et al., 2009). Mutations in both gyrA and parC have been described in $A$. baumannii with the most common substitutions being Ser83 to Leu83 for gyrA and Ser80 to Leu80 in parC (Vila et al., 1995, 1997b; Seward and Towner, 1998; Spence and Towner, 2003;
Wisplinghoff et al., 2003; Hamouda and Amyes, 2004; Higgins et al., 2004; Valentine et al., 2008). It is worth mentioning that mutations in parC are always accompanied by a concurrent mutation in $g y r A$, probably suggesting that DNA gyrase is the preferred target for fluoroquinolones in A. baumannii (Vila et al., 1995, 1997b; Hamouda and Amyes, 2004).

Several efflux pumps in A. baumannii are also involved in fluoroquinolone resistance and their specific contribution will be discussed later. Interestingly, plasmid-mediated fluoroquinolone resistance mechanisms such as $q n r, a a c\left(6^{\prime}\right)-I b-c r$, or qepA (Fàbrega et al., 2009) have not yet been described in A. baumannii (Yin et al., 2008; Srinivasan et al., 2009b).

\section{POLYMYXINS}

To date, most multidrug A. baumannii strains still remain susceptible to polymyxins, prompting an increased use of these compounds despite previous concerns regarding toxicity issues (Falagas and Kasiakou, 2005). Polymyxin E (Colistin), acts by modifying the negative charges of the outer membranes of Gramnegative bacteria, ultimately leading to the disruption of the bacterial membrane. There is very little information regarding the mechanisms of colistin resistance in A. baumannii, but it appears that colistin resistance might be multifactorial. By comparing the proteomes of colistin-susceptible versus colistin-resistant A. baumannii isolates Fernández-Reyes et al. (2009) were able to identify the differential expression of 35 proteins, including OMPs, chaperons, protein biosynthesis factors, and metabolic enzymes. Other studies, however, have focused on modifications in the bacterial lipopolysaccharide. It has been shown that mutations causing an up-regulated expression of the $p m r A$ and $p m r B$ genes lead to colistin resistance in A. baumannii (Adams et al., 2009). pmrA and pmrB constitute a two-component regulatory system that governs the expression of $p m r C$, encoding a phosphoethanolamine transferase enzyme involved in lipid A modification. Up-regulation of $p m r A$ and $p m r B$ also causes the overexpression of $p m r C$ and the addition of phosphoethanolamine to the lipid A, which impairs the self-promoted uptake of colistin across the outer membrane (Arroyo et al., 2011; Beceiro et al., 2011).

On the other hand, Moffatt et al. (2010) demonstrated that colistin resistance could also be achieved by the complete loss of lipopolysaccharide production due to mutations affecting several genes involved in lipid A biosynthesis $\left(l_{p} x A, l p x C\right.$, or $\left.l p x D\right)$. Mutations in these genes ranged from single point mutations to large deletions or even the presence of an insertion element, ISAba11, truncating either $l p x A$ or $l p x C$ (Moffatt et al., 2011). Interestingly, Moffatt et al. observed that colistin-resistant mutants lacking LPS had a 32- to 256-fold increase in susceptibility to other classes of antibiotics. The authors attributed this observation to a direct consequence of LPS loss causing an increased permeability of the outer membrane.

Interestingly, some reports seem to indicate that colistin resistance in A. baumannii is associated with lower bacterial fitness in vivo as well as decreased virulence, suggesting that colistin usage for the treatment of A. baumannii infections might constitute a safe and effective strategy (López-Rojas et al., 2011b). Nevertheless, reduced bacterial fitness in colistin-resistant A. baumannii strains does not always occur as acquisition of compensatory mutations 
might contribute to maintain the virulence of resistant isolates (López-Rojas et al., 2011c; Rolain et al., 2011).

\section{EFFLUX}

Antimicrobial efflux is yet another important mechanism of resistance in A. baumannii. In general, efflux constitutes a resistance mechanism that involves the extrusion of antimicrobial agents (as well as other compounds) from the inner side of bacterial membranes to the external environment by means of specific proteins typically named efflux pumps. Although only a few efflux systems have been described in this microorganism, their importance should not be taken lightly since most are capable of pumping out several antimicrobial agents and, therefore, contribute to the greatly feared multidrug-resistant phenotype of nosocomial $A$. baumannii.

Efflux pumps in bacteria are classified into up to five distinct families according to amino acid sequence similarities, energy source, number of components, number of transmembranespanning regions and types of substrates: (i) The adenosine triphosphate (ATP)-binding cassette (ABC) superfamily, (ii) the multidrug and toxic compound extrusion (MATE) family, (iii) the small multidrug resistance (SMR) family, (iv) the major facilitator superfamily (MFS), and (v) the RND family (Piddock, 2006).

The RND family usually plays a predominant role in MDR in Gram-negative bacteria and species of Acinetobacter are not an exception (Li and Nikaido, 2009). Members of this family consist of a tripartite system including a transporter protein embedded within the inner membrane, an OMP channel, and a membrane fusion protein linking the other two (Magnet et al., 2001). The first RND pump to be identified in A. baumannii was named AdeABC, with AdeB constituting the multidrug transporter protein, AdeC being the OMP and AdeA the periplasmic linking protein (Magnet et al., 2001). The adeABC genes are also preceded by two additional genes in inverted orientation, adeSR, which encode a two-component regulatory system apparently involved in controlling adeABC expression (Marchand et al., 2004). Expression of AdeABC confers decreased susceptibility to a wide variety of antimicrobials such as kanamycin, gentamicin, tobramycin, netilmicin, amikacin, erythromycin, tetracycline, chloramphenicol, trimethoprim, sparfloxacin, ofloxacin, perfloxacin, norfloxacin, ethidium bromide and, more recently, tigecycline (Ruzin et al., 2007) and meropenem (Koh et al., 2007a). Not all A. baumannii isolates seem to carry this system, though: Huys et al. (2005a) detected the adeB gene in 49 out of 51 (96\%) highly related A. baumannii strains, Chu et al. (2006) found adeB in 39 out of $56(70 \%)$ A. baumannii isolates from Hong Kong, Nemec et al. (2007) in roughly $83 \%$ of 116 isolates tested and Courvalin and co-workers identified the adeB gene in 24 out of 27 A. baumannii strains (88\%; Damier-Piolle et al., 2008), altogether indicating that although AdeABC might not be intrinsic to A. baumannii, it is indeed highly widespread among clinical isolates. Interestingly, the adeSRABC genes have recently been identified in one isolate of the closely related $A$. nosocomialis together with two additional RND pumps not found in A. baumannii (Roca et al., 2011). Very little is known about the resistance mechanisms in this particular microorganism but A. nosocomialis has appeared as a recent emergent pathogen with a great potential to cause disease and acquire a multidrug-resistant phenotype (Espinal et al., 2011b). Hence, the presence of three major efflux systems in an emerging multidrug-resistant pathogen is alarming.

Some studies also seem to suggest a correlation between the presence of this efflux system and the resistant phenotype of $A$. baumannii clinical isolates, since AdeABC is commonly associated with class 1 integron genes in resistant strains but missing in highly susceptible isolates (Fournier et al., 2006; Lin et al., 2009).

The second RND efflux system (AdeIJK) described in A. baumannii was reported in the same clinical isolate that led to the identification of AdeABC (Damier-Piolle et al., 2008). Overexpression of this pump either in E. coli or A. baumannii is apparently toxic, suggesting the presence of a tight regulation mechanism to maintain its expression levels low. No adjacent regulatory genes, however, have been found in the vicinity of adeIJK.

Inactivation of AdeIJK by allelic replacement showed decreased resistance to substrates similar to those of the AdeABC pump, and a double mutant $(\triangle a d e A B C / \triangle a d e I J K)$ displayed even lower MICs of chloramphenicol, tetracyclines, erythromycin, clindamycin, fluoroquinolones, and tigecycline than each of the single mutants, thus indicating both a cumulative effect of the pumps as well as overlapping substrate profiles, which is, nevertheless, interesting from a clinical point of view. However, opposed to AdeABC, AdeIJK did not seem capable of extruding ethidium bromide or azithromycin, despite the latter being a preferred substrate for AdeABC (Damier-Piolle et al., 2008). Unfortunately, extrusion of aminoglycosides could not be tested in this system since the allelic replacement mutants incorporated either kanamycin or apramycin resistance cassettes.

AdeIJK has so far been detected in all the A. baumannii strains tested (Damier-Piolle et al., 2008) and is therefore considered to have a more predominant role in the intrinsic low-level resistant phenotype of A. baumannii. The AdeIJK efflux transporter seems highly specific to A. baumannii and has not yet been described in other species of the Acinetobacter genus. It is worth mentioning, however, that adeIJK and adeXYZ (an RND efflux pump described in A. pittii and A. nosocomialis; Chu et al., 2006; Roca et al., 2011) are extremely alike, sharing $93 \%$ identity at the nucleotide level and $99 \%$ similarity at the protein level. Similarity percentages obtained when comparing already described adeJ sequences from different A. baumannii strains also provide similar figures which might suggest that they actually constitute the same efflux system that has been described twice in different genomic species and has been given different names.

Coyne et al. (2010a) reported a third RND-type efflux pump (AdeFGH) within a derivative mutant $(\triangle a d e A B C / \triangle a d e I J K)$ from the same A. baumannii strain in which AdeABC and AdeIJK had been characterized. Expression of AdeFGH was responsible for high-level resistance to chloramphenicol, clindamycin, fluoroquinolones, and trimethoprim as well as decreased susceptibility to tetracycline-tigecycline and sulfonamides, but $\beta$-lactams, erythromycin, and rifampin remained unchanged (Coyne et al., 2010b). Once again, substrate specificity toward aminoglycosides could not be assessed due to the presence of the respective kanamycin and apramycin resistance cassettes. 
A small ORF encoding a putative LysR-type transcriptional regulator, named adeL, was also identified in inverted orientation upstream from adeFGH and mutations within the adeL gene have been associated with the overexpression of this efflux system (Coyne et al., 2010b).

As for the presence of efflux pumps included within the remaining families of efflux transporters in A. baumannii, there is even less information than that available for the RND family.

Roca et al. (2009) identified the MFS efflux pump CraA, for chloramphenicol resistance Acinetobacter, in an A. baumannii clinical isolate from Spain. This protein was similar in sequence and secondary structure to the MdfA efflux pump from E. coli but differed in its substrate profile. CraA was shown to be highly specific for chloramphenicol and has, so far, been found in all the A. baumannii strains tested and might be responsible for the intrinsic resistance of A. baumannii to this antimicrobial agent.

More recently, Rajamohan et al. described a second MFS efflux pump, AmvA, mainly involved in the extrusion of dyes, disinfectants, and detergents and also erythromycin, although only causing a fourfold decrease in the MIC of this antibiotic. AmvA is also present in all A. baumannii strains studied so far (Rajamohan et al., 2010).

The third type of MFS efflux pumps present in A. baumannii is made of the acquired tetracycline efflux systems (Tet) that are part of plasmids, transposons, or resistance islands (see below). TetA and TetB constitute the most prevalent Tet efflux pumps in A. baumannii with TetA conferring resistance to tetracycline and TetB to both tetracycline and minocycline (Vila et al., 2007), although the $\operatorname{tet}(M)$ gene, involved in tetracycline ribosomal protection, has also been identified in one clinical isolate of A. baumannii (Ribera et al., 2003b). tet(A), together with the gene encoding its transcriptional regulator, tet $R$, is located in a Tn1721-like transposon that, in turn, might be part of a larger resistance island (Ribera et al., 2003a; Fournier et al., 2006). On the other hand, tet $(\mathrm{B})$ is located in small plasmids ranging from 5 - to $9-\mathrm{kDa}$ (Srinivasan et al., 2009b). Prevalence studies seemed to indicate that tet(B) is more commonly found in multidrug-resistant $A$. baumannii clinical isolates, with at least $50 \%$ of the strains containing this determinant (Guardabassi et al., 2000; Huys et al., 2005b; Martí et al., 2006; Mak et al., 2009; Srinivasan et al., 2009b).

The only efflux pump of the MATE family described so far in A. baumannii, AbeM, was identified in Su et al. (2005) and it was shown to extrude aminoglycosides, fluoroquinolones, chloramphenicol, trimethoprim, ethidium bromide and several dyes. Although AbeM has also been found in all A. baumannii strains studied to date, the role of this pump in antimicrobial resistance remains unclear since substrate-profiling studies carried out in $E$. coli did not fins any correlation between antibiotic resistance and overexpression of this pump.

AbeS is yet another efflux pump identified in A. baumannii that confers low-level resistance to several antimicrobial agents, including chloramphenicol, fluoroquinolones, erythromycin, and novobiocin, as well as resistance to dyes and detergents, but it is not present in all fully sequenced A. baumannii genomes. AbeS belongs to the SMR family and retains a certain degree of similarity with the EmrE system of E. coli (Srinivasan et al., 2009a).

\section{GENOME PLASTICITY}

As already mentioned, probably one of the most intriguing characteristics of A. baumannii is its capacity to acquire, retain, and disseminate multiple resistance mechanisms which, combined with its ability to survive desiccation as well as most disinfectants, accounts for the prolonged survival of A. baumannii strains in the clinical setting and makes this microorganism almost impossible to eradicate.

Acquisition and dissemination of antimicrobial resistance determinants in A. baumannii are achieved by combining resistance genes with an array of mobile elements that mediate the exchange of genetic material and rearrange bacterial genomes, giving rise to multiple genetic combinations and providing an endless source of genetic adaptability.

Such an array includes IS, transposons, integrons, plasmids and, ultimately, resistance islands.

\section{INSERTION SEOUENCES}

Insertion sequences indeed have a predominant role in the acquisition of resistance within A. baumannii. They are generally defined as the smallest mobile DNA elements $(<2.5 \mathrm{~kb})$, carrying only the genetic information required for their mobilization. In practical terms IS are constituted by a pair of short inverted-repeat sequences (IR) bracketing one or perhaps two ORFs encoding a transposase, the enzyme involved in the transposition or "jumping" of the IS element.

More than 30 different types of ISs have been reported in Acinetobacter spp. (Siguier et al., 2006) being ISAbaI and ISAba125 the most prevalent ISs in this microorganism (Adams et al., 2010). The genome of the A. baumannii AYE strain has been shown to contain up to 21 copies of ISAbaI (Vallenet et al., 2008) but this IS has also been identified in additional A. baumannii isolates from around the world (Goic-Barisic et al., 2009; Andriamanantena et al., 2010; Culebras et al., 2010; Higgins et al., 2010; Koo et al., 2010; AdamsHaduch et al., 2011; Karunasagar et al., 2011; Kusradze et al., 2011; Nigro et al., 2011b; Zhou et al., 2011).

As a consequence of IS mobilization these genetic elements can contribute to resistance in three different ways:

(i) Insertion of an IS immediately upstream from a given ORF might provide additional promoters to enhance transcriptional levels of genes that are otherwise poorly expressed. In this respect, ISAbaI is commonly found upstream from bla $a_{\mathrm{ampC}}$ and bla $a_{\mathrm{OXA}-51}$-like genes in A. baumannii, being responsible for ceftazidime and carbapenem resistance, respectively, in isolates lacking additional resistance mechanisms (Héritier et al., 2006; Turton et al., 2006). In addition, ISAbaI, ISAba2, ISAba3, ISAba4, IS $A b a 10$, ISAba16, ISAba125, ISA $b a 825$, and IS 18 have also been found upstream from $b l a_{\text {OXA-23 }}$ and $b l a_{\text {OXA-58 }}$ (Poirel and Nordmann, 2006b; Bertini et al., 2007; Corvec et al., 2007; Giannouli et al., 2009; Lee et al., 2011b; Ravasi et al., 2011; Lopes et al., 2012) and IS $A b a 9$ has been described upstream from both $b l a_{\mathrm{OXA}-51}$ and the gene encoding CARB-10 (Figueiredo et al., 2009; Potron et al., 2009).

CHDLs however, are not the only $\beta$-lactamases whose expression is enhanced by the presence of upstream ISs, both 
bla $a_{\text {PER-1 }}$ and bla $a_{\text {PER-2 }}$ contain a novel IS element, ISPa12, that has been shown to up-regulate their expression (Poirel et al., 2005a; Pasterán et al., 2006). Similarly, expression of bla $a_{\text {PER-7 }}$ is also driven by a promoter sequence located within an upstream ISCR1 element (Bonnin et al., 2011b).

(ii) IS elements can also contribute to resistance by inserting within certain ORFs and disrupting their coding sequences. Insertional inactivation leading to resistance has been associated with the disruption of transcriptional regulators, such as the insertion of ISAbal within the adeS gene leading to overexpression of the AdeABC efflux pump, but also with the disruption of genes involved in membrane permeability, such as ISAba10, ISAba10, ISAba825, and ISAba125 insertion within the carO gene leading to carbapenem resistance (Lu et al., 2009; Lee et al., 2011b; Ravasi et al., 2011) or the insertion of ISAba11 within the $l p x A$ or $l p x C$ genes causing loss of lipopolysaccharide production and colistin resistance (Moffatt et al., 2011).

(iii) Without any doubt, however, the major contribution of ISs to the development of pan-resistant A. baumannii strains lies in their ability to mobilize gene cassettes, either within the bacterial chromosome or between the chromosome and plasmids, allowing for a rapid dissemination of such cassettes not only among different A. baumannii strains but also among isolates belonging to different taxonomic genera (Roberts et al., 2008).

Insertion sequences-mediated mobilization might take place when two IS elements bracket a gene cassette, usually containing antimicrobial resistance genes, and the terminal IR from each IS cooperate to displace the intervening DNA sequence, thereby forming a compound transposon (Roberts et al., 2008). Bear in mind that ISs involved in compound transposons can still provide promoter sequences for the transcriptional expression of the genes they carry.

A single IS can also mediate the mobilization of flanking DNA by a rare mechanism known as "one-ended" transposition that combines one authentic end together with a surrogate end displaying a certain degree of similarity and located nearby (Motsch et al., 1985). In addition, ISs belonging to the IS91 family (which includes ISCR1 and ISCR2) are able to transpose by means of a rolling-circle replication mechanism (Toleman et al., 2006) and mobilization of DNA elements adjacent to ISs can also be achieved due to homologous recombination between two ISs, although this mechanism feeds on the copy number of ISs.

In A. baumannii, mobilization of the bla $a_{\mathrm{OXA}-23}$ gene is mediated either by two copies of ISAbal in inverted or direct orientation and generating a compound transposon designated Tn2006 or Tn2009, respectively (Corvec et al., 2007; Adams et al., 2008; Zhou et al., 2011); by a single copy of ISAbal forming a transposonlike structure named Tn2008 (Adams-Haduch et al., 2008); or by a similar structure comprising a single ISAba4 copy forming another transposon-like structure named Tn2007 (Corvec et al., 2007).

Of note, the chromosome of the non-pathogenic and environmental Acinetobacter radioresistens was recently identified as the original source of the acquired bla $a_{\mathrm{OXA}-23}$ gene of A. baumannii, and other OXA-23 variants have also been found in other $A$. radioresistens isolates (Poirel et al., 2008a), suggesting that the diversity of structures surrounding the bla $a_{\mathrm{OXA}-23}$ gene might have arisen from independent transposition events from the chromosome of commensal $A$. radioresistens strains to transferable plasmids that have subsequently been mobilized into A. baumannii.

The plasmid-encoded $b l a_{\text {OXA-58 }}$ gene is also commonly bracketed by distinct combinations of IS elements that usually contain ISAba3 downstream from $b l a_{\text {OXA-58 }}$ and differ in the presence of ISs in the $5^{\prime}$ flanking end. Specifically, ISAba3 seems to be more prevalent, but ISAba825, IS $A b a 1$, ISAba2, IS 18 , and IS 26 can also be present (Poirel and Nordmann, 2006b; Bertini et al., 2007; Giannouli et al., 2009). The role of such upstream ISs in providing additional promoters has been clearly demonstrated, but their role in the genetic mobilization of bla $a_{\text {OXA- } 58}$ is not yet clear. Apparently, each of these IS elements shows a distinct geographic distribution and since the bla $a_{\text {OXA-58 }}$ is usually plasmid-borne they might have been acquired through horizontal gene transfer and homologous recombination (Poirel and Nordmann, 2006b; Giannouli et al., 2009). Of note, the bla OXA-58 gene flanked by two ISAba3 elements has also been identified in plasmids recovered from $A$. pittii isolates but, then again, this probably reflects the inter-genus transferability of these plasmids rather than transposon-mediated acquisition (Evans et al., 2010; Huang et al., 2010).

Additional resistance determinants thought to have been mobilized by means of IS-mediated transfer include the ESBLs bla $a_{\mathrm{PER}-1}$, bracketed by ISPa12 and ISPa13 and forming a compound transposon named Tn 1213 (Poirel et al., 2005a), bla $a_{\mathrm{PER}-7}$ and bla $a_{\mathrm{VEB}-1}$ mobilized by the upstream ISCR1 and ISCR2, respectively, by means of rolling-circle transposition (Poirel et al., 2009; Bonnin et al., 2011b), and also CARB-10, whose transfer is apparently due to a one-ended transposition event from an upstream ISAba9 (Potron et al., 2009).

More recently, Potron et al. (2011) characterized a novel compound transposon in the chromosome of A. baumannii isolates from Haiti containing the $b l a_{\mathrm{CTX}-\mathrm{M}-15}$ gene flanked by ISEcp 1 and a truncated IS26, reflecting a transfer event from Enterobacteriaceae.

Among MBLs, the $b l a_{\mathrm{NDM}}$ sequences from Enterobacteriaceae have been shown to contain different ISs upstream from the $b l a_{\text {NDM-1 }}$ gene, although the role of these ISs in the expression of NDM is not clear and they are most likely involved in the genetic mobilization of the resistance gene (Yong et al., 2009; Poirel et al., 2010; Ho et al., 2011). Sequence analysis of some of these $b l a_{\mathrm{NDM}}$ genes from Enterobacteriaceae identified a fragment of variable length containing the right-end repeat from the insertion sequence ISAba125 in-between the $b l a_{\mathrm{NDM}-1}$ gene and the corresponding IS element as a remnant of ISAba125 insertion, and the IS element ISEc33 from E. coli strain 271 is bracketed by the sequence upstream from the ISAba125 right-end (Poirel et al., 2011b; Solé et al., 2011). ISAba125 belongs to the IS30 family and, until recently, had only been found in A. baumannii, either chromosomally or on a plasmid upstream from the bla $a_{\text {OXA-58 }}$ gene (Mussi et al., 2005; Evans et al., 2010) but never linked to $b l a_{\mathrm{NDM}}$ genes. Interestingly, Solé et al. recently identified a complete ISAba125 copy upstream from a bla $a_{\mathrm{NDM}-1}$ gene in $E$. coli and both Pfeifer et al. (2011) and Espinal et al. (2011a) have also found $b l a_{\mathrm{NDM}-1}$ and $b l a_{\mathrm{NDM}-2}$ sequences in $A$. baumannii 
bracketed between two copies of ISAba125, thereby defining a novel transposon. In view of these results, it has been postulated that some of the bla $a_{\mathrm{NDM}}$ sequences found in Enterobacteriaceae might have originated from Acinetobacter by means of ISAba125mediated mobilization (Solé et al., 2011). ISAba125 has also been found flanking the aminoglycoside-resistance gene aphA6 and constituting the compound transposon TnaphA6 (Nigro et al., 2011a).

Insertion sequences are also involved in the mobilization of the tet $(A)$ and tetR genes, encoding the tetracycline efflux pump and its transcriptional regulator, respectively, and commonly found within a Tn1721-like transposon that might also be present in multiple copies within the bacterial chromosome (Ribera et al., 2003a; Fournier et al., 2006).

It is worth mentioning that conserved inverted repeats homologous to binding sites acting as targets for the XerC and XerD recombinases, usually involved in site-specific recombination mechanisms, have been described flanking bla OXA-24/40 genes in different plasmids recovered from A. baumannii isolates (D’Andrea et al., 2009; Merino et al., 2010; Acosta et al., 2011; Tian et al., 2011). In view of these results, XerC/XerD recombinases have been postulated as a novel mechanism driving mobilization of the bla $a_{\text {OXA-24/40 }}$ gene (Merino et al., 2010).

Conjugative plasmids are also known to play a central role in the intra- and inter-species transfer of resistance determinants. However, although some resistance genes such as bla $a_{\mathrm{OXA}-58}$ and bla $a_{\text {OXA-23 }}$ are commonly plasmid-borne in Acinetobacter spp., a recent study of plasmid replicons in A. baumannii suggested that replicon types within this microorganism do not correspond to those circulating among Enterobacteriaceae, which might provide a plausible explanation for the observation that prevalent plasmidencoded resistance mechanisms identified among Gram-negative bacteria (ESBLs, KPC, etc.) are rarely present in Acinetobacter spp. while this genus seems to contain its own type (CHDLs) of plasmid-borne carbapenemases (Bertini et al., 2010).

\section{INTEGRONS}

Integrons constitute another important vehicle for the spread and accumulation of resistance genes in A. baumannii, and several studies have demonstrated a positive correlation in A. baumannii between the carriage of integrons and the degree of MDR (Huang et al., 2008; Lee et al., 2009b). Integrons are genetic elements that mediate the integration of gene cassettes by a site-specific recombinational mechanism and direct their coordinated expression. All integrons bear three key elements: a specific recombination site (attI), a gene encoding an integrase (intI) and a common promoter region ( $\mathrm{P} 1-\mathrm{P} 2)$ oriented toward the site of integration. The integrase recombinates discrete units of circular DNA known as gene cassettes (often carrying resistance genes) into the attI site allowing the coordinated expression of the genes in the cassette from the common promoter (Mazel, 2006).

Although integrons are not mobile by themselves (but gene cassettes can readily be exchanged to other integrons), they can be spread to different chromosomal locations, plasmids or even other microorganisms by means of IS-mediated transposition or homologous recombination (Mazel, 2006). There are several classes of integrons mainly classified according to the sequence of the encoded integrases, which show $40-58 \%$ identity. Class 1 integrons displaying a wide variety of gene cassettes are commonly found in A. baumannii, and typically encode aminoglycosideresistance genes as well as genes conferring resistance to antiseptics and sulfonamides (Nemec et al., 2004; Zhao and Hu, 2011). Other resistance determinants associated with class 1 integrons in A. baumannii include $b l a_{\mathrm{IMP}}, b l a_{\mathrm{VIM}}$, and bla $a_{\mathrm{SIM}} \mathrm{MBL}$ types (Lee et al., 2003, 2005, 2008; Yamamoto et al., 2011) as well as some Ambler class A $\beta$-lactamases such as CARB, GES, PER, VEB, and narrowspectrum OXA-types (Vila et al., 1997a; Navia et al., 2002; Poirel et al., 2003; Zarrilli et al., 2004; Naas et al., 2006a; Moubareck et al., 2009; Potron et al., 2009; Bonnin et al., 2011a).

Class 2 integrons, which are embedded within the Tn7 transposon, display a narrower diversity of gene cassettes and those described in A. baumannii have been shown to contain several resistance determinants such as aadB, catB2, dfrA1, sat2, and aadA1, conferring resistance to aminoglycosides, chloramphenicol, trimethoprim, streptothricin, and streptomycin, respectively (Ramírez et al., 2010a). More recently, Ramírez et al. reported an A. baumannii isolate carrying $b l a_{\mathrm{CARB}-4}$ in a class 2 integron together with 6 additional resistance determinants comprising four families of antibiotics. This novel integron constitutes the longest class 2 integron described so far and also represents the only example of a $\beta$-lactamase gene encoded within such a class (Ramírez et al., 2010b).

\section{RESISTANCE ISLANDS}

In addition to the huge diversity of resistance mechanisms displayed by A. baumannii isolates, this microorganism is also able to accumulate multiple resistance determinants in what has been termed as "resistance islands." Resistance islands are specific regions of the genome that harbor large clusters of horizontally transferred genetic DNA including a great deal of antimicrobial resistance genes. Such regions provide a "safe haven" for mobile elements since insertion at this site is not likely to cause any damage to the host cell. They are often inserted at the same locus on the A. baumannii chromosome and are assembled by discrete genes or gene packages usually associated with mobile elements (IS and Tn), integrons, or both.

The first resistance island described in A. baumannii was found in the multidrug-resistant A. baumannii AYE strain and was hence termed AbaR1. AbaR 1 comprised an $86 \mathrm{~kb}$ region integrated within the com $M$ gene and contained up to 45 antibiotic and heavy metal resistance genes. Interestingly, AbaR1 was flanked at both ends by 5 bp perfect direct repeats (DR) and included two ORFs near the $3^{\prime} \operatorname{com} M$ end annotated as putative transposition genes, thereby suggesting acquisition by means of a transposition event.

At the time of this review, more than 22 resistance islands have been described (Fournier et al., 2006; Adams et al., 2008, 2010; Iacono et al., 2008; Post and Hall, 2009; Krizova and Nemec, 2010; Post et al., 2010; Rose, 2010; Krizova et al., 2011; Nigro et al., 2011b; Zhou et al., 2011) and, with only three exceptions (Adams et al., 2008; Rose, 2010), all have been found inserted within the comM gene (Table 2).

Shaikh et al. (2009) studied a collection of 50 multidrugresistant A. baumannii isolates and found that $82 \%$ contained a truncated comM gene. Deeper sequence analysis of 10 such isolates 
Table 2 | Resistance Islands in A. baumannii.

\begin{tabular}{|c|c|c|c|c|c|}
\hline AbaR-type & $\begin{array}{l}\text { Size } \\
\text { (kb) }\end{array}$ & Strain & EC & $\begin{array}{l}\text { comM } \\
\text { Insertion }\end{array}$ & Reference \\
\hline AbaR1 & 86 & AYE & 1 & + & Fournier et al. (2006) \\
\hline AbaR2 & 17 & $\mathrm{ACICU}$ & II & + & lacono et al. (2008) \\
\hline AbaR3 & 63 & AB0057 & 1 & + & Adams et al. (2008) \\
\hline AbaR4 & 18 & AB0057 & 1 & - & Adams et al. (2008) \\
\hline AbaR5 & 56 & 3208 & 1 & + & Post and Hall (2009) \\
\hline AbaR6 & 27 & D2 & 1 & + & Post et al. (2010) \\
\hline AbaR7 & 20 & A92 & 1 & + & Post et al. (2010) \\
\hline AbaR8 & 29 & D13 & 1 & + & \\
\hline AbaR9 & 39 & AB056 & 1 & + & Adams et al. (2010) \\
\hline AbaR10 & 30 & AB058 & 1 & + & Adams et al. (2010) \\
\hline AbaR11 & 20 & $\mathrm{NIPH} 470$ & 1 & + & Krizova et al. (2011) \\
\hline AbaR12 & 38 & LUH 6013 & I & + & Krizova et al. (2011) \\
\hline AbaR13 & 45 & LUH6015 & I & + & Krizova et al. (2011) \\
\hline AbaR14 & 21 & LUH5881 & I & + & Krizova et al. (2011) \\
\hline AbaR15 & 55 & LUH6125 & I & + & Krizova et al. (2011) \\
\hline AbaR16 & 39 & LUH7140 & I & + & Krizova et al. (2011) \\
\hline AbaR17 & 58 & LUH8592 & 1 & + & Krizova et al. (2011) \\
\hline AbaR18 & 52 & NIPH2713 & 1 & + & Krizova et al. (2011) \\
\hline AbaR19 & 30 & NIPH2554 & 1 & + & Krizova et al. (2011) \\
\hline AbaR21 & 64 & RUH875 & 1 & + & Nigro et al. (2011b) \\
\hline AbaR22 & 39 & MDR-ZJ06 & II & + & Zhou et al. (2011) \\
\hline n.a. & n.f. & A473 & I & - & Rose (2010) \\
\hline n.a. & n.f. & A473 & I & - & Rose (2010) \\
\hline
\end{tabular}

EC, European clone lineage; n.a., not assigned; n.f., not found.

identified AbaR-like sequences in 8, thus confirming that the comM is likely a preferred integration site for this sort of genetic structures (Shaikh et al., 2009).

In addition, all AbaR sequences identified in A. baumannii isolates belonging to the European Clone I (EC I) lineage seem to have a common genetic structure. They share a $16.3-\mathrm{kb}$ backbone transposon, designated Tn6019, containing two ORFs annotated as putative transposition genes, an arsenate resistance operon (arsH$B R C$ ), a putative sulfate permease gene (sup), and a universal stress protein gene ( $u s p A)$ that, in turn, is disrupted by a second compound transposon formed by two copies of a cadmium and zinc resistance transposon (Tn6018) bracketing a multiple antibiotic resistance region (MARR). The MARR region contains most of the variability found among all AbaRs, with only a few exceptions displaying additional differences within the left-hand copy of Tn6018 and the Tn6019 backbone region (Post et al., 2010; Figure 2).

Although AbaR1 is so far the largest resistance island described in A. baumannii (Fournier et al., 2006), there is general agreement that AbaR5 to AbaR21 are all derivatives of AbaR3 that have originated as a result of either deletions mediated by one of the three IS26 elements present within $\mathrm{AbaR} 3$, deletions caused by a single homologous recombination event or arisen due to integron shuffling (Krizova et al., 2011; Nigro et al., 2011b). AbaR1 displays the same general structure as AbaR3 but contains an additional $29 \mathrm{~kb}$ region consisting of a very complex class 1 integron that might have been incorporated into AbaR3.

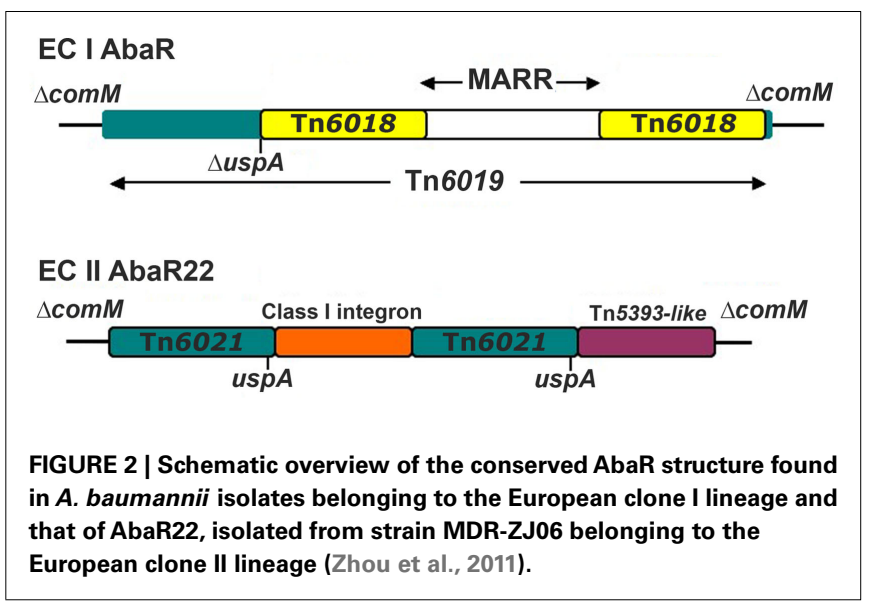

Interestingly, some AbaR-related structures found in A. baumannii isolates belonging to the EC II lineage present some noticeable differences compared to AbaRs from EC I. Several EC II isolates have been shown to contain a Tn6019-related transposon (termed Tn6021) as well as some genes present in AbaR1 but they also possess an intact $u s p A$ gene and, therefore, lack the Tn6018 compound transposon and the MARR region (Post et al., 2010; Zhou et al., 2011; Bonnin et al., 2012). These differences reinforce the delineation of $A$. baumannii isolates in different European clones since AbaRs structures seem to have appeared independently in each of these isolates (Figure 2).

Krizova et al. have recently suggested that the origin of AbaRs in strains of the EC I might lie in the antibiotic regimes administered in Europe during the 1970s and 1980s, since AbaRs seem to provide resistance to antimicrobials mostly used during that period, thereby facilitating the survival and spread of AbaRsbearing strains. The subsequent modification of the treatment of choice might have then diminished the selective pressure on such determinants and accounted for the truncated AbaR3-derivatives in the current population of A. baumannii clinical isolates (Krizova et al., 2011).

The combination of IS, Tn, integrons, conjugative plasmids, and resistance islands accounts for the extreme genomic plasticity of $A$. baumannii and partly explains the successful emergence of this microorganism as a dreadful nosocomial human pathogen. Recent studies comparing the whole genome sequence of closely related $A$. baumannii isolates have demonstrated a unique genetic repertoire in terms of IS, plasmids, and AbaRs even in A. baumannii isolates belonging to the same sequence type (ST; Adams et al., 2010; Di Nocera et al., 2011; Snitkin et al., 2011).

\section{CLINICAL IMPORTANCE AND TREATMENT OPTIONS}

Acinetobacter baumannii is currently considered one of the most important nosocomial pathogens. In a prevalence study of infections in intensive care units conducted among 75 countries of the 5 continents, this microorganism was found to be the fifth most common pathogen, although with a high variability among the different countries (Vincent et al., 2009). Different surveillance studies have found this pathogen to be the fifth cause of pneumonia, after $P$. aeruginosa, in hospitalized patients, mainly in intensive 
care units (Jones, 2010). In addition, these microorganisms are also frequently reported to cause other nosocomial infections such as bacteremia and urinary tract and surgical infections. In fact, $A$. baumannii was found to be third most frequent cause of nosocomial bloodstream infection in a large multicenter study with an estimation of $34 \%$ of all patients and $43 \%$ in patients in intensive care units (Wisplinghoff et al., 2004).

With respect to the treatment of $A$. baumannii infections it is important to take into account the resistant profile involved to thereby consider the different treatment options available. As mentioned above, A. baumannii is currently resistant to multiple antibacterial agents, including carbapenems and, occasionally, colistin. Therefore, in many cases, optimal treatment for nosocomial infections caused by this microorganism is sometimes not available. A decade ago sulbactam, which has intrinsic activity against A. baumannii and shows in vivo efficacy in a murine model of pneumoniae, was used to treat infections caused by carbapenemresistant clinical isolates (Rodríguez-Hernández et al., 2001; Levin et al., 2003). However, nowadays the percentage of resistance to sulbactam has reached such a high level that its use as antimicrobial agent against infections caused by $A$. baumannii has been invalidated

Rifampicin has demonstrated consistent results related to in vivo efficacy in experimental models of infection and in some open studies of human infections, especially when combined with colistin. These studies suggest that the possible use of rifampicin for the treatment of multidrug-resistant A. baumannii infections should be analyzed in well-designed clinical trials (Pachón-Ibáñez et al., 2006; Pachón-Ibánez et al., 2010). Bassetti et al. (2008) studied the use of colistin in combination with rifampin in critically ill patients with pneumonia (19 patients) and bacteremia (10 patients) caused by A. baumannii resistant to all antibiotics except colistin in medical and surgical intensive care units. Clinical and microbiological response was observed in 22 of 29 cases (76\%), suggesting that the combination of colistin and rifampicin appears to be an effective and safe therapy for severe infections due to multidrug-resistant A. baumannii.

There is some heterogenicity concerning the clinical data to determine the utility of tigecycline in the treatment of nosocomial infections caused by A. baumannii. The possible development of resistance during treatment with tigecycline suggests that it should only be used in combined regimens with other antimicrobials. Two studies have reported the combination of tigecycline with other antimicrobial agents. Principe et al. (2009) found that tigecycline showed synergism with levofloxacin, amikacin, imipenem, and colistin, whereas antagonism was observed for the tigecycline/piperacillin-tazobactam combination. Considering all antimicrobials in combination with tigecycline, checkerboard analysis showed 5.9\% synergy, 85.7\% indifference, and 8.3\% antagonism. Tigecycline showed synergism with levofloxacin (four strains; $16.6 \%$ ), amikacin (two strains; 8.3\%), imipenem (two strains; $8.3 \%$ ), and colistin (two strains; 8.3\%). Synergism was detected only among tigecycline non-susceptible strains. Time-kill assays confirmed the synergistic interaction between tigecycline and levofloxacin, amikacin, imipenem, and colistin in five out of seven selected isolates. Ozbek and Senturk (2010) isolated six meropenem-resistant $A$. baumannii strains in which synergy of tigecycline/colistin and tigecycline/levofloxacin was observed using checkerboard analysis in just one strain each.

Other combinations have recently been described in the scientific literature. Liang et al. isolated 14 extensive drug-resistant A. baumannii strains from patients admitted to the intensive care units of a Chinese hospital. Most of the strains were resistant to all antimicrobials except colistin and minocycline, and the combinatory results by killing curves showed a synergistic effect between colistin/meropenem, colistin/rifampicin meropenem/minocycline and colistin/minocycline. It is worth mentioning that the combination of meropenem/minocycline could be a possible alternative when colistin is not available as in China (Liang et al., 2011). In a recent study the combination of teicoplanin/colistin was investigated against multidrugresistant A. baumannii isolates (resistant to third-generation cephalosporins, quinolones, and aminoglycosides), with checkerboard analysis showing synergy between the two antibiotics. Bactericidal activity was shown in the first $4 \mathrm{~h}$ for both colistin alone and in combination with teicoplanin, however regrowth was observed when colistin was used alone (Wareham et al., 2011). Although the mechanism of action of colistin is not completely known, it is thought to act in the bacterial membrane by disrupting it (Lam et al., 1986). Therefore, the use of colistin in combination with antibiotics such as teicoplanin or vancomycin which are effective against Gram-positive microorganisms (Gordon et al., 2010), likely helps glycopeptides to reach the target.

Of particular concern are infections caused by pan-drugresistant $A$. baumannii isolates, which are steadily increasing in various regions worldwide. There is an urgent need for new therapeutic strategies since isolates resistant to all antibacterial agents, including colistin, have been reported (Park et al., 2009) and this scenario will likely progress in association with the increased use of this antibiotic.

\section{FUTURE POTENTIAL THERAPEUTIC ALTERNATIVES}

The emergence of bacteria resistant to most of the antibiotics available has lead to the appearance of different terms concerning resistance. Only a short time ago, experts in the topic homogenized all these terms, in the case of A. baumannii, MDR may be referred when the strain is non-susceptible to $\geq 1$ antimicrobial agent in $\geq 3$ antimicrobial categories; an increase in resistance now refers to extensive drug resistance (XDR) when non-susceptible to $\geq 1$ antimicrobial agents in all but $\leq 2$ categories (i.e., bacterial isolates remain susceptible to only one or two categories), and pandrug resistance (PDR) is considered when the microorganism is non-susceptible to all the antimicrobial agents in all antimicrobial categories (Magiorakos et al., 2012).

In regard to future potential therapeutic alternatives, the perspectives are not good, at least within the next decade (Payne et al., 2007). Nonetheless there are two main options for the design of new drugs to treat infections caused by PDR-resistant $A$. baumannii. The first is related to knowledge of the biochemical bases of resistance and has been used to design rational strategy to counteract resistance. This strategy can follow two approaches: (i) Modification of the basic structure of the antibacterial agent, circumventing antibacterial resistant mechanisms, and (ii) Development of compounds inhibiting the mechanisms of resistance 
for an antibacterial agent, whereby the concomitant administration of the antibacterial agent plus the inhibitor, as a co-drug, potentiates this activity (Li and Heide, 2005). Some studies have used this strategy to develop drugs active against MDR A. baumannii. A derivative of ciprofloxacin (UB-8902) showed good activity against $A$. baumannii strains carrying a mutation in the gyrA gene, with a $\mathrm{MIC}_{50}$ of $4 \mathrm{mg} / \mathrm{L}$ (range $<0.06-8 \mathrm{mg} / \mathrm{L}$ ) in comparison with ciprofloxacin displaying a $\mathrm{MIC}_{50}$ of $64 \mathrm{mg} / \mathrm{L}$ (Vila et al., 2006). Further in vivo studies using this new quinolone have also been performed in a murine pneumonia model, showing that UB-8902 presented bactericidal activity against $A$. baumannii strains resistant to ciprofloxacin. Moreover, this quinolone was effective at reducing mortality with a dose lower than the toxic dose in a model of peritoneal sepsis (López-Rojas et al., 2011a). BAL30072 is a new monocyclic $\beta$-lactam belonging to the sulbactam class of antibiotics active against MDR A. baumannii. BAL30072 possesses a dihydropyrimidinone siderophore in its side chain and has shown better activity than meropenem in five MDR A. baumannii strains, with increased activity when a combination of the two was used (Russo et al., 2011).

The second option is to design a new compound involving antimicrobial peptides (AMPs) as the principal candidates. The use of AMPs as antibiotics has several advantages and disadvantages, the main disadvantage being the instability of the compound against proteases present in the blood and serum. Several methods may be used to overcome this issue although these may sometimes not be easy to apply due to a possible loss of the effectiveness of peptides upon changes in their structure. D-Amino acids, stable to proteases (Chen et al., 2006; Friedman, 2010) may be used as well as both methylation and fluorination of specific amino acids (Meng and Kumar, 2007; Fernández-Reyes et al., 2010). Another option, albeit sometimes less effective in terms of activity due to the loss of one positive charge which is important for the interaction with membranes, is cyclation (Molhoek et al., 2011). On the other hand, the advantages of AMPs are that they are a less specific target and, compared to antibiotics, acquisition of resistance is difficult (Marr et al., 2006).

Braunstein et al. (2004) used a gentamicin-resistant A. baumannii strain to test an AMP containing $33 \%$ of $\mathrm{D}$-amino acids that showed better activity $(5.6-11.2 \mathrm{mg} / \mathrm{L})$ and greater stability to hemolysis (0-100\% at $180 \mathrm{mg} / \mathrm{L})$ than the $\mathrm{L}$-amino acid form. The same effect was seen by Jiang et al. in which a totally synthetic Damino acid AMP was tested against 550 clinical isolates involving $74 \%$ of MDR strains. Although no resistance profile was reported in the article, the AMP showed good values for both $\mathrm{MIC}_{50}$ and

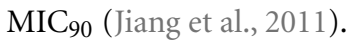

In another study using strains resistant to ciprofloxacin, the $\mathrm{MIC}_{50}$ and $\mathrm{MIC}_{90}$ values of pexiganan, an analog of magainin, were 2 and $8 \mathrm{mg} / \mathrm{L}$, respectively (Ge et al., 1999). In another analog, but in this case a short version of the peptide of human lactoferrin, 11 residues from the $\mathrm{N}$-terminal were studied. The $A$. baumannii strains used were resistant or intermediate to 16 and 19 out of 20 antimicrobial agents, including imipenem and meropenem. This peptide was tested in vivo and a reduction of 3-4 log CFU/ml was observed in an experimental infection in mice. However at peptide concentration ranging from 49.5 to $98.9 \mathrm{mg} / \mathrm{L}$, this effect was not seen in the control. In addition the effect of this peptide was very rapid, achieving the minimal number of CFU in 5-15 min (Dijkshoorn et al., 2004). Other peptides present in the human body such as $\beta$-defensin 3 have been tested against $A$. baumannii. This AMPs belongs to the cysteine-rich peptides, and a bactericidal effect was achieved in vitro after $1.5 \mathrm{~h}$ using $4 \mathrm{mg} / \mathrm{L}$ of the peptide against MDR A. baumannii (Maisetta et al., 2006).

The origin of the peptides tested so far is different, some being totally synthetic, some isolated from humans or others from animals. In the case of animals, amphibians are a large source of peptides as in the case of the study published by Mangoni et al. (2008) in which most of the peptides were isolated from frogs and showed good MIC values against MDR A. baumannii. The same strategy was used in the report published by Conlon et al. (2009) however the MIC values were higher compared to the other peptides. Other peptides isolated from toad skin secretions were also tested against XDR strains obtaining values from 112.8 to $2.8 \mathrm{mg} / \mathrm{L}$ (Conlon et al., 2010). The A3-APO peptide is shown to be more effective and less toxic against $A$. baumannii than colistin, however this has only been observed in vivo and the effect could not be shown in vitro, suggesting that this peptide may prevent inflammation at the site of the infection (Ostorhazi et al., 2010, 2011).

Different AMPs have been tested against A. baumannii, however the peptide constituted by the mixture of cecropin A and melittin (Andreu et al., 1992) has been extensively studied. The first hybrid tested against MDR A. baumannii was cecropin A(1-8)melittin(1$18)$, or $\mathrm{CA}(1-8) \mathrm{M}(1-18)$. This hybrid was tested under different experimental conditions, with all showing a lower MIC compared to polymixin B (Saugar et al., 2002). The next hybrid tested was $\mathrm{CA}(1-7) \mathrm{M}(2-9)$ and, compared to the original peptides cecropin A and melittin as well as to other antibiotics, the MIC of this hybrid peptide was $0.25-8 \mathrm{mg} / \mathrm{L}$, being the lowest value compared to other hybrid peptides. In addition, this hybrid peptide also showed synergy with co-amoxiclav, ceftazidime, piperacillin, and imipenem (Giacometti et al., 2003). Synergy of other AMPs and currently used antibiotics has also been studied by Giacometti et al. (2000), observing synergy of magainin II with coamoxiclav, aztreonam, chloramphenicol, ceftazidime, piperacillin, and meropenem. CA(1-7) $\mathrm{M}(2-9)$ was also tested against PDR A. baumannii strains, Similar to other hybrids, CA(1-8)M(1-18), Oct-CA(1-7) $\mathrm{M}(2-9)$, and $\mathrm{CA}(1-7) \mathrm{M}(5-9)$, the MIC values ranged from 2 to $8 \mathrm{mg} / \mathrm{L}$ compared to 4 to $64 \mathrm{mg} / \mathrm{L}$ for colistin. In addition, the hybrids showed bactericidal activity at $4 \times$ MIC (RodríguezHernández et al., 2006). Several commercial peptides have also been tested against colistin-resistant A. baumannii strains. Most did not show any activity, although indolicidin and particularly mastoparan showed MIC values of 2 and $1 \mathrm{mg} / \mathrm{L}$, respectively, compared to the colistin MIC of $256 \mathrm{mg} / \mathrm{L}$. Moreover, a bactericidal effect was found for mastoparan along all the killing curve for $8 \times$ MIC (Vila-Farrés et al., 2012).

Although AMPs and AMPs in combination with antibiotics are potential future therapeutic alternatives against PDR A. baumannii clinical isolates, another therapeutic alternative might involve the use of vaccines, specifically those administered through OMVs (McConnell et al., 2011a,b). 


\section{CONCLUSION}

Over the past few decades A. baumannii has emerged as one of the most successful nosocomial pathogens throughout the world. This is partly due to its intrinsic aptitude to persist in the hospital setting and acquire multiple resistance mechanisms, but also to its capacity to cause acute infections especially in severely ill patients. While we know a great deal about the mechanisms responsible for antimicrobial resistance in this microorganism we see ourselves unable to stop it. Pan-drug strains resistant even to colistin have already been reported and we are running out of options to deal with this novel menace. On the other hand, there is little knowledge regarding the mechanisms driving the pathogenesis of A. baumannii and there is much to learn on this issue. Novel therapeutic strategies are urgently needed and while research on

\section{REFERENCES}

Acosta, J., Merino, M., Viedma, E., Poza, M., Sanz, F., Otero, J. R., Chaves, F., and Bou, G. (2011). Multidrugresistant Acinetobacter baumannii Harboring OXA-24 carbapenemase, Spain. Emerging Infect. Dis. 17, 1064-1067.

Adams, M. D., Chan, E. R., Molyneaux, N. D., and Bonomo, R. A. (2010). Genomewide analysis of divergence of antibiotic resistance determinants in closely related isolates of Acinetobacter baumannii. Antimicrob. Agents Chemother. 54, 3569-3577.

Adams, M. D., Goglin, K., Molyneaux, N., Hujer, K. M., Lavender, H., Jamison, J. J., MacDonald, I. J., Martin, K. M., Russo, T., Campagnari, A. A., Hujer, A. M., Bonomo, R. A., and Gill, S. R. (2008). Comparative genome sequence analysis of multidrug-resistant Acinetobacter baumannii. J. Bacteriol. 190, 8053-8064.

Adams, M. D., Nickel, G. C., Bajaksouzian, S., Lavender, H., Murthy, A. R., Jacobs, M. R., and Bonomo, R. A. (2009). Resistance to colistin in Acinetobacter baumannii associated with mutations in the PmrAB two-component system. Antimicrob. Agents Chemother. 53, 3628-3634.

Adams-Haduch, J. M., Onuoha, E. O., Bogdanovich, T., Tian, G. B., Marschall, J., Urban, C. M., Spellberg, B. J., Rhee, D., Halstead, D. C., Pasculle, A. W., and Doi, Y. (2011). Molecular epidemiology of carbapenem-non-susceptible Acinetobacter baumannii in the United States. J. Clin. Microbiol. 49, 3849-3854.

Adams-Haduch, J. M., Paterson, D. L., Sidjabat, H. E., Pasculle, A. W., Potoski, B. A., Muto, C. A., Harrison, L. H., and Doi, Y. (2008). Genetic basis of multidrug resistance in Acinetobacter baumannii clinical isolates at a tertiary medical center in Pennsylvania. Antimicrob. Agents Chemother. 52, 3837-3843.

Afzal-Shah, M., Woodford, N., and Livermore, D. M. (2001). Characterization of OXA-25, OXA-26, and OXA-27, molecular class D $\beta$-lactamases associated with carbapenem resistance in clinical isolates of Acinetobacter baumannii. Antimicrob. Agents Chemother. 45, 583-588.

Al-Sweih, N. A., Al-Hubail, M. A., and Rotimi, V. O. (2011). Emergence of tigecycline and colistin resistance in Acinetobacter species isolated from patients in Kuwait hospitals. J. Chemother. 23, 13-16.

Ambler, R. P. (1980). The structure of $\beta$-lactamases. Philos. Trans. R. Soc. Lond. B. Biol. Sci. 289, 321-331.

Andreu, D., Ubach, J., Boman, A., Wahlin, B., Wade, D., Merrifield, R. B., and Boman, H. G. (1992). Shortened cecropin A-melittin hybrids. Significant size reduction retains potent antibiotic activity. FEBS Lett. 296, 190-194.

Andriamanantena, T. S., Ratsima, E., Rakotonirina, H. C., Randrianirina, F., Ramparany, L., Carod, J. F., Richard, V., and Talarmin, A. (2010). Dissemination of multidrug resistant Acinetobacter baumannii in various hospitals of Antananarivo Madagascar. Ann. Clin. Microbiol. Antimicrob. 9, 17.

Antunes, L. C., Imperi, F., Carattoli, A., and Visca, P. (2011a). Deciphering the multifactorial nature of Acinetobacter baumannii pathogenicity. PLOS ONE 6, e22674. doi:10.1371/journal.pone.0022674.g003

Antunes, L. C., Imperi, F., Towner, K. J., and Visca, P. (2011b). Genomeassisted identification of putative

novel antimicrobial agents does not seem very promising, the quest for novel drugs interfering with A. baumannii pathogenicity and not just bacterial growth opens up as a novel and challenging alternative.

\section{ACKNOWLEDGMENTS}

This work was supported by the Spanish Ministry of Health (FIS 08/00195), by grant 2009SGR1256 from the Generalitat de Catalunya and by Ministerio de Sanidad y Consumo, Instituto de Salud Carlos III - FEDER, Spanish Network for the Research in Infectious Diseases (REIPI RD06/0008). This work has also been supported by funding from the European Community (TROCAR contract HEALTH-F3-2008-223031 and AntiPathoGN contract HEALTH-F3-2008-223101).

iron-utilization genes in Acinetobacter baumannii and their distribution among a genotypically diverse collection of clinical isolates. Res. Microbiol. 162, 279-284.

Arroyo, L. A., Herrera, C. M., Fernández, L., Hankins, J. V., Trent, M. S., and Hancock, R. E. (2011). The pmr$\mathrm{CAB}$ operon mediates polymyxin resistance in Acinetobacter bauman nii ATCC 17978 and clinical isolates through phosphoethanolamine modification of lipid A. Antimicrob. Agents Chemother. 55, 3743-3751.

Bassetti, M., Repetto, E., Righi, E., Boni, S., Diverio, M., Molinari, M. P., Mussap, M., Artioli, S., Ansaldi, F., Durando, P., Orengo, G., Bobbio Pallavicini, F., and Viscoli, C. (2008). Colistin and rifampicin in the treatment of multidrug-resistant Acinetobacter baumannii infections. J. Antimicrob. Chemother. 61, 417-420.

Beceiro, A., Llobet, E., Aranda, J., Bengoechea, J. A., Doumith, M., Hornsey, M., Dhanji, H., Chart, H., Bou, G., Livermore, D. M., and Woodford, N. (2011). Phosphoethanolamine modification of lipid A in colistin-resistant variants of Acinetobacter baumannii mediated by the pmrAB two-component regulatory system. Antimicrob. Agents Chemother. 55, 3370-3379.

Bernards, A. T., van der Toorn, J., van Boven, C. P., and Dijkshoorn, L. (1996). Evaluation of the ability of a commercial system to identify Acinetobacter genomic species. Eur. J. Clin. Microbiol. Infect. Dis. 15, 303-308.

Bertini, A., Poirel, L., Bernabeu, S., Fortini, D., Villa, L., Nordmann, P., and Carattoli, A. (2007). Multicopy blaOXA-58 gene as a source of high-level resistance to carbapenems in Acinetobacter baumannii. Antimicrob. Agents Chemother. 51, 2324-2328.
Bertini, A., Poirel, L., Mugnier, P. D., Villa, L., Nordmann, P., and Carattoli, A. (2010). Characterization and PCR-based replicon typing of resistance plasmids in Acinetobacter baumannii. Antimicrob. Agents Chemother. 54, 4168-4177.

Bhargava, N., Sharma, P., and Capalash, N. (2010). Quorum sensing in Acinetobacter: an emerging pathogen. Crit. Rev. Microbiol. 36, 349-360.

Bogaerts, P., Naas, T., El Garch, F., Cuzon, G., Deplano, A., Delaire, T., Huang, T. D., Lissoir, B., Nordmann, P., and Glupczynski, Y. (2010). GES extended-spectrum $\beta$-lactamases in Acinetobacter baumannii isolates in Belgium. Antimicrob. Agents Chemother. 54, 4872-4878.

Bonnet, R., Marchandin, H., Chanal, C., Sirot, D., Labia, R., De Champs, C., Jumas-Bilak, E., and Sirot, J. (2002). Chromosome-encoded class D $\beta$-lactamase OXA-23 in Proteus mirabilis. Antimicrob. Agents Chemother. 46, 2004-2006.

Bonnin, R. A., Nordmann, P., Potron, A., Lecuyer, H., Zahar, J. R., and Poirel, L. (2011a). Carbapenemhydrolyzing GES-type extendedspectrum $\beta$-lactamase in Acinetobacter baumannii. Antimicrob. Agents Chemother. 55, 349-354.

Bonnin, R. A., Potron, A., Poirel, L., Lecuyer, H., Neri, R., and Nordmann, P. (2011b). PER-7, an extended-spectrum beta-lactamase with increased activity toward broad-spectrum cephalosporins in Acinetobacter baumannii. Antimicrob. Agents Chemother. 55, 2424-2427.

Bonnin, R. A., Poirel, L., and Nordmann, P. (2012). AbaR-type transposon structures in Acinetobacter baumannii. J. Antimicrob. Chemother. 67, 234-236. 
Bou, G., Cervero, G., Domínguez, M. A., Quereda, C., and MartínezBeltran, J. (2000a). Characterization of a nosocomial outbreak caused by a multiresistant Acinetobacter baumannii strain with a carbapenemhydrolyzing enzyme: high-level carbapenem resistance in A. baumannii is not due solely to the presence of $\beta$-lactamases. J. Clin. Microbiol. 38, 3299-3305.

Bou, G., and Martinez-Beltran, J. (2000b). Cloning, nucleotide sequencing, and analysis of the gene encoding an AmpC $\beta$-lactamase in Acinetobacter baumannii. Antimicrob. Agents Chemother. 44, 428-432.

Bou, G., Oliver, A., and MartínezBeltran, J. (2000c). OXA-24, a novel class $\mathrm{D} \beta$-lactamase with carbapenemase activity in an Acinetobacter baumannii clinical strain. Antimicrob. Agents Chemother. 44, 1556-1561.

Braunstein, A., Papo, N., and Shai, Y. (2004). In vitro activity and potency of an intravenously injected antimicrobial peptide and its DL amino acid analog in mice infected with bacteria. Antimicrob. Agents Chemother. 48, 3127-3129.

Bresser, P., van Alphen, L., Habets, F. J., Hart, A. A., Dankert, J., Jansen, H. M., and Lutter, R. (1997). Persisting Haemophilus influenzae strains induce lower levels of interleukin6 and interleukin-8 in H292 lung epithelial cells than nonpersisting strains. Eur. Respir. J. 10, 2319-2326.

Brown, S., Young, H. K., and Amyes, S. G. (2005). Characterisation of OXA51, a novel class D carbapenemase found in genetically unrelated clinical strains of Acinetobacter baumannii from Argentina. Clin. Microbiol. Infect. 11, 15-23.

Bush, K., and Jacoby, G. A. (2010). Updated functional classification of $\beta$-lactamases. Antimicrob. Agents Chemother. 54, 969-976.

Camarena, L., Bruno, V., Euskirchen, G., Poggio, S., and Snyder, M. (2010). Molecular mechanisms of ethanolinduced pathogenesis revealed by RNA-sequencing. PLoS Pathog. 6, e1000834. doi:10.1371/journal.ppat.1000834.t001

Canton, R., and Coque, T. M. (2006). The CTX-M $\beta$-lactamase pandemic. Curr. Opin. Microbiol. 9, 466-475.

Cayo, R., Rodríguez, M. C., Espinal, P., Fernández-Cuenca, F., OcampoSosa, A. A., Pascual, A., Ayala, J. A., Vila, J., and Martínez-Martínez, L. (2011). Analysis of genes encoding for penicillin-binding proteins in clinical isolates of Acinetobacter baumannii. Antimicrob. Agents Chemother. 55, 5907-5913.

Celenza, G., Pellegrini, C., Caccamo, M., Segatore, B., Amicosante, G., and Perilli, M. (2006). Spread of blaCTX-M-type and blaPER$2 \beta$-lactamase genes in clinical isolates from Bolivian hospitals. J. Antimicrob. Chemother. 57, 975-978.

Cerqueira, G. M., and Peleg, A. Y. (2011). Insights into Acinetobacter baumannii pathogenicity. IUBMB Life 63, 1055-1060.

Chan, K. G., Atkinson, S., Mathee, K., Sam, C. K., Chhabra, S. R., Camara, M., Koh, C. L., and Williams, P. (2011). Characterization of $\mathrm{N}$-acylhomoserine lactonedegrading bacteria associated with the Zingiber officinale (ginger) rhizosphere: co-existence of quorum quenching and quorum sensing in Acinetobacter and Burkholderia. BMC Microbiol. 11, 51. doi:10.1186/1471-2180-11-51

Chen, Y., Vasil, A. I., Rehaume, L., Mant, C. T., Burns, J. L., Vasil, M. L., Hancock, R. E., and Hodges, R. S. (2006). Comparison of biophysical and biologic properties of alphahelical enantiomeric antimicrobial peptides. Chem. Biol. Drug Des. 67, 162-173.

Chen, Y., Zhou, Z., Jiang, Y., and Yu, Y. (2011). Emergence of NDM-1producing Acinetobacter baumannii in China. J. Antimicrob. Chemother. 66, 1255-1259.

Cho, Y. J., Moon, D. C., Jin, J. S., Choi, C. H., Lee, Y. C., and Lee, J. C. (2009). Genetic basis of resistance to aminoglycosides in Acinetobacter spp. and spread of armA in Acinetobacter baumannii sequence group 1 in Korean hospitals. Diagn. Microbiol. Infect. Dis. 64, 185-190.

Choi, A. H., Slamti, L., Avci, F. Y., Pier, G. B., and Maira-Litran, T. (2009). The pgaABCD locus of Acinetobacter baumannii encodes the production of poly-beta-1-6-Nacetylglucosamine, which is critical for biofilm formation. J. Bacteriol. 191, 5953-5963.

Choi, C. H., Lee, E. Y., Lee, Y. C., Park, T. I., Kim, H. J., Hyun, S. H., Kim, S. A., Lee, S. K., and Lee, J. C. (2005). Outer membrane protein 38 of Acinetobacter baumannii localizes to the mitochondria and induces apoptosis of epithelial cells. Cell. Microbiol. 7, 1127-1138

Choi, C. H., Lee, J. S., Lee, Y. C., Park, T. I., and Lee, J. C. (2008). Acinetobacter baumannii invades epithelial cells and outer membrane protein A mediates interactions with epithelial cells. BMC Microbiol. 8, 216. doi:10.1186/1471-2180-8-216

Chu, Y. W., Afzal-Shah, M., Houang, E. T., Palepou, M. I., Lyon, D. J., Woodford, N., and Livermore, D. M. (2001). IMP-4, a novel metallo- $\beta$ lactamase from nosocomial Acinetobacter spp. collected in Hong Kong between 1994 and 1998. Antimicrob. Agents Chemother. 45, 710-714.

Chu, Y. W., Chau, S. L., and Houang, E. T. (2006). Presence of active efflux systems AdeABC, AdeDE and AdeXYZ in different Acinetobacter genomic DNA groups. J. Med. Microbiol. 55, 477-478.

Clemmer, K. M., Bonomo, R. A., and Rather, P. N. (2011). Genetic analysis of surface motility in Acinetobacter baumannii. Microbiology 157, 2534-2544.

Conlon, J. M., Ahmed, E., and Condamine, E. (2009). Antimicrobial properties of brevinin-2-related peptide and its analogs: efficacy against multidrug-resistant Acinetobacter baumannii. Chem. Biol. Drug Des. 74, 488-493.

Conlon, J. M., Ahmed, E., Pal, T., and Sonnevend, A. (2010). Potent and rapid bactericidal action of alyteserin-1c and its [E4K] analog against multidrug-resistant strains of Acinetobacter baumannii. Peptides 31, 1806-1810.

Cornaglia, G., Giamarellou, H., and Rossolini, G. M. (2011). Metallo$\beta$-lactamases: a last frontier for $\beta$-lactams? Lancet Infect. Dis. 11, 381-393.

Corvec, S., Poirel, L., Naas, T., Drugeon, H., and Nordmann, P. (2007). Genetics and expression of the carbapenem-hydrolyzing oxacillinase gene blaOXA-23 in Acinetobacter baumannii. Antimicrob. Agents Chemother. 51, 1530-1533.

Costerton, J. (1995). Overview of microbial biofilsm. J. Ind. Microbiol. $15,137-140$.

Coyne, S., Guigon, G., Courvalin, P., and Périchon, B. (2010a). Screening and quantification of the expression of antibiotic resistance genes in Acinetobacter baumannii with a microarray. Antimicrob. Agents Chemother. 54, 333-340.

Coyne, S., Rosenfeld, N., Lambert, T., Courvalin, P., and Périchon, B. (2010b). Overexpression of resistance-nodulation-cell division pump AdeFGH confers multidrug resistance in Acinetobacter baumannii. Antimicrob. Agents Chemother. 54, 4389-4393.

Culebras, E., Gonzalez-Romo, F., Head, J., Gomez, M., Morales, G., and
Picazo, J. J. (2010). Outbreak of Acinetobacter baumannii producing OXA-66 in a Spanish hospital: epidemiology and study of patient movements. Microb. Drug Resist. 16, 309-315.

Da Silva, G. J., Correia, M., Vital, C., Ribeiro, G., Sousa, J. C., Leitao, R., Peixe, L., and Duarte, A. (2002). Molecular characterization of blaIMP5 , a new integron-borne metallo- $\beta$ lactamase gene from an Acinetobacter baumannii nosocomial isolate in Portugal. FEMS Microbiol. Lett. 215, 33-39.

Damier-Piolle, L., Magnet, S., Brémont, S., Lambert, T., and Courvalin, P. (2008). AdeIJK, a resistancenodulation-cell division pump effluxing multiple antibiotics in Acinetobacter baumannii. Antimicrob. Agents Chemother. 52, 557-562.

D’Andrea, M. M., Giani, T., D’Arezzo, S., Capone, A., Petrosillo, N., Visca, P., Luzzaro, F., and Rossolini, G. M. (2009). Characterization of PABVA01, a plasmid encoding the OXA- 24 carbapenemase from Italian isolates of Acinetobacter baumannii. Antimicrob. Agents Chemother. 53, 3528-3533.

D’Arezzo, S., Capone, A., Petrosillo, N., Visca, P., Ballardini, M., Bartolini, S., Bordi, E., Di Stefano, A., Galie, M., Minniti, R., Meledandri, M., Pacciani, L., Parisi, G., Prignano, G., Santini, C., Valmarin, M., Venditti, M., and Ziantoni, S. (2009). Epidemic multidrug-resistant Acinetobacter baumannii related to European Clonal Types I and II in Rome (Italy). Clin. Microbiol. Infect. 15, 347-357.

Davies, T. A., Marie Queenan, A., Morrow, B. J., Shang, W., Amsler, K., He, W., Lynch, A. S., Pillar, C., and Flamm, R. K. (2011). Longitudinal survey of carbapenem resistance and resistance mechanisms in Enterobacteriaceae and non-fermenters from the USA in 2007-09. J. Antimicrob. Chemother. 66, 2298-2307.

de Breij, A., Dijkshoorn, L., Lagendijk, E., van der Meer, J., Koster, A., Bloemberg, G., Wolterbeek, R., van den Broek, P., and Nibbering, P. (2010). Do biofilm formation and interactions with human cells explain the clinical success of Acinetobacter baumannii? PLoS ONE 5, e10732. doi:10.1371/journal.pone.0010732

de Breij, A., Gaddy, J., van der Meer, J., Koning, R., Koster, A., van den Broek, P., Actis, L., Nibbering, P., and Dijkshoorn, L. (2009). CsuA/BABCDE-dependent 
pili are not involved in the adherence of Acinetobacter baumannii ATCC19606(T) to human airway epithelial cells and their inflammatory response. Res. Microbiol. 160, 213-218.

De La Fuente, L., Burr, T. J., and Hoch, H. C. (2007). Mutations in type I and type IV pilus biosynthetic genes affect twitching motility rates in Xylella fastidiosa. J. Bacteriol. 189, 7507-7510.

del Mar Tomas, M., Beceiro, A., Perez, A., Velasco, D., Moure, R., Villanueva, R., Martinez-Beltran, J., and Bou, G. (2005). Cloning and functional analysis of the gene encoding the 33to 36-kilodalton outer membrane protein associated with carbapenem resistance in Acinetobacter baumannii. Antimicrob. Agents Chemother. 49, 5172-5175.

Di Nocera, P. P., Rocco, F., Giannouli, M., Triassi, M., and Zarrilli, R. (2011). Genome organization of epidemic Acinetobacter baumannii strains. BMC Microbiol. 11, 224. doi:10.1186/1471-2180-11-224

Di Popolo, A., Giannouli, M., Triassi, M., Brisse, S., and Zarrilli, R. (2011). Molecular epidemiological investigation of multidrug-resistant Acinetobacter baumannii strains in four Mediterranean countries with a multilocus sequence typing scheme. Clin. Microbiol. Infect. 17, 197-201.

Dijkshoorn, L., Brouwer, C. P., Bogaards, S. J., Nemec, A., van den Broek, P. J., and Nibbering, P. H. (2004). The synthetic N-terminal peptide of human lactoferrin, hLF(1-11), is highly effective against experimental infection caused by multidrug-resistant Acinetobacter baumannii. Antimicrob. Agents Chemother. 48, 4919-4921.

Dijkshoorn, L., Nemec, A., and Seifert, H. (2007). An increasing threat in hospitals: multidrug-resistant Acinetobacter baumannii. Nat. Rev. Microbiol. 5, 939-951.

Docquier, J. D., Lamotte-Brasseur, J., Galleni, M., Amicosante, G., Frere, J. M., and Rossolini, G. M. (2003). On functional and structural heterogeneity of VIM-type metallo- $\beta$-lactamases. J. Antimicrob. Chemother. 51, 257-266.

Doi, Y., Adams, J. M., Yamane, K., and Paterson, D. L. (2007). Identification of $16 \mathrm{~S}$ rRNA methylaseproducing Acinetobacter baumannii clinical strains in North America. Antimicrob. Agents Chemother. 51, 4209-4210.

Doi, Y., and Arakawa, Y. (2007). 16S ribosomal RNA methylation: emerging resistance mechanism against aminoglycosides. Clin. Infect. Dis. 45, 88-94.

Donlan, R. (2002). Biofilms: microbial life on surfaces. Emerging Infect. Dis. 8, 881-890.

Donnarumma, F., Sergi, S., Indorato, C., Mastromei, G., Monnanni, R., Nicoletti, P., Pecile, P., Cecconi, D., Mannino, R., Bencini, S., Fanci, R., Bosi, A., and Casalone, E. (2010). Molecular characterization of Acinetobacter isolates collected in intensive care units of six hospitals in Florence, Italy, during a 3-year surveillance program: a population structure analysis. J. Clin. Microbiol. 48, 1297-1304.

Dorsey, C. W., Beglin, M. S., and Actis, L. A. (2003a). Detection and analysis of iron uptake components expressed by Acinetobacter baumannii clinical isolates. J. Clin. Microbiol. 41, 4188-4193.

Dorsey, C. W., Tolmasky, M. E., Crosa, J. H., and Actis, L. A. (2003b). Genetic organization of an Acinetobacter baumannii chromosomal region harbouring genes related to siderophore biosynthesis and transport. Microbiology 149, 1227-1238.

Drawz, S. M., Babic, M., Bethel, C. R., Taracila, M., Distler, A. M., Ori, C., Caselli, E., Prati, F., and Bonomo, R. A. (2010). Inhibition of the class C $\beta$-lactamase from Acinetobacter spp.: insights into effective inhibitor design. Biochemistry 49, 329-340.

Dupont, M., Pages, J. M., Lafitte, D., Siroy, A., and Bollet, C. (2005). Identification of an OprD homologue in Acinetobacter baumannii. J. Proteome Res. 4, 2386-2390.

Eijkelkamp, B. A., Stroeher, U. H., Hassan, K. A., Papadimitrious, M. S., Paulsen, I. T., and Brown, M. H. (2011). Adherence and motility characteristics of clinical Acinetobacter baumannii isolates. FEMS Microbiol. Lett. 323, 44-51.

Endimiani, A., Luzzaro, F., Migliavacca, R., Mantengoli, E., Hujer, A. M., Hujer, K. M., Pagani, L., Bonomo, R. A., Rossolini, G. M., and Toniolo, A. (2007). Spread in an Italian hospital of a clonal Acinetobacter baumannii strain producing the TEM92 extended-spectrum $\beta$-lactamase. Antimicrob. Agents Chemother. 51, 2211-2214.

Erridge, C., Moncayo-Nieto, O. L., Morgan, R., Young, M., and Poxton, I. R. (2007). Acinetobacter baumannii lipopolysaccharides are potent stimulators of human monocyte activation via Toll-like receptor 4 signalling. J. Med. Microbiol. 56, 165-171.
Espinal, P., Fugazza, G., Lopez, Y., Kasma, M., Lerman, Y., MalhotraKumar, S., Goosens, H., Carmeli, Y. and Vila, J. (2011a). Dissemination of the NDM-2-producing Acinetobacter baumannii clone in an Israeli Rehabilitation Center. Antimicrob. Agents Chemother. 55, 5396-5398.

Espinal, P., Roca, I., and Vila, J. (2011b). Clinical impact and molecular basis of antimicrobial resistance in non-baumannii Acinetobacter. Future Microbiol. 6, 495-511.

Espinal, P., Seifert, H., Dijkshoorn, L., Vila, J., and Roca, I. (2011c). Rapid and accurate identification of genomic species from the Acinetobacter baumannii (Ab) group by MALDI-TOF MS Clin. Microbiol. Infect. (in press). doi:10.1111/j.1469-0691.2011.03696.x Espinal, P., Martí, S., and Vila, J. (2012). Effect of biofilm formation on the survival of Acinetobacter baumanni on dry surfaces. J. Hosp. Infect. 80 , 56-60.

Evans, B. A., Hamouda, A., Towner K. J., and Amyes, S. G. (2010). Novel genetic context of multiple blaOXA-58 genes in Acinetobacter genospecies 3. J. Antimicrob. Chemother. 65, 1586-1588.

Fàbrega, A., Madurga, S., Giralt, E., and Vila, J. (2009). Mechanism of action of and resistance to quinolones. Microb. Biotechnol. 2, 40-61.

Falagas, M. E., and Kasiakou, S. K. (2005). Colistin: the revival of polymyxins for the management of multidrug-resistant Gram-negative bacterial infections. Clin. Infect. Dis. 40, 1333-1341.

Fernández-Cuenca, F., MartínezMartínez, L., Conejo, M. C., Ayala, J. A., Perea, E. J., and Pascual, A. (2003). Relationship between $\beta$-lactamase production, outer membrane protein and penicillinbinding protein profiles on the activity of carbapenems against clinical isolates of Acinetobacter baumannii. J. Antimicrob. Chemother. 51, 565-574.

Fernández-Cuenca, F., Smani, Y., Gómez-Sánchez, M. C., DocoboPérez, F., Caballero-Moyano, F. J., Domínguez-Herrera, J., Pascual, A., and Pachón, J. (2011). Attenuated virulence of a slow-growing pandrug-resistant Acinetobacter baumannii is associated with decreased expression of genes encoding the porins $\mathrm{CarO}$ and OprD-like. Int. J. Antimicrob. Agents $38,548-549$.

Fernández-Reyes, M., Díaz, D., de la Torre, B. G., Cabrales-Rico, A., Vallès-Miret, M., Jiménez-Barbero,
J., Andreu, D., and Rivas, L. (2010). Lysine $\mathrm{N}$ (epsilon)-trimethylation, a tool for improving the selectivity of antimicrobial peptides. J. Med. Chem. 53, 5587-5596.

Fernández-Reyes, M., RodríguezFalcón, M., Chiva, C., Pachón, J., Andreu, D., and Rivas, L. (2009). The cost of resistance to colistin in Acinetobacter baumannii: a proteomic perspective. Proteomics 9, 1632-1645.

Figueiredo, S., Poirel, L., Papa, A. Koulourida, V., and Nordmann, P. (2008). First identification of VIM-4 metallo- $\beta$-lactamase in Acinetobacter spp. Clin. Microbiol. Infect. 14, 289-290.

Figueiredo, S., Poirel, L., Papa, A., Koulourida, V., and Nordmann, P. (2009). Overexpression of the naturally occurring blaOXA-51 gene in Acinetobacter baumannii mediated by novel insertion sequence ISAba 9 . Antimicrob. Agents Chemother. 53, 4045-4047.

Fournier, P. E., Vallenet, D., Barbe, V., Audic, S., Ogata, H., Poirel, L., Richet, H., Robert, C., Mangenot, S., Abergel, C., Nordmann, P., Weissenbach, J., Raoult, D., and Claverie, J. M. (2006). Comparative genomics of multidrug resistance in Acinetobacter baumannii. PLoS Genet. 2, e7. doi:10.1371/journal.pgen.0020007

Friedman, M. (2010). Origin, microbiology, nutrition, and pharmacology of D-amino acids. Chem. Biodivers. 7, 1491-1530.

Gaddy, J. A., and Actis, L. A. (2009). Regulation of Acinetobacter baumannii biofilm formation. Future Microbiol. 4, 273-278.

Gaddy, J. A., Tomaras, A. P., and Actis, L. A. (2009). The Acinetobacter baumannii 19606 OmpA protein plays a role in biofilm formation on abiotic surfaces and in the interaction of this pathogen with eukaryotic cells. Infect. Immun. 77, 3150-3160.

Gales, A. C., Tognim, M. C., Reis, A. O., Jones, R. N., and Sader, H. S. (2003). Emergence of an IMP-like metalloenzyme in an Acinetobacter baumannii clinical strain from a Brazilian teaching hospital. Diagn. Microbiol. Infect. Dis. 45, 77-79.

García, A., Salgado, F., Solar, H., González, C. L., Zemelman, R., and Onate, A. (1999). Some immunological properties of lipopolysaccharide from Acinetobacter baumannii. J. Med. Microbiol. 48, 479-483.

Ge, Y., MacDonald, D. L., Holroyd, K. J., Thornsberry, C., Wexler, H., and Zasloff, M. (1999). In vitro antibacterial properties of pexiganan, an 
analog of magainin. Antimicrob. Agents Chemother. 43, 782-788.

Gehrlein, M., Leying, H., Cullmann, W., Wendt, S., and Opferkuch, W. (1991). Imipenem resistance in Acinetobacter baumanii is due to altered penicillin-binding proteins. Chemotherapy 37, 405-412.

Giacometti, A., Cirioni, O., Del Prete, M. S., Barchiesi, F., Paggi, A. M., Petrelli, E., and Scalise, G. (2000). Comparative activities of polycationic peptides and clinically used antimicrobial agents against multidrugresistant nosocomial isolates of Acinetobacter baumannii. J. Antimicrob. Chemother. 46, 807-810.

Giacometti, A., Cirioni, O., Kamysz, W., D'Amato, G., Silvestri, C., Del Prete, M. S., Lukasiak, J., and Scalise, G. (2003). Comparative activities of cecropin A, melittin, and cecropin A-melittin peptide CA(1-7)M(29) $\mathrm{NH} 2$ against multidrug-resistant nosocomial isolates of Acinetobacter baumannii. Peptides 24, 1315-1318.

Giannouli, M., Tomasone, F., Agodi, A., Vahaboglu, H., Daoud, Z., Triassi, M., Tsakris, A., and Zarrilli, R. (2009). Molecular epidemiology of carbapenem-resistant Acinetobacter baumannii strains in intensive care units of multiple Mediterranean hospitals. J. Antimicrob. Chemother. 63, 828-830.

Gogou, V., Pournaras, S., Giannouli, M., Voulgari, E., Piperaki, E. T., Zarrilli, R., and Tsakris, A. (2011). Evolution of multidrug-resistant Acinetobacter baumannii clonal lineages: a 10 year study in Greece (200009). J. Antimicrob. Chemother. 66, 2767-2772.

Goic-Barisic, I., Bedenic, B., Tonkic, M., Novak, A., Katic, S., Kalenic, S., Punda-Polic, V., and Towner, K. J. (2009). Occurrence of OXA-107 and ISAbal in carbapenem-resistant isolates of Acinetobacter baumannii from Croatia. J. Clin. Microbiol. 47, 3348-3349.

Goic-Barisic, I., Towner, K. J., Kovacic, A., Sisko-Kraljevic, K., Tonkic, M., Novak, A., and Punda-Polic, V. (2011). Outbreak in Croatia caused by a new carbapenem-resistant clone of Acinetobacter baumannii producing OXA-72 carbapenemase. J. Hosp. Infect. 77, 368-369.

González, R. H., Dijkshoorn, L., Van den Barselaar, M., and Nudel, C. (2009). Quorum sensing signal profile of Acinetobacter strains from nosocomial and environmental sources. Rev. Argent. Microbiol. 41, 73-78.

González, R. H., Nusblat, A., and Nudel, B. C. (2001). Detection and characterization of quorum sensing signal molecules in Acinetobacter strains. Microbiol. Res. 155, 271-277.

Gopalakrishnan, R., and Sureshkumar, D. (2010). Changing trends in antimicrobial susceptibility and hospital acquired infections over an 8 year period in a tertiary care hospital in relation to introduction of an infection control programme. J. Assoc. Physicians India 58(Suppl.), 25-31.

Gordon, N. C., Png, K., and Wareham, D. W. (2010). Potent synergy and sustained bactericidal activity of a vancomycin-colistin combination versus multidrug-resistant strains of Acinetobacter baumannii. Antimicrob. Agents Chemother. 54, 5316-5322.

Gribun, A., Nitzan, Y., Pechatnikov, I., Hershkovits, G., and Katcoff, D. J. (2003). Molecular and structural characterization of the HMP-AB gene encoding a pore-forming protein from a clinical isolate of Acinetobacter baumannii. Curr. Microbiol. 47, 434-443.

Guardabassi, L., Dijkshoorn, L., Collard, J. M., Olsen, J. E., and Dalsgaard, A. (2000). Distribution and in-vitro transfer of tetracycline resistance determinants in clinical and aquatic Acinetobacter strains. J. Med. Microbiol. 49, 929-936.

Hamouda, A., and Amyes, S. G. (2004). Novel gyrA and parC point mutations in two strains of Acinetobacter baumannii resistant to ciprofloxacin. J. Antimicrob. Chemother. 54, 695-696.

Henrichsen, J., and Blom, J. (1975). Correlation between twitching motility and possession of polar fimbriae in Acinetobacter calcoaceticus. Acta Pathol. Microbiol. Scand. B 83, 103-115.

Héritier, C., Poirel, L., Fournier, P. E., Claverie, J. M., Raoult, D., and Nordmann, P. (2005a). Characterization of the naturally occurring oxacillinase of Acinetobacter baumannii. Antimicrob. Agents Chemother. 49, 4174-4179.

Héritier, C., Poirel, L., Lambert, T., and Nordmann, P. (2005b). Contribution of acquired carbapenemhydrolyzing oxacillinases to carbapenem resistance in Acinetobacter baumannii. Antimicrob. Agents Chemother. 49, 3198-3202.

Héritier, C., Poirel, L., and Nordmann, P. (2006). Cephalosporinase overexpression resulting from insertion of ISAbal in Acinetobacter baumannii. Clin. Microbiol. Infect. 12, 123-130.

Higgins, P. G., Dammhayn, C., Hackel, M., and Seifert, H. (2010).
Global spread of carbapenemresistant Acinetobacter baumannii. J. Antimicrob. Chemother. 65, 233-238.

Higgins, P. G., Poirel, L., Lehmann, M., Nordmann, P., and Seifert, H. (2009). OXA-143, a novel carbapenem-hydrolyzing class D $\beta$ lactamase in Acinetobacter baumannii. Antimicrob. Agents Chemother. 53, 5035-5038.

Higgins, P. G., Wisplinghoff, H., Stefanik, D., and Seifert, H. (2004) Selection of topoisomerase mutations and overexpression of adeB mRNA transcripts during an outbreak of Acinetobacter baumannii. J. Antimicrob. Chemother. 54, 821-823.

Ho, P. L., Lo, W. U., Yeung, M. K., Lin, C. H., Chow, K. H., Ang, I., Tong, A. H., Bao, J. Y., Lok, S., and Lo, J. Y. (2011). Complete sequencing of pNDMHK encoding NDM-1 carbapenemase from a multidrug-resistant Escherichia coli strain isolated in Hong Kong. PLoS ONE 6, e17989. doi:10.1371/journal.pone.0017989

Houang, E. T., Chu, Y. W., Lo, W. S., Chu, K. Y., and Cheng, A. F. (2003). Epidemiology of rifampin ADP-ribosyltransferase (arr-2) and metallo- $\beta$-lactamase (blaIMP-4) gene cassettes in class 1 integrons in Acinetobacter strains isolated from blood cultures in 1997 to 2000. Antimicrob. Agents Chemother. 47, 1382-1390.

Hu, Y., Zhang, W., Liang, H., Liu, L., Peng, G., Pan, Y., Yang, X., Zheng, B., Gao, G. F., Zhu, B., and $\mathrm{Hu}, \mathrm{H}$. (2011). Whole-genome sequence of a multidrug-resistant clinical isolate of Acinetobacter lwoffii. J. Bacteriol. 193, 5549-5550.

Huang, L. Y., Chen, T. L., Lu, P. L., Tsai, C. A., Cho, W. L., Chang, F. Y., Fung, C. P., and Siu, L. K. (2008). Dissemination of multidrug-resistant, class 1 integron-carrying Acinetobacter baumannii isolates in Taiwan. Clin. Microbiol. Infect. 14, 1010-1019.

Huang, L. Y., Lu, P. L., Chen, T. L., Chang, F. Y., Fung, C. P., and Siu, L. K. (2010). Molecular characterization of $\beta$-lactamase genes and their genetic structures in Acinetobacter genospecies 3 isolates in Taiwan. Antimicrob. Agents Chemother. 54, 2699-2703.

Hujer, K. M., Hamza, N. S., Hujer A. M., Perez, F., Helfand, M. S. Bethel, C. R., Thomson, J. M., Anderson, V. E., Barlow, M., Rice, L. B., Tenover, F. C., and Bonomo, R. A. (2005). Identification of a new allelic variant of the Acinetobacter baumannii cephalosporinase, ADC-7 beta-lactamase: defining a unique family of class $\mathrm{C}$ enzymes. Antimicrob. Agents Chemother. 49, 2941-2948.

Huys, G., Cnockaert, M., Nemec, A., and Swings, J. (2005a). Sequencebased typing of adeB as a potential tool to identify intraspecific groups among clinical strains of multidrugresistant Acinetobacter baumannii. J. Clin. Microbiol. 43, 5327-5331.

Huys, G., Cnockaert, M., Vaneechoutte, M., Woodford, N., Nemec, A., Dijkshoorn, L., and Swings, J. (2005b). Distribution of tetracycline resistance genes in genotypically related and unrelated multiresistant Acinetobacter baumannii strains from different European hospitals. Res. Microbiol. 156, 348-355.

Iacono, M., Villa, L., Fortini, D., Bordoni, R., Imperi, F., Bonnal, R. J. P., Sicheritz-Ponten, T., De Bellis, G., Visca, P., Cassone, A., and Carattoli, A. (2008). Whole-genome pyrosequencing of an epidemic multidrugresistant Acinetobacter baumannii strain belonging to the European clone II group. Antimicrob. Agents Chemother. 52, 2616-2625.

Irie, Y., and Parsek, M. R. (2008). Quorum sensing and microbial biofilms. Curr. Top. Microbiol. Immunol. 322, 67-84.

Jacobs, A. C., Hood, I., Boyd, K. L., Olson, P. D., Morrison, J. M., Carson, S., Sayood, K., Iwen, P. C., Skaar, E. P., and Dunman, P. M. (2010). Inactivation of phospholipase D diminishes Acinetobacter baumannii pathogenesis. Infect. Immun. 78, 1952-1962.

Jarrell, K. F., and McBride, M. J. (2008). The surprisingly diverse ways that prokaryotes move. Nat. Rev. Microbiol. 6, 466-476.

Jawad, A., Heritage, J., Snelling, A. M., Gascoyne-Binzi, D. M., and Hawkey, P. M. (1996). Influence of relative humidity and suspending menstrua on survival of Acinetobacter spp. on dry surfaces. J. Clin. Microbiol. 34, 2881-2887.

Jawad, A., Seifert, H., Snelling, A., Heritage, J., and Hawkey, P. (1998). Survival of Acinetobacter baumannii on dry surfaces: comparison of outbreak and sporadic isolates. J. Clin. Microbiol. 36, 1938-1941.

Jiang, Z., Vasil, A. I., Gera, L., Vasil, M. L., and Hodges, R. S. (2011). Rational design of alpha-helical antimicrobial peptides to target Gramnegative pathogens, Acinetobacter baumannii and Pseudomonas aeruginosa: utilization of charge, 'specificity determinants', total hydrophobicity, hydrophobe type and location as design parameters to improve the 
therapeutic ratio. Chem. Biol. Drug Des. 77, 225-240.

Jin, J. S., Kwon, S. O., Moon, D. C., Gurung, M., Lee, J. H., Kim, S. I., and Lee, J. C. (2011). Acinetobacter baumannii secretes cytotoxic outer membrane protein A via outer membrane vesicles. PLoS ONE 6, e17027. doi:10.1371/journal.pone.0017027.g001

Jones, R. N. (2010). Microbial etiologies of hospital-acquired bacterial pneumonia and ventilator-associated bacterial pneumonia. Clin. Infect. Dis. 51(Suppl. 1), S81-S87.

Kaase, M., Nordmann, P., Wichelhaus, T. A., Gatermann, S. G., Bonnin, R. A., and Poirel, L. (2011). NDM-2 carbapenemase in Acinetobacter baumannii from Egypt. J. Antimicrob. Chemother. 66, 1260-1262.

Kang, Y. S., and Park, W. (2010a). Contribution of quorum-sensing system to hexadecane degradation and biofilm formation in Acinetobacter sp. strain DR1. J. Appl. Microbiol. 109, 1650-1659.

Kang, Y. S., and Park, W. (2010b). Tradeoff between antibiotic resistance and biological fitness in Acinetobacter sp. strain DR1. Environ. Microbiol. 12, 1304-1318.

Karthikeyan, K., Thirunarayan, M. A., and Krishnan, P. (2010). Coexistence of blaOXA-23 with blaNDM1 and $\operatorname{armA}$ in clinical isolates of Acinetobacter baumannii from India. J. Antimicrob. Chemother. 65, 2253-2254.

Karunasagar, A., Maiti, B., Shekar, M., Shenoy, M. S., and Karunasagar, I. (2011). Prevalence of OXA-type carbapenemase genes and genetic heterogeneity in clinical isolates of Acinetobacter spp. from Mangalore, India. Microbiol. Immunol. 55, 239-246.

Kim, J. W., Heo, S. T., Jin, J. S., Choi, C. H., Lee, Y. C., Jeong, Y. G., Kim, S. J., and Lee, J. C. (2008). Characterization of Acinetobacter baumannii carrying blaOXA-23, blaPER-1 and armA in a Korean hospital. Clin. Microbiol. Infect. 14, 716-718.

Kim, S. W., Choi, C. H., Moon, D. C., Jin, J. S., Lee, J. H., Shin, J. H., Kim, J. M., Lee, Y. C., Seol, S. Y., Cho, D. T., and Lee, J. C. (2009). Serum resistance of Acinetobacter baumannii through the binding of factor $\mathrm{H}$ to outer membrane proteins. FEMS Microbiol. Lett. 301, 224-231.

Kitchel, B., Rasheed, J. K., Endimiani, A., Hujer, A. M., Anderson, K. F., Bonomo, R. A., and Patel, J. B. (2010). Genetic factors associated with elevated carbapenem resistance in KPC-producing Klebsiella pneumoniae. Antimicrob. Agents Chemother. 54, 4201-4207.

Klieve, A. V., Yokoyama, M. T., Forster, R. J., Ouwerkerk, D., Bain, P. A., and Mawhinney, E. L. (2005). Naturally occurring DNA transfer system associated with membrane vesicles in cellulolytic Ruminococcus spp. of ruminal origin. Appl. Environ. Microbiol. 71, 4248-4253.

Koh, T. H., Sng, L. H., Wang, G. C., Hsu, L. Y., and Zhao, Y. (2007a). Carbapenemase and efflux pump genes in Acinetobacter calcoaceticusAcinetobacter baumannii complex strains from Singapore. J. Antimicrob. Chemother. 60, 1173-1174.

Koh, T. H., Sng, L. H., Wang, G. C., Hsu, L. Y., and Zhao, Y. (2007b). IMP-4 and OXA $\beta$-lactamases in Acinetobacter baumannii from Singapore. J. Antimicrob. Chemother. 59, 627-632.

Koo, S. H., Kwon, K. C., Cho, H. H., and Sung, J. Y. (2010). Genetic basis of multidrug-resistant Acinetobacter baumannii clinical isolates from three university hospitals in Chungcheong Province, Korea. Korean J. Lab. Med. 30, 498-506.

Krizova, L., Dijkshoorn, L., and Nemec, A. (2011). Diversity and evolution of AbaR genomic resistance islands in Acinetobacter baumannii strains of European clone I. Antimicrob. Agents Chemother. 55, 3201-3206.

Krizova, L., and Nemec, A. (2010). A 63 $\mathrm{kb}$ genomic resistance island found in a multidrug-resistant Acinetobacter baumannii isolate of European clone I from 1977. J. Antimicrob. Chemother. 65, 1915-1918.

Kropec, A., Maira-Litran, T., Jefferson, K. K., Grout, M., Cramton, S. E., Gotz, F., Goldmann, D. A., and Pier, G. B. (2005). Poly$\mathrm{N}$-acetylglucosamine production in Staphylococcus aureus is essential for virulence in murine models of systemic infection. Infect. Immun. 73, 6868-6876.

Kusradze, I., Diene, S. M., Goderdzishvili, M., and Rolain, J. M. (2011). Molecular detection of OXA carbapenemase genes in multidrug-resistant Acinetobacter baumannii isolates from Iraq and Georgia. Int. J. Antimicrob. Agents 38, 164-168.

Kwon, S. O., Gho, Y. S., Lee, J. C., and Kim, S. I. (2009). Proteome analysis of outer membrane vesicles from a clinical Acinetobacter baumannii isolate. FEMS Microbiol. Lett. 297, 150-156.

Lam, C., Hildebrandt, J., Schutze, E., and Wenzel, A. F. (1986). Membrane-disorganizing property of polymyxin $\mathrm{B}$ nonapeptide. $\mathrm{J}$.
Antimicrob. Chemother. 18, 9-15.

Lauretti, L., Riccio, M. L., Mazzariol, A., Cornaglia, G., Amicosante, G., Fontana, R., and Rossolini, G. M. (1999). Cloning and characterization of blaVIM, a new integron-borne metallo- $\beta$ lactamase gene from a Pseudomonas aeruginosa clinical isolate. Antimicrob. Agents Chemother. 43, 1584-1590.

Lee, H., Yong, D., Yum, J. H., Roh, K. H., Lee, K., Yamane, K., Arakawa, Y., and Chong, Y. (2006a). Dissemination of $16 \mathrm{~S}$ rRNA methylase-mediated highly amikacin-resistant isolates of Klebsiella pneumoniae and Acinetobacter baumannii in Korea. Diagn. Microbiol. Infect. Dis. 56, 305-312.

Lee, J. C., Koerten, H., van den Broek, P., Beekhuizen, H., Wolterbeek, R., van den Barselaar, M., van der Reijden, T., van der Meer, J., van de Gevel, J., and Dijkshoorn, L. (2006b). Adherence of Acinetobacter baumannii strains to human bronchial epithelial cells. Res. Microbiol. 157, 360-366.

Lee, J. C., Oh, J. Y., Kim, K. S., Jeong, Y. W., Park, J. C., and Cho, J. W. (2001). Apoptotic cell death induced by Acinetobacter baumannii in epithelial cells through caspase- 3 activation. APMIS 109, 679-684.

Lee, K., Kim, M. N., Choi, T. Y., Cho, S. E., Lee, S., Whang, D. H., Yong, D., Chong, Y., Woodford, N., and Livermore, D. M. (2009a). Wide dissemination of OXA-type carbapenemases in clinical Acinetobacter spp. isolates from South Korea. Int. J. Antimicrob. Agents 33, 520-524.

Lee, Y. T., Huang, L. Y., Chen, T. L., Siu, L. K., Fung, C. P., Cho, W. L., Yu, K. W., and Liu, C. Y. (2009b). Gene cassette arrays, antibiotic susceptibilities, and clinical characteristics of Acinetobacter baumannii bacteremic strains harboring class 1 integrons. J. Microbiol. Immunol. Infect. 42, 210-219.

Lee, K., Kim, M. N., Kim, J. S., Hong, H. L., Kang, J. O., Shin, J. H., Park, Y. J., Yong, D., Jeong, S. H., and Chong, Y. (2011a). Further Increases in carbapenem-, amikacin-, and fluoroquinolone-resistant isolates of Acinetobacter spp. and $P$. aeruginosa in Korea: KONSAR study 2009. Yonsei Med. J. 52, 793-802.

Lee, Y., Kim, C. K., Lee, H., Jeong, S. H., Yong, D., and Lee, K. (2011b). A novel insertion sequence, ISAba10, inserted into ISAbal adjacent to the blaOXA-23 gene and disrupting the outer membrane protein gene carO in Acinetobacter baumannii. Antimicrob. Agents Chemother. 55, 361-363.
Lee, K., Lee, W. G., Uh, Y., Ha, G. Y., Cho, J., and Chong, Y. (2003). VIMand IMP-type metallo- $\beta$-lactamaseproducing Pseudomonas spp. and Acinetobacter spp. in Korean hospitals. Emerging Infect. Dis. 9, 868-871.

Lee, K., Yum, J. H., Yong, D., Lee, H. M., Kim,H. D., Docquier, J. D., Rossolini, G. M., and Chong, Y. (2005). Novel acquired metallo- $\beta$-lactamase gene, blaSIM-1, in a class 1 integron from Acinetobacter baumannii clinical isolates from Korea. Antimicrob. Agents Chemother. 49, 4485-4491.

Lee, M. F., Peng, C. F., Hsu, H. J., and Chen, Y. H. (2008). Molecular characterisation of the metallo$\beta$-lactamase genes in imipenemresistant Gram-negative bacteria from a university hospital in southern Taiwan. Int. J. Antimicrob. Agents 32, 475-480.

Levin, A. S., Levy, C. E., Manrique, A. E., Medeiros, E. A., and Costa, S. F. (2003). Severe nosocomial infections with imipenemresistant Acinetobacter baumanni treated with ampicillin/sulbactam. Int. J. Antimicrob. Agents 21, 58-62.

Li, S. M., and Heide, L. (2005). New aminocoumarin antibiotics from genetically engineered Streptomyces strains. Curr. Med. Chem. 12, 419-427.

Li, X. Z., and Nikaido, H. (2009). Effluxmediated drug resistance in bacteria: an update. Drugs 69, 1555-1623.

Liang, W., Liu, X. F., Huang, J., Zhu, D. M., Li, J., and Zhang, J. (2011). Activities of colistin- and minocyclinebased combinations against extensive drug resistant Acinetobacter baumannii isolates from intensive care unit patients. BMC Infect. Dis. 11, 109. doi:10.1186/1471-2334-11-109

Limansky, A. S., Mussi, M. A., and Viale, A. M. (2002). Loss of a 29kilodalton outer membrane protein in Acinetobacter baumannii is associated with imipenem resistance. $J$. Clin. Microbiol. 40, 4776-4778.

Lin, L., Ling, B. D., and Li, X. Z. (2009). Distribution of the multidrug efflux pump genes, adeABC, adeDE and adeIJK, and class 1 integron genes in multiple-antimicrobial-resistant clinical isolates of Acinetobacter baumannii-Acinetobacter calcoaceticus complex. Int. J. Antimicrob. Agents 33, 27-32.

Lin, Y. C., Hsia, K. C., Chen, Y. C., Sheng, W. H., Chang, S. C., Liao, M. H., and Li, S. Y. (2010). Genetic basis of multidrug resistance in Acinetobacter clinical isolates in Taiwan. Antimicrob. Agents Chemother. 54, 2078-2084. 
Livermore, D. M., Hope, R., Brick, G., Lillie, M., and Reynolds, R. (2008). Non-susceptibility trends among Pseudomonas aeruginosa and other non-fermentative Gram-negative bacteria from bacteraemias in the UK and Ireland, 2001-06. J. Antimicrob. Chemother. 62(Suppl. 2), ii55-ii63.

Loehfelm, T., Luke, N., and Campagnari, A. (2008). Identification and characterization of an Acinetobacter baumannii biofilm-associated protein. J. Bacteriol. 190, 1036-1044.

Lolans, K., Rice, T. W., Munoz-Price, L. S., and Quinn, J. P. (2006). Multicity outbreak of carbapenemresistant Acinetobacter baumannii isolates producing the carbapenemase OXA-40. Antimicrob. Agents Chemother. 50, 2941-2945.

Lopes, B. S., Evans, B. A., and Amyes, S. G. (2012). Disruption of the blaOXA-51-like gene by ISAba16 and activation of the blaOXA-58 gene leading to carbapenem resistance in Acinetobacter baumannii Ab244. J. Antimicrob. Chemother. 67, 59-63.

López-Rojas, R., Docobo-Pérez, F., Pachón-Ibánez, M. E., de la Torre, B. G., Fernández-Reyes, M., March, C., Bengoechea, J. A., Andreu, D., Rivas, L., and Pachón, J. (2011a). Efficacy of cecropin A-melittin peptides on a sepsis model of infection by pan-resistant Acinetobacter baumannii. Eur. J. Clin. Microbiol. Infect. Dis. 30, 1391-1398.

López-Rojas, R., Domínguez-Herrera, J., McConnell, M. J., Docobo-Perez, F., Smani, Y., Fernández-Reyes, M., Rivas, L., and Pachón, J. (2011b). Impaired virulence and in vivo fitness of colistin-resistant Acinetobacter baumannii. J. Infect. Dis. 203, 545-548.

López-Rojas, R., Jiménez-Mejías, M. E., Lepe, J. A., and Pachón, J. (2011c). Acinetobacter baumannii resistant to colistin alters its antibiotic resistance profile: a case report from Spain. J. Infect. Dis. 204, 1147-1148.

Lu, P. L., Doumith, M., Livermore, D. M., Chen, T. P., and Woodford, N. (2009). Diversity of carbapenem resistance mechanisms in Acinetobacter baumannii from a Taiwan hospital: spread of plasmid-borne OXA-72 carbapenemase. J. Antimicrob. Chemother. 63, 641-647.

Magiorakos, A. P., Srinivasan, A., Carey, R. B., Carmeli, Y., Falagas, M. E., Giske, C. G., Harbarth, S., Hindler, J. F., Kahlmeter, G., Olsson-Liljequist, B., Paterson, D. L., Rice, L. B., Stelling, J., Struelens, M. J., Vatopoulos, A., Weber, J. T., and Monnet, D. L.
(2012). Multidrug-resistant, extensively drug-resistant and pandrugresistant bacteria: an international expert proposal for interim standard definitions for acquired resistance. Clin. Microbiol. Infect. 18, 268-281.

Magnet, S., Courvalin, P., and Lambert, T. (2001). Resistance-nodulationcell division-type efflux pump involved in aminoglycoside resistance in Acinetobacter baumannii strain BM4454. Antimicrob. Agents Chemother. 45, 3375-3380.

Maisetta, G., Batoni, G., Esin, S., Florio, W., Bottai, D., Favilli, F., and Campa, M. (2006). In vitro bactericidal activity of human beta-defensin 3 against multidrug-resistant nosocomial strains. Antimicrob. Agents Chemother. 50, 806-809.

Mak, J. K., Kim, M. J., Pham, J., Tapsall, J., and White, P. A. (2009). Antibiotic resistance determinants in nosocomial strains of multidrug-resistant Acinetobacter baumannii. J. Antimicrob. Chemother. 63, 47-54.

Mammeri, H., Poirel, L., Mangeney, N., and Nordmann, P. (2003). Chromosomal integration of a cephalosporinase gene from Acinetobacter baumannii into Oligella urethralis as a source of acquired resistance to $\beta$-lactams. Antimicrob. Agents Chemother. 47, 1536-1542.

Mangoni, M. L., Maisetta, G., Di Luca, M., Gaddi, L. M., Esin, S., Florio, W., Brancatisano, F. L., Barra, D., Campa, M., and Batoni, G. (2008). Comparative analysis of the bactericidal activities of amphibian peptide analogues against multidrug-resistant nosocomial bacterial strains. Antimicrob. Agents Chemother. 52, 85-91.

Marchand, I., Damier-Piolle, L., Courvalin, P., and Lambert, T. (2004). Expression of the RND-type efflux pump AdeABC in Acinetobacter baumannii is regulated by the AdeRS two-component system. Antimicrob. Agents Chemother. 48, 3298-3304.

Marqué, S., Poirel, L., Héritier, C., Brisse, S., Blasco, M. D., Filip, R., Coman, G., Naas, T., and Nordmann, P. (2005). Regional occurrence of plasmidmediated carbapenem-hydrolyzing oxacillinase OXA-58 in Acinetobacter spp. in Europe. J. Clin. Microbiol. 43, 4885-4888.

Marr, A. K., Gooderham, W. J., and Hancock, R. E. (2006). Antibacterial peptides for therapeutic use: obstacles and realistic outlook. Curr. Opin. Pharmacol. 6, 468-472.

Martí, S., Fernández-Cuenca, F., Pascual, A., Ribera, A., Rodríguez-Baño, J., Bou, G., Miguel Cisneros, J., Pachón, J., Martínez-Martínez, L., and Vila, J. (2006). Prevalence of the tet $\mathrm{A}$ and tetB genes as mechanisms of resistance to tetracycline and minocycline in Acinetobacter baumannii clinical isolates. Enferm. Infecc. Microbiol. Clin. 24, 77-80.

Martí, S., Sánchez-Céspedes, J., Blasco, M. D., Espinal, P., Ruiz, M., Alba, V., and Vila, J. (2008a). Characterization of the carbapenem-hydrolyzing oxacillinase OXA-58 in an Acinetobacter phenon 6/ct13TU clinical isolate. Diagn. Microbiol. Infect. Dis. 61, 468-470.

Martí, S., Sánchez-Céspedes, J., Blasco, M. D., Ruiz, M., Espinal, P., Alba, V., Fernández-Cuenca, F., Pascual, A., and Vila, J. (2008b). Characterization of the carbapenem-hydrolyzing oxacillinase OXA-58 in an Acinetobacter genospecies 3 clinical isolate. Antimicrob. Agents Chemother. 52, 2955-2958.

Mattick, J. S. (2002). Type IV pili and twitching motility. Annu. Rev. Microbiol. 56, 289-314.

Mazel, D. (2006). Integrons: agents of bacterial evolution. Nat. Rev. Microbiol. 4, 608-620.

McBride, M. J. (2010). Shining a light on an opportunistic pathogen. J. Bacteriol. 192, 6325-6326.

McConnell, M. J., Domínguez-Herrera, J., Smani, Y., López-Rojas, R., Docobo-Pérez, F., and Pachón, J. (2011a). Vaccination with outer membrane complexes elicits rapid protective immunity to multidrugresistant Acinetobacter baumannii. Infect. Immun. 79, 518-526.

McConnell, M. J., Rumbo, C., Bou, G., and Pachon, J. (2011b). Outer membrane vesicles as an acellular vaccine against Acinetobacter baumannii. Vaccine 29, 5705-5710.

McKean, S. C., Davies, J. K., and Moore, R. J. (2007). Expression of phospholipase $\mathrm{D}$, the major virulence factor of Corynebacterium pseudotuberculosis, is regulated by multiple environmental factors and plays a role in macrophage death. Microbiology 153, 2203-2211.

Meng, H., and Kumar, K. (2007). Antimicrobial activity and protease stability of peptides containing fluorinated amino acids. J. Am. Chem. Soc. 129, 15615-15622.

Merino, M., Acosta, J., Poza, M., Sanz, F., Beceiro, A., Chaves, F., and Bou, G. (2010). OXA-24 carbapenemase gene flanked by XerC/XerD-like recombination sites in different plasmids from different Acinetobacter species isolated during a nosocomial outbreak. Antimicrob. Agents Chemother. 54, 2724-2727.

Mihara, K., Tanabe, T., Yamakawa, Y., Funahashi, T., Nakao, H., Narimatsu,
S., and Yamamoto, S. (2004). Identification and transcriptional organization of a gene cluster involved in biosynthesis and transport of acinetobactin, a siderophore produced by Acinetobacter baumannii ATCC 19606T. Microbiology 150 2587-2597.

Moffatt, J. H., Harper, M., Adler, B., Nation, R. L., Li, J., and Boyce, J. D. (2011). Insertion sequence ISAba11 is involved in colistin resistance and loss of lipopolysaccharide in Acinetobacter baumannii. Antimicrob. Agents Chemother. 55, 3022-3024.

Moffatt, J. H., Harper, M., Harrison, P., Hale, J. D., Vinogradov, E., Seemann, T., Henry, R., Crane, B., St Michael, F., Cox, A. D., Adler, B., Nation, R. L., Li, J., and Boyce, J. D. (2010). Colistin resistance in Acinetobacter baumannii is mediated by complete loss of lipopolysaccharide production. Antimicrob. Agents Chemother. 54, 4971-4977.

Molhoek, E. M., van Dijk, A., Veldhuizen, E. J., Haagsman, H. P., and Bikker, F. J. (2011). Improved proteolytic stability of chicken cathelicidin-2 derived peptides by d-amino acid substitutions and cyclization. Peptides 32, 875-880.

Morgan, D. J., Weisenberg, S. A., Augenbraun, M. H., Calfee, D. P., Currie, B. P., Furuya, E. Y., Holzman, R., Montecalvo, M. C., Phillips, M., Polsky, B., and Sepkowitz, K. A. (2009). Multidrug-resistant Acinetobacter baumannii in New York City - 10 years into the epidemic. Infect. Control Hosp. Epidemiol. 30, 196-197.

Motsch, S., Schmitt, R., Avila, P., de la Cruz, F., Ward, E., and Grinsted, J. (1985). Junction sequences generated by 'one-ended transposition.' Nucleic Acids Res. 13, 3335-3342.

Moubareck, C., Bremont, S., Conroy, M. C., Courvalin, P., and Lambert, T. (2009). GES-11, a novel integron-associated GES variant in Acinetobacter baumannii. Antimicrob. Agents Chemother. 53, 3579-3581.

Mussi, M. A., Limansky, A. S., and Viale, A. M. (2005). Acquisition of resistance to carbapenems in multidrugresistant clinical strains of Acinetobacter baumannii: natural insertional inactivation of a gene encoding a member of a novel family of $\beta$-barrel outer membrane proteins. Antimicrob. Agents Chemother. 49, 1432-1440.

Naas, T., Bogaerts, P., Bauraing, C., Degheldre, Y., Glupczynski, Y., and Nordmann, P. (2006a). Emergence 
of PER and VEB extended-spectrum $\beta$-lactamases in Acinetobacter baumannii in Belgium. J. Antimicrob. Chemother. 58, 178-182.

Naas, T., Coignard, B., Carbonne, A., Blanckaert, K., Bajolet, O., Bernet, C., Verdeil, X., Astagneau, P., Desenclos, J. C., and Nordmann, P. (2006b). VEB-1 extended-spectrum $\beta$-lactamase-producing Acinetobacter baumannii, France. Emerging Infect. Dis. 12, 1214-1222.

Naas, T., Namdari, F., Reglier-Poupet, H., Poyart, C., and Nordmann, P. (2007). Panresistant extended-spectrum $\quad \beta$-lactamase SHV-5-producing Acinetobacter baumannii from New York City. J. Antimicrob. Chemother. 60, 1174-1176.

Naas, T., Poirel, L., and Nordmann, P. (2008). Minor extended-spectrum $\beta$-lactamases. Clin. Microbiol. Infect. 14(Suppl. 1), 42-52.

Nagano, N., Nagano, Y., Cordevant, C., Shibata, N., and Arakawa, Y. (2004). Nosocomial transmission of CTXM-2 $\beta$-lactamase-producing Acinetobacter baumannii in a neurosurgery ward. J. Clin. Microbiol. 42, 3978-3984.

Naiemi, N. A., Duim, B., Savelkoul, P. H., Spanjaard, L., de Jonge, E., Bart, A., Vandenbroucke-Grauls, C. M., and de Jong, M. D. (2005). Widespread transfer of resistance genes between bacterial species in an intensive care unit: implications for hospital epidemiology. J. Clin. Microbiol. 43, 4862-4864.

Navia, M. M., Ruiz, J., and Vila, J. (2002). Characterization of an integron carrying a new class $D \beta$ lactamase (OXA-37) in Acinetobacter baumannii. Microb. Drug Resist. 8, 261-265.

Nemec, A., Dolzani, L., Brisse, S., van den Broek, P., and Dijkshoorn, L. (2004). Diversity of aminoglycosideresistance genes and their association with class 1 integrons among strains of pan-European Acinetobacter baumannii clones. J. Med. Microbiol. 53, 1233-1240.

Nemec, A., Krizova, L., Maixnerova, M., van der Reijden, T. J., Deschaght, P., Passet, V., Vaneechoutte, M., Brisse, S., and Dijkshoorn, L. (2011). Genotypic and phenotypic characterization of the Acinetobacter calcoaceticus-Acinetobacter baumannii complex with the proposal of Acinetobacter pittii sp. nov. (formerly Acinetobacter genomic species 3) and Acinetobacter nosocomialis sp. nov. (formerly Acinetobacter genomic species 13TU). Res. Microbiol. 162, 393-404.
Nemec, A., Maixnerova, M., van der Reijden, T. J., van den Broek, P. J., and Dijkshoorn, L. (2007). Relationship between the AdeABC efflux system gene content, netilmicin susceptibility and multidrug resistance in a genotypically diverse collection of Acinetobacter baumannii strains. J. Antimicrob. Chemother. 60, 483-489.

Nigro, S. J., Post, V., and Hall, R. M. (2011a). Aminoglycoside resistance in multiply antibiotic-resistant Acinetobacter baumannii belonging to global clone 2 from Australian hospitals. J. Antimicrob. Chemother. 66, 1504-1509.

Nigro, S. J., Post, V., and Hall, R. M. (2011b). The multiresistant Acinetobacter baumannii European clone I type strain RUH875 (A297) carries a genomic antibiotic resistance island AbaR21, plasmid pRAY and a cluster containing ISAba1-sul2-CR2-strBstrA. J. Antimicrob. Chemother. 66, 1928-1930.

Niu, C., Clemmer, K. M., Bonomo, R. A., and Rather, P. N. (2008). Isolation and characterization of an autoinducer synthase from Acinetobacter baumannii. J. Bacteriol. 190, 3386-3392.

Nordmann, P., Couard, J. P., Sansot, D., and Poirel, L. (2012). Emergence of an autochthonous and communityacquired NDM-1-producing Klebsiella pneumoniae in Europe. Clin. Infect. Dis. 54, 150-151.

Nordmann, P., Poirel, L., Toleman, M. A., and Walsh, T. R. (2011). Does broad-spectrum $\beta$-lactam resistance due to NDM-1 herald the end of the antibiotic era for treatment of infections caused by Gram-negative bacteria? J. Antimicrob. Chemother. 66, 689-692.

Ostorhazi, E., Holub, M. C., Rozgonyi, F., Harmos, F., Cassone, M., Wade, J. D., and Otvos, L. Jr. (2011). Broadspectrum antimicrobial efficacy of peptide A3-APO in mouse models of multidrug-resistant wound and lung infections cannot be explained by in vitro activity against the pathogens involved. Int. J. Antimicrob. Agents 37, 480-484.

Ostorhazi, E., Rozgonyi, F., Sztodola, A., Harmos, F., Kovalszky, I., Szabo, D., Knappe, D., Hoffmann, R., Cassone, M., Wade, J. D., Bonomo, R. A., and Otvos, L. Jr. (2010). Preclinical advantages of intramuscularly administered peptide A3-APO over existing therapies in Acinetobacter baumannii wound infections. J. Antimicrob. Chemother. 65, 2416-2422.

Ozbek, B., and Senturk, A. (2010). Postantibiotic effects of tigecycline, colistin sulfate, and levofloxacin alone or tigecycline-colistin sulfate and tigecycline-levofloxacin combinations against Acinetobacter baumannii. Chemotherapy 56, 466-471.

Pachón-Ibánez, M. E., Docobo-Peréz, F., López-Rojas, R., DomínguezHerrera, J., Jiménez-Mejias, M. E., García-Curiel, A., Pichardo, C. Jiménez, L., and Pachón, J. (2010). Efficacy of rifampin and its combinations with imipenem, sulbactam and colistin in experimental models of infection caused by imipenemresistant Acinetobacter baumannii. Antimicrob. Agents Chemother. 54, 1165-1172.

Pachón-Ibáñez, M. E., FernándezCuenca, F., Docobo-Pérez, F., Pachón, J., and Pascual, A. (2006). Prevention of rifampicin resistance in Acinetobacter baumannii in an experimental pneumonia murine model, using rifampicin associated with imipenem or sulbactam. $J$. Antimicrob. Chemother. 58, 689-692.

Pantophlet, R., Brade, L., Dijkshoorn, L., and Brade, H. (1998). Specificity of rabbit antisera against lipopolysaccharide of Acinetobacter. J. Clin. Microbiol. 36, 1245-1250.

Papa, A., Koulourida, V., and Souliou, E. (2009). Molecular epidemiology of carbapenem-resistant Acinetobacter baumannii in a newly established Greek hospital. Microb. Drug Resist. 15, 257-260.

Park, Y. K., Jung, S. I., Park, K. H., Cheong, H. S., Peck, K. R. Song, J. H., and Ko, K. S. (2009). Independent emergence of colistinresistant Acinetobacter spp. isolates from Korea. Diagn. Microbiol. Infect. Dis. 64, 43-51.

Pasterán, F., Rapoport, M., Petroni, A., Faccone, D., Corso, A., Galas, M., Vázquez, M., Procopio, A., Tokumoto, M., and Cagnoni, V. (2006). Emergence of PER-2 and VEB-1a in Acinetobacter baumannii strains in the Americas. Antimicrob. Agents Chemother. 50, 3222-3224.

Paton, R., Miles, R. S., Hood, J., Amyes, S. G., Miles, R. S., and Amyes, S. G. (1993). ARI 1: $\beta$-lactamasemediated imipenem resistance in Acinetobacter baumannii. Int. J. Antimicrob. Agents 2, 81-87.

Payne, D. J., Gwynn, M. N., Holmes, D. J., and Pompliano, D. L. (2007) Drugs for bad bugs: confronting the challenges of antibacterial discovery. Nat. Rev. Drug Discov. 6, 29-40.

Peleg, A. Y., Franklin, C., Walters, L. J., Bell, J. M., and Spelman, D. W. (2006). OXA-58 and IMP-4 carbapenem-hydrolyzing $\beta$ lactamases in an Acinetobacter junii blood culture isolate from Australia. Antimicrob. Agents Chemother. 50, 399-400.

Peleg, A. Y., Seifert, H., and Paterson, D. L. (2008). Acinetobacter baumannii: emergence of a successful pathogen. Clin. Microbiol. Rev. 21, 538-582.

Perez, F., Ponce-Terashima, R., Adams, M. D., and Bonomo, R. A. (2011). Are we closing in on an "elusive enemy?" The current status of our battle with Acinetobacter baumannii. Virulence 2, 86-90.

Pfeifer, Y., Wilharm, G., Zander, E., Wichelhaus, T. A., Gottig, S., Hunfeld, K. P., Seifert, H., Witte, W. and Higgins, P. G. (2011). Molecular characterization of blaNDM-1 in an Acinetobacter baumannii strain isolated in Germany in 2007. J. Antimicrob. Chemother. 66, 1998-2001.

Piddock, L. J. (2006). Clinically relevant chromosomally encoded multidrug resistance efflux pumps in bacteria. Clin. Microbiol. Rev. 19, 382-402.

Pitart, C., Solé, M., Roca, I., Fàbrega, A., Vila, J., and Marco, F. (2011). First outbreak of a plasmid-mediated carbapenem-hydrolyzing OXA-48 $\beta$-lactamase in Klebsiella pneumoniae in Spain. Antimicrob. Agents Chemother. 55, 4398-4401.

Poirel, L., Cabanne, L., Vahaboglu, H., and Nordmann, P. (2005a). Genetic environment and expression of the extended-spectrum $\beta$ lactamase blaPER-1 gene in Gramnegative bacteria. Antimicrob. Agents Chemother. 49, 1708-1713.

Poirel, L., Marqué, S., Héritier, C. Segonds, C., Chabanon, G., and Nordmann, P. (2005b). OXA58 , a novel class $\mathrm{D} \beta$-lactamase involved in resistance to carbapenems in Acinetobacter baumannii. Antimicrob. Agents Chemother. 49, 202-208.

Poirel, L., Corvec, S., Rapoport, M., Mugnier, P., Petroni, A., Pasteran, F., Faccone, D., Galas, M., Drugeon, H., Cattoir, V., and Nordmann, P. (2007). Identification of the novel narrow-spectrum $\beta$ lactamase SCO-1 in Acinetobacter spp. from Argentina. Antimicrob. Agents Chemother. 51, 2179-2184.

Poirel, L., Dortet, L., Bernabeu, S., and Nordmann, P. (2011a). Genetic features of blaNDM-1-positive Enterobacteriaceae. Antimicrob. Agents Chemother. 44, 5403-5407.

Poirel, L., Schrenzel, J., Cherkaoui, A., Bernabeu, S., Renzi, G., and Nordmann, P. (2011b). Molecular analysis of NDM-1-producing enterobacterial isolates from Geneva, Switzerland. J. Antimicrob. Chemother. 66, 1730-1733. 
Poirel, L., Figueiredo, S., Cattoir, V., Carattoli, A., and Nordmann, P. (2008a). Acinetobacter radioresistens as a silent source of carbapenem resistance for Acinetobacter spp. Antimicrob. Agents Chemother. 52, 1252-1256.

Poirel, L., Mansour, W., Bouallegue, O., and Nordmann, P. (2008b). Carbapenem-resistant Acinetobacter baumannii isolates from Tunisia producing the OXA-58-like carbapenem-hydrolyzing oxacillinase OXA-97. Antimicrob. Agents Chemother. 52, 1613-1617.

Poirel, L., Lagrutta, E., Taylor, P., Pham, J., and Nordmann, P. (2010). Emergence of metallo$\beta$-lactamase NDM-1-producing multidrug-resistant Escherichia coli in Australia. Antimicrob. Agents Chemother. 54, 4914-4916.

Poirel, L., Lebessi, E., Héritier, C., Patsoura, A., Foustoukou, M., and Nordmann, P. (2006). Nosocomial spread of OXA-58-positive carbapenem-resistant Acinetobacter baumannii isolates in a paediatric hospital in Greece. Clin. Microbiol. Infect. 12, 1138-1141.

Poirel, L., Menuteau, O., Agoli, N., Cattoen, C., and Nordmann, P. (2003). Outbreak of extended-spectrum $\beta$ lactamase VEB-1-producing isolates of Acinetobacter baumannii in a French hospital. J. Clin. Microbiol. 41, 3542-3547.

Poirel, L., Mugnier, P. D., Toleman, M. A., Walsh, T. R., Rapoport, M. J., Petroni, A., and Nordmann, P. (2009). ISCR2, another vehicle for blaVEB gene acquisition. Antimicrob. Agents Chemother. 53, 4940-4943.

Poirel, L., and Nordmann, P. (2006a). Carbapenem resistance in Acinetobacter baumannii: mechanisms and epidemiology. Clin. Microbiol. Infect. 12, 826-836.

Poirel, L., and Nordmann, P. (2006b). Genetic structures at the origin of acquisition and expression of the carbapenem-hydrolyzing oxacillinase gene blaOXA-58 in Acinetobacter baumannii. Antimicrob. Agents Chemother. 50, 1442-1448.

Post, V., and Hall, R. M. (2009). AbaR5, a large multiple-antibiotic resistance region found in Acinetobacter baumannii. Antimicrob. Agents Chemother. 53, 2667-2671.

Post, V., White, P. A., and Hall, R. M. (2010). Evolution of AbaR-type genomic resistance islands in multiply antibiotic-resistant Acinetobacter baumannii. J. Antimicrob. Chemother. 65, 1162-1170.
Potron, A., Munoz-Price, L. S., Nordmann, P., Cleary, T., and Poirel, L. (2011). Genetic features of CTXM-15-producing Acinetobacter baumannii from Haiti. Antimicrob. Agents Chemother. 55, 5946-5948.

Potron, A., Poirel, L., Croize, J., Chanteperdrix, V., and Nordmann, P. (2009). Genetic and biochemical characterization of the first extended-spectrum CARB-type $\beta$ lactamase, RTG-4, from Acinetobacter baumannii. Antimicrob. Agents Chemother. 53, 3010-3016.

Pournaras, S., Markogiannakis, A., Ikonomidis, A., Kondyli, L., Bethimouti, K., Maniatis, A. N., Legakis, N. J., and Tsakris, A. (2006). Outbreak of multiple clones of imipenem-resistant Acinetobacter baumannii isolates expressing OXA58 carbapenemase in an intensive care unit. J. Antimicrob. Chemother. 57, 557-561.

Principe, L., D’Arezzo, S., Capone, A., Petrosillo, N., and Visca, P. (2009). In vitro activity of tigecycline in combination with various antimicrobials against multidrug resistant Acinetobacter baumannii. Ann. Clin. Microbiol. Antimicrob. 21, 8-18.

Qi, C., Malczynski, M., Parker, M. and Scheetz, M. H. (2008). Characterization of genetic diversity of carbapenem-resistant Acinetobacter baumannii clinical strains collected from 2004 to 2007. J. Clin. Microbiol. 46, 1106-1109.

Quale, J., Bratu, S., Landman, D., and Heddurshetti, R. (2003). Molecular epidemiology and mechanisms of carbapenem resistance in Acinetobacter baumannii endemic in New York City. Clin. Infect. Dis. 37, 214-220.

Queenan, A. M., and Bush, K. (2007). Carbapenemases: the versatile $\beta$ lactamases. Clin. Microbiol. Rev. 20, 440-458.

Quinteira, S., Grosso, F., Ramos, H., and Peixe, L. (2007). Molecular epidemiology of imipenem-resistant Acinetobacter haemolyticus and Acinetobacter baumannii isolates carrying plasmid-mediated OXA-40 from a Portuguese hospital. Antimicrob. Agents Chemother. 51, 3465-3466.

Rajamohan, G., Srinivasan, V. B., and Gebreyes, W. A. (2010). Molecular and functional characterization of a novel efflux pump, AmvA, mediating antimicrobial and disinfectant resistance in Acinetobacter baumannii. J. Antimicrob. Chemother. 65, 1919-1925.

Ramírez, M. S., Bello, H., González Rocha, G., Márquez, C., and Centrón, D. (2010a). Tn7::In2-8 dispersion in multidrug resistant isolates of Acinetobacter baumanni from Chile. Rev. Argent. Microbiol. 42, 138-140.

Ramírez, M. S., Piñeiro, S., and Centrón, D. (2010b). Novel insights about class 2 integrons from experimental and genomic epidemiology. Antimicrob. Agents Chemother. 54, 699-706.

Rasko, D. A., and Sperandio, V. (2010). Anti-virulence strategies to combat bacteria-mediated disease. Nat. Rev. Drug Discov. 9, 117-128.

Ravasi, P., Limansky, A. S., Rodriguez, R. E., Viale, A. M., and Mussi, M. A. (2011). ISAba825, a functional insertion sequence modulating genomic plasticity and blaOXA-58 expression in Acinetobacter baumannii. Antimicrob. Agents Chemother. 55, 917-920.

Ribera, A., Roca, I., Ruiz, J., Gibert, I. and Vila, J. (2003a). Partial characterization of a transposon containing the tet(A) determinant in a clinical isolate of Acinetobacter baumannii. J. Antimicrob. Chemother. 52, 477-480.

Ribera, A., Ruiz, J., and Vila, J. (2003b). Presence of the Tet $\mathrm{M}$ determinant in a clinical isolate of Acinetobacter baumannii. Antimicrob. Agents Chemother. 47, 2310-2312.

Riccio, M. L., Franceschini, N., Boschi, L., Caravelli, B., Cornaglia, G., Fontana, R., Amicosante, G., and Rossolini, G. M. (2000). Characterization of the metallo- $\beta$-lactamase determinant of Acinetobacter baumannii AC-54/97 reveals the existence of blaIMP allelic variants carried by gene cassettes of different phylogeny. Antimicrob. Agents Chemother. 44, 1229-1235.

Roberts, A. P., Chandler, M., Courvalin, P., Guedon, G., Mullany, P., Pembroke, T., Rood, J. I., Smith, C. J., Summers, A. O., Tsuda, M., and Berg, D. E. (2008). Revised nomenclature for transposable genetic elements. Plasmid 60, 167-173.

Robledo, I. E., Aquino, E. E., Santé, M. I., Santana, J. L., Otero, D. M., León, C. F., and Vázquez, G. J. (2010). Detection of KPC in Acinetobacter spp. in Puerto Rico. Antimicrob. Agents Chemother. 54, 1354-1357.

Roca, I., Espinal, P., Marti, S., and Vila, J. (2011). First identification and characterization of an AdeABClike efflux pump in Acinetobacter genomospecies 13TU. Antimicrob. Agents Chemother. 55, 1285-1286.

Roca, I., Marti, S., Espinal, P., Martinez, P., Gibert, I., and Vila, J. (2009). CraA, a major facilitator superfamily efflux pump associated with chloramphenicol resistance in Acinetobacter baumannii. Antimicrob. Agents Chemother. 53, 4013-4014.

Rodríguez-Baño, J., Martí, S., Soto, S., Fernández-Cuenca, F., Miguel Cisneros, J., Pachón, J., Pascual, A., Martínez-Martínez, L., McQueary, C., Actis, L., Vila, J., and Spanish Group for the Study of Nosocomial Infections (GEIH). (2008). Biofilm formation in Acinetobacter baumannii: associated features and clinical implications. Clin. Microbiol. Infect. 14, 276-278.

Rodríguez-Hernández, M. J., Cuberos, L., Pichardo, C., Caballero, F. J., Moreno, I., Jiménez-Mejías, M. E., García-Curiel, A., and Pachón, J. (2001). Sulbactam efficacy in experimental models caused by susceptible and intermediate Acinetobacter baumannii strains. J. Antimicrob. Chemother. 47, 479-482.

Rodríguez-Hernández, M. J., Saugar, J., Docobo-Peréz, F., de la Torre, B. G., Pachón-Ibánez, M. E., GarcíaCuriel, A., Fernández-Cuenca, F., Andreu, D., Rivas, L., and Pachón, J. (2006). Studies on the antimicrobial activity of cecropin A-melittin hybrid peptides in colistin-resistant clinical isolates of Acinetobacter baumannii. J. Antimicrob. Chemother. 58, 95-100.

Rolain, J. M., Roch, A., Castanier, M., Papazian, L., and Raoult, D. (2011). Acinetobacter baumannii resistant to colistin with impaired virulence: a case report from France. J. Infect. Dis. 204, 1146-1147.

Rose, A. (2010). TnAbaR1: a novel Tn7related transposon in Acinetobacter baumannii that contributes to the accumulation and dissemination of large repertoires of resistance genes. Biosci. Horizons 3, 40-48.

Rossolini, G. M., and Mantengoli, E. (2008). Antimicrobial resistance in Europe and its potential impact on empirical therapy. Clin. Microbiol. Infect. 14(Suppl. 6), 2-8.

Ruiz, M., Marti, S., Fernandez-Cuenca, F., Pascual, A., and Vila, J. (2007). High prevalence of carbapenemhydrolysing oxacillinases in epidemiologically related and unrelated Acinetobacter baumannii clinical isolates in Spain. Clin. Microbiol. Infect. 13, 1192-1198.

Rumbo, C., Fernandez-Moreira, E. Merino, M., Poza, M., Mendez, J. A. Soares, N. C., Mosquera, A., Chaves, F., and Bou, G. (2011). Horizontal transfer of the OXA-24 carbapenemase gene via outer membrane vesicles: a new mechanism of dissemination of carbapenem resistance genes in Acinetobacter baumannii. 
Antimicrob. Agents Chemother. 55, 3084-3090.

Russo, T. A., Luke, N. R., Beanan, J. M., Olson, R., Sauberan, S. L., MacDonald, U., Schultz, L. W., Umland, T. C., and Campagnari, A. A. (2010). The K1 capsular polysaccharide of Acinetobacter baumannii strain 307-0294 is a major virulence factor. Infect. Immun. 78, 3993-4000.

Russo, T. A., MacDonald, U., Beanan, J. M., Olson, R., MacDonald, I. J., Sauberan, S. L., Luke, N. R., Schultz, L. W., and Umland, T. C. (2009). Penicillin-binding protein $7 / 8$ contributes to the survival of Acinetobacter baumannii in vitro and in vivo. J. Infect. Dis. 199, 513-521.

Russo, T. A., Page, M. G., Beanan, J. M., Olson, R., Hujer, A. M., Hujer, K. M., Jacobs, M., Bajaksouzian, S., Endimiani, A., and Bonomo, R. A. (2011). In vivo and in vitro activity of the siderophore monosulfactam BAL30072 against Acinetobacter baumannii. J. Antimicrob. Chemother. 66, 867-873.

Ruzin, A., Keeney, D., and Bradford, P. A. (2007). AdeABC multidrug efflux pump is associated with decreased susceptibility to tigecycline in Acinetobacter calcoaceticus-Acinetobacter baumannii complex. J. Antimicrob. Chemother. 59, 1001-1004.

Sarkar, S., and Chakraborty, R. (2008). Quorum sensing in metal tolerance of Acinetobacter junii BB1A is associated with biofilm production. FEMS Microbiol. Lett. 282, 160-165.

Sauer, F. G., Mulvey, M. A., Schilling, J. D., Martinez, J. J., and Hultgren, S. J. (2000). Bacterial pili: molecular mechanisms of pathogenesis. Curr. Opin. Microbiol. 3, 65-72.

Saugar, J. M., Alarcón, T., LópezHernández, S., López-Brea, M., Andreu, D., and Rivas, L. (2002). Activities of polymyxin $\mathrm{B}$ and cecropin A-,melittin peptide CA(18) $\mathrm{M}(1-18)$ against a multiresistant strain of Acinetobacter baumannii. Antimicrob. Agents Chemother. 46, 875-878.

Sauvage, E., Kerff, F., Terrak, M., Ayala, J. A., and Charlier, P. (2008). The penicillin-binding proteins: structure and role in peptidoglycan biosynthesis. FEMS Microbiol. Rev. 32, 234-258.

Schild, S., Nelson, E. J., and Camilli, A. (2008). Immunization with Vibrio cholerae outer membrane vesicles induces protective immunity in mice. Infect. Immun. 76, 4554-4563.

Seward, R. J., and Towner, K. J. (1998). Molecular epidemiology of quinolone resistance in
Acinetobacter spp. Clin. Microbiol. Infect. 4, 248-254.

Shaikh, F., Spence, R. P., Levi, K., Ou, H. Y., Deng, Z., Towner, K. J., and Rajakumar, K. (2009). ATPase genes of diverse multidrug-resistant Acinetobacter baumannii isolates frequently harbour integrated DNA. J. Antimicrob. Chemother. 63, 260-264.

Shakil, S., and Khan, A. U. (2010). Detection of CTX-M-15-producing and carbapenem-resistant Acinetobacter baumannii strains from urine from an Indian hospital. J. Chemother. 22, 324-327.

Siguier, P., Perochon, J., Lestrade, L., Mahillon, J., and Chandler, M. (2006). ISfinder: the reference centre for bacterial insertion sequences. Nucleic Acids Res. 34, D32-D36.

Siroy, A., Cosette, P., Seyer, D., LemaitreGuillier, C., Vallenet, D., Van Dorsselaer, A., Boyer-Mariotte, S., Jouenne, T., and Dé, E. (2006). Global comparison of the membrane subproteomes between a multidrugresistant Acinetobacter baumannii strain and a reference strain. J. Proteome Res. 5, 3385-3398.

Siroy, A., Molle, V., Lemaitre-Guillier, C., Vallenet, D., Pestel-Caron, M. Cozzone, A. J., Jouenne, T., and Dé, E. (2005). Channel formation by CarO, the carbapenem resistanceassociated outer membrane protein of Acinetobacter baumannii. Antimicrob. Agents Chemother. 49, 4876-4883.

Smith, C. A., and Baker, E. N. (2002). Aminoglycoside antibiotic resistance by enzymatic deactivation. Curr. Drug Targets Infect. Disord. 2, 143-160.

Smith, M. G., Des Etages, S. G., and Snyder, M. (2004). Microbial synergy via an ethanol-triggered pathway. Mol. Cell. Biol. 24, 3874-3884.

Smith, M. G., Gianoulis, T. A., Pukatzki, S., Mekalanos, J. J., Ornston, L. N., Gerstein, M., and Snyder, M. (2007). New insights into Acinetobacter baumannii pathogenesis revealed by high-density pyrosequencing and transposon mutagenesis. Genes Dev. 21, 601-614.

Snitkin, E. S., Zelazny, A. M., Montero, C. I., Stock, F., Mijares, L., Program, N. C. S., Murray, P. R., and Segre, J. A. (2011). Genome-wide recombination drives diversification of epidemic strains of Acinetobacter baumannii. Proc. Natl. Acad. Sci. U.S.A. 108, 13758-13763.

Solé, M., Pitart, C., Roca, I., Fàbrega, A., Salvador, P., Muñoz, L., Oliveira, I., Gascón, J., Marco, F., and Vila, J. (2011). First description of an Escherichia coli strain producing
NDM-1 carbapenemase in Spain. Antimicrob. Agents Chemother. 55, 4402-4404.

Spence, R. P., and Towner, K. J. (2003). Frequencies and mechanisms of resistance to moxifloxacin in nosocomial isolates of Acinetobacter baumannii. J. Antimicrob. Chemother. 52, 687-690.

Srinivasan, V. B., Rajamohan, G., and Gebreyes, W. A. (2009a). Role of AbeS, a novel efflux pump of the SMR family of transporters, in resistance to antimicrobial agents in Acinetobacter baumannii. Antimicrob. Agents Chemother. 53, 5312-5316.

Srinivasan, V. B., Rajamohan, G., Pancholi, P., Stevenson, K., Tadesse, D., Patchanee, P., Marcon, M., and Gebreyes, W. A. (2009b). Genetic relatedness and molecular characterization of multidrug resistant Acinetobacter baumannii isolated in central Ohio, USA. Ann. Clin. Microbiol. Antimicrob. 8, 21.

Stanley, N., and Lazazzera, B. A. (2004). Environmental signals and regulatory pathways that influence biofilm formation. Mol. Microbiol. 52, 917-924.

Su, X. Z., Chen, J., Mizushima, T., Kuroda, T., and Tsuchiya, T. (2005). AbeM, an $\mathrm{H}+$-coupled Acinetobacter baumannii multidrug efflux pump belonging to the MATE family of transporters. Antimicrob. Agents Chemother. 49, 4362-4364.

Sutherland, I. (2001). Biofilm exopolysaccharides: a strong and sticky framework. Microbiology 147, 3-9.

Taneja, N., Singh, G., Singh, M., and Sharma, M. (2011). Emergence of tigecycline \& colistin resistant Acinetobacter baumanii in patients with complicated urinary tract infections in north India. Indian J. Med. Res. 133, 681-684.

Tian, G. B., Adams-Haduch, J. M., Bogdanovich, T., Pasculle, A. W., Quinn, J. P., Wang, H. N., and Doi, Y. (2011). Identification of diverse OXA-40 group carbapenemases, including a novel variant, OXA-160, from Acinetobacter baumannii in Pennsylvania. Antimicrob. Agents Chemother. 55, 429-432.

Toleman, M. A., Bennett, P. M., and Walsh, T. R. (2006). ISCR elements: novel gene-capturing systems of the 21st century? Microbiol. Mol. Biol. Rev. 70, 296-316.

Tomaras, A., Dorsey, C., Edelmann, R., and Actis, L. (2003). Attachment to and biofilm formation on abiotic surfaces by Acinetobacter baumannii: involvement of a novel chaperone-usher pili assembly system. Microbiology 149, 3473-3484.

Towner, K. J. (2009). Acinetobacter: an old friend, but a new enemy. J. Hosp. Infect. 73, 355-363.

Towner, K. J., Gee, T., and Boswell, T. (2002). An unwanted import to the UK: a carbapenem-resistant clinical isolate of Acinetobacter baumannii producing metallo- $\beta$ lactamase. J. Antimicrob. Chemother. 50, 1092-1093.

Tsakris, A., Ikonomidis, A., Poulou, A., Spanakis, N., Vrizas, D., Diomidous, M., Pournaras, S., and Markou, F. (2008). Clusters of imipenemresistant Acinetobacter baumanni clones producing different carbapenemases in an intensive care unit. Clin. Microbiol. Infect. 14, 588-594.

Tsakris, A., Ikonomidis, A., Pournaras, S., Tzouvelekis, L. S., Sofianou, D. Legakis, N. J., and Maniatis, A. N. (2006). VIM-1 metallo- $\beta$-lactamase in Acinetobacter baumannii. Emerging Infect. Dis. 12, 981-983.

Turton, J. F., Ward, M. E., Woodford, N., Kaufmann, M. E., Pike, R., Livermore, D. M., and Pitt, T. L. (2006). The role of ISAbal in expression of OXA carbapenemase genes in Acinetobacter baumannii. FEMS Microbiol. Lett. 258, 72-77.

Urban, C., Go, E., Mariano, N., and Rahal, J. J. (1995). Interaction of sulbactam, clavulanic acid and tazobactam with penicillin-binding proteins of imipenem-resistant and susceptible Acinetobacter baumannii. FEMS Microbiol. Lett. 125 193-197.

Vahaboglu, H., Ozturk, R., Aygun, G., Coskunkan, F., Yaman, A., Kaygusuz, A., Leblebicioglu, H., Balik, I., Aydin, K., and Otkun, M. (1997). Widespread detection of PER-1-type extended-spectrum $\beta$-lactamases among nosocomial Acinetobacter and Pseudomonas aeruginosa isolates in Turkey: a nationwide multicenter study. Antimicrob. Agents Chemother. 41, 2265-2269.

Valentine, S. C., Contreras, D., Tan, S., Real, L. J., Chu, S., and Xu, H. H. (2008). Phenotypic and molecular characterization of Acinetobacter baumannii clinical isolates from nosocomial outbreaks in Los Angeles County, California. J. Clin. Microbiol. 46, 2499-2507.

Vallenet, D., Nordmann, P., Barbe, V., Poirel, L., Mangenot, S., Bataille, E., Dossat, C., Gas, S., Kreimeyer, A., Lenoble, P., Oztas, S., Poulain, J., Segurens, B., Robert, C., Abergel, C., 
Claverie, J. M., Raoult, D., Medigue, C., Weissenbach, J., and Cruveiller, S. (2008). Comparative analysis of Acinetobacters: three genomes for three lifestyles. PLoS ONE 3, el805. doi:10.1371/journal.pone.0001805

Vidal, R., Domínguez, M., Urrutia, H., Bello, H., González, G., García, A., and Zemelman, R. (1996). Biofilm formation by Acinetobacter baumannii. Microbios 86, 49-58.

Vila, J., Martí, S., and Sánchez-Céspedes, J. (2007). Porins, efflux pumps and multidrug resistance in Acinetobacter baumannii. J. Antimicrob. Chemother. 59, 1210-1215.

Vila, J., Navia, M., Ruiz, J., and Casals, C. (1997a). Cloning and nucleotide sequence analysis of a gene encoding an OXA-derived $\beta$ lactamase in Acinetobacter baumannii. Antimicrob. Agents Chemother. 41, 2757-2759.

Vila, J., Ruiz, J., Goni, P., and Jimenez de Anta, T. (1997b). Quinoloneresistance mutations in the topoisomerase IV parC gene of Acinetobacter baumannii. J. Antimicrob. Chemother. 39, 757-762.

Vila, J., Ruiz, J., Goni, P., Marcos, A., and Jimenez de Anta, T. (1995). Mutation in the gyrA gene of quinolone-resistant clinical isolates of Acinetobacter baumannii. Antimicrob. Agents Chemother. 39, 1201-1203.

Vila, J., Sánchez-Céspedes, J., Sierra, J. M., Piqueras, M., Nicolás, E., Freixas, J., and Giralt, E. (2006). Antibacterial evaluation of a collection of norfloxacin and ciprofloxacin derivatives against multiresistant bacteria. Int. J. Antimicrob. Agents 28, 19-24.

Vila-Farrés, X., García de la Maria, C., López-Rojas, R., Pachón, J., Giralt, E. and Vila, J. (2012). In vitro activity of several antimicrobial peptides against colistin-susceptible and colistin-resistant Acinetobacter baumannii. Clin. Microbiol. Infect. 18, 383-387.

Vincent, J. L., Rello, J., Marshall, J., Silva, E., Anzueto, A., Martin, C. D., Moreno, R., Lipman, J., Gomersall, C., Sakr, Y., and Reinhart, K. (2009). International study of the prevalence and outcomes of infection in intensive care units. JAMA 302, 2323-2329.

Visca, P., Seifert, H., and Towner, K. J. (2011). Acinetobacter infection - an emerging threat to human health. IUBMB Life 63, 1048-1054.

Wang, H., Guo, P., Sun, H., Wang, H., Yang, Q., Chen, M., Xu, Y., and Zhu, Y. (2007). Molecular epidemiology of clinical isolates of carbapenem-resistant Acinetobacter spp. from Chinese hospitals. Antimicrob. Agents Chemother. 51, 4022-4028.

Wareham, D. W., Gordon, N. C., and Hornsey, M. (2011). In vitro activity of teicoplanin combined with colistin versus multidrug-resistant strains of Acinetobacter baumannii. J. Antimicrob. Chemother. 66, 1047-1051.

Watanabe, M., Iyobe, S., Inoue, M., and Mitsuhashi, S. (1991). Transferable imipenem resistance in Pseudomonas aeruginosa. Antimicrob. Agents Chemother. 35, 147-151.

Wendt, C., Dietze, B., Dietz, E., and Ruden, H. (1997). Survival of Acinetobacter baumannii on dry surfaces. J. Clin. Microbiol. 35, 1394-1397.

Whitehead, N. A., Barnard, A. M., Slater, H., Simpson, N. J., and Salmond, G. P. (2001). Quorumsensing in Gram-negative bacteria. FEMS Microbiol. Rev. 25, 365-404.

Wisplinghoff, H., Bischoff, T., Tallent, S. M., Seifert, H., Wenzel, R. P., and Edmond, M. B. (2004). Nosocomial bloodstream infections in US hospitals: analysis of 24,179 cases from a prospective nationwide surveillance study. Clin. Infect. Dis. 39, 309-317.

Wisplinghoff, H., Decker, M., Haefs, C., Krut, O., Plum, G., and Seifert, H. (2003). Mutations in gyrA and parC associated with resistance to fluoroquinolones in epidemiologically defined clinical strains of Acinetobacter baumannii. J. Antimicrob. Chemother. 51, 177-180.

Wong, E. W., Yusof, M. Y., Mansor, M. B., Anbazhagan, D., Ong, S. Y., and Sekaran, S. D. (2009). Disruption of adeB gene has a greater effect on resistance to meropenems than adeA gene in Acinetobacter spp. isolated from University Malaya Medical Centre. Singapore Med. J. 50, 822-826.

Wroblewska, M., Sawicka-Grzelak, A., Luczak, M., and Sivan, A. (2008). Biofilm production by clinical strains of Acinetobacter baumannii isolated from patients hospitalized in two tertiary care hospitals. FEMS Immunol. Med. Microbiol. 53, 140-144.

Wroblewska, M. M., Towner, K. J., Marchel, H., and Luczak, M. (2007). Emergence and spread of carbapenem-resistant strains of Acinetobacter baumannii in a tertiary-care hospital in Poland. Clin. Microbiol. Infect. 13, 490-496.

Yamamoto, M., Nagao, M., Matsumura, Y., Matsushima, A., Ito, Y., Takakura, S., and Ichiyama, S. (2011). Interspecies dissemination of a novel class 1 integron carrying blaIMP19 among Acinetobacter species in Japan. J. Antimicrob. Chemother. 66, 2480-2483.

Yamamoto, S., Okujo, N., and Sakakibara, Y. (1994). Isolation and structure elucidation of acinetobactin, a novel siderophore from Acinetobacter baumannii. Arch. Microbiol. 162, 249-254.

Yamane, K., Wachino, J., Doi, Y., Kurokawa, H., and Arakawa, Y. (2005). Global spread of multiple aminoglycoside resistance genes. Emerging Infect. Dis. 11, 951-953.

Yin, X. L., Hou, T. W., Xu, S. B., Ma, C. Q., Yao, Z. Y., Li, W., and Wei, L. (2008). Detection of drug resistance-associated genes of multidrug-resistant Acinetobacter baumannii. Microb. Drug Resist. 14, 145-150.

Yong, D., Toleman, M. A., Giske, C. G., Cho, H. S., Sundman, K., Lee, K. and Walsh, T. R. (2009). Characterization of a new metallo- $\beta$-lactamase gene, blaNDM-1, and a novel erythromycin esterase gene carried on a unique genetic structure in Klebsiella pneumoniae sequence type 14 from India. Antimicrob. Agents Chemother. 53, 5046-5054.

Yu, Y. S., Zhou, H., Yang, Q., Chen, Y. G., and Li, L. J. (2007). Widespread occurrence of aminoglycoside resistance due to ArmA methylase in imipenem-resistant Acinetobacter baumannii isolates in China. J. Antimicrob. Chemother 60, 454-455.

Yum, J. H., Yi, K., Lee, H., Yong, D., Lee, K., Kim, J. M., Rossolini, G. M., and Chong, Y. (2002). Molecular characterization of metallo$\beta$-lactamase-producing Acinetobacter baumannii and Acinetobacter genomospecies 3 from Korea: identification of two new integrons carrying the blaVIM-2 gene cassettes. J. Antimicrob. Chemother. 49, 837-840.

Yun, S. H., Choi, C. W., Kwon, S. O., Park, G. W., Cho, K., Kwon, K. H., Kim, J. Y., Yoo, J. S., Lee, J. C., Choi, J. S., Kim, S., and Kim, S. I. (2011). Quantitative proteomic analysis of cell wall and plasma membrane fractions from multidrug-resistant Acinetobacter baumannii. J. Proteome Res. $10,459-469$.
Zarrilli, R., Crispino, M., Bagattini, M., Barretta, E., Di Popolo, A., Triassi, M., and Villari, P. (2004). Molecular epidemiology of sequential outbreaks of Acinetobacter baumannii in an intensive care unit shows the emergence of carbapenem resistance. J. Clin. Microbiol. 42, 946-953.

Zhao, W. H., and Hu, Z. Q. (2011). IMP-type metallo- $\beta$-lactamases in Gram-negative bacilli: distribution, phylogeny, and association with integrons. Crit. Rev. Microbiol. 37, 214-226.

Zhao, W. H., and Hu, Z. Q. (2012). Acinetobacter: a potential reservoir and dispenser for $\beta$-lactamases. Crit. Rev. Microbiol. 38, 30-51.

Zhou, H., Zhang, T., Yu, D., Pi, B., Yang, Q., Zhou, J., Hu, S., and Yu, Y. (2011). Genomic analysis of the multidrug-resistant Acinetobacter baumannii strain MDRZJ06 widely spread in China. Antimicrob. Agents Chemother. 55, 4506-4512.

Zimbler, D. L., Penwell, W. F., Gaddy, J. A., Menke, S. M., Tomaras, A. P., Connerly, P. L., and Actis, L. A. (2009). Iron acquisition functions expressed by the human pathogen Acinetobacter baumannii. Biometals 22, 23-32.

Conflict of Interest Statement: The authors declare that the research was conducted in the absence of any commercial or financial relationships that could be construed as a potential conflict of interest.

Received: 11 November 2011; paper pending published: 29 January 2012; accepted: 28 March 2012; published online: 23 April 2012.

Citation: Roca I, Espinal P, Vila-Farrés $X$ and Vila J (2012) The Acinetobacter baumannii oxymoron: commensal hospital dweller turned pan-drug-resistant menace. Front. Microbio. 3:148. doi: 10.3389/fmicb.2012.00148

This article was submitted to Frontiers in Antimicrobials, Resistance and Chemotherapy, a specialty of Frontiers in Microbiology.

Copyright () 2012 Roca, Espinal, VilaFarrés and Vila. This is an open-access article distributed under the terms of the Creative Commons Attribution Non Commercial License, which permits noncommercial use, distribution, and reproduction in other forums, provided the original authors and source are credited. 